\title{
Prevalence and spread of antibiotic resistant microorganisms in a cross border region
}

Citation for published version (APA):

van der Donk, C. F. M. (2013). Prevalence and spread of antibiotic resistant microorganisms in a cross border region. [Doctoral Thesis, Maastricht University]. Uitgeverij BOXPress. https://doi.org/10.26481/dis.20130605cd

Document status and date:

Published: 01/01/2013

DOI:

10.26481/dis.20130605cd

Document Version:

Publisher's PDF, also known as Version of record

\section{Please check the document version of this publication:}

- A submitted manuscript is the version of the article upon submission and before peer-review. There can be important differences between the submitted version and the official published version of record.

People interested in the research are advised to contact the author for the final version of the publication, or visit the DOI to the publisher's website.

- The final author version and the galley proof are versions of the publication after peer review.

- The final published version features the final layout of the paper including the volume, issue and page numbers.

Link to publication

\footnotetext{
General rights rights.

- You may freely distribute the URL identifying the publication in the public portal. please follow below link for the End User Agreement:

www.umlib.nl/taverne-license

Take down policy

If you believe that this document breaches copyright please contact us at:

repository@maastrichtuniversity.nl

providing details and we will investigate your claim.
}

Copyright and moral rights for the publications made accessible in the public portal are retained by the authors and/or other copyright owners and it is a condition of accessing publications that users recognise and abide by the legal requirements associated with these

- Users may download and print one copy of any publication from the public portal for the purpose of private study or research.

- You may not further distribute the material or use it for any profit-making activity or commercial gain

If the publication is distributed under the terms of Article $25 \mathrm{fa}$ of the Dutch Copyright Act, indicated by the "Taverne" license above, 


\section{Prevalence and spread of antibiotic resistant microorganisms in a cross border region}


ISBN: 978-90-8891-592-5

Cover design: Christel van der Donk en Proefschriftmaken.nl - Uitgeverij BOXPress

Printed and published: Proefschriftmaken.nl - Uitgeverij BOXPress

(c) C.F.M. van der Donk, Eindhoven 2013

All rights reserved. No parts of this thesis may be reproduced or transmitted in any form or by any means, electronic or mechanical including photocopying, recording or any information storage or retrieval system, without written permission from the author, or, when appropriate from the publisher of the publications.

The research in this thesis was financially supported by:

Provincie Limburg - the Netherlands, Ministerium für Wirtschaft, Energie, Bauen, Wohnen und Verkehr des Landes Nordrhein-Westfalen - Germany, Ministerium der Deutschsprachige Gemeinschaft Belgiens - Belgium, Provincie Limburg - Belgium, Wallonie - Belgium, RheinlandWestfalen - Germany, Interreg and the Euregio Maas-Rijn with support of the European fund for regional development (EFRO)

and

the Dutch Working Party on Antibiotic Policy.

Printing of this thesis was financially supported by the Netherlands Society of Medical Microbiology (NVMM) and the Royal Netherlands Society for Microbiology (KNVM) 


\title{
Prevalence and spread of antibiotic resistant microorganisms in a cross border region
}

\author{
PROEFSCHRIFT
}

Ter verkrijging van de graad van doctor aan de Universiteit Maastricht, op gezag van de Rector Magnificus, prof. dr. L.L.G. Soete, volgens het besluit van het College van Decanen, in het openbaar te verdedigen op woensdag 5 juni 2013 om 14.00 uur

$$
\text { door }
$$

Christina Francina Maria van der Donk

geboren op 19 november 1984 te 's-Hertogenbosch 


\section{Promotor}

em. prof. dr. C.A. Bruggeman

\section{Co-promotor}

dr. E.E. Stobberingh

Beoordelingscommissie

prof. dr. J.F.M. Metsemakers

prof. dr. C.A. Hoebe

prof. dr. H.A. Verbrugh (Erasmus MC, Rotterdam)

dr. D.C.J.J. Bergmans 
Aan ons pap en mam 



\section{Contents}

$\begin{array}{lc}\text { Abbreviations } & 8\end{array}$

Map of the Euregion Meuse-Rhine $\quad 11$

Chapter $1 \quad$ General introduction and Aim \& Outline of the thesis 13

Chapter $2 \quad$ Antimicrobial resistance and spread of multi drug resistant $\quad 37$

Escherichia coli isolates collected from nine urology

services in the Euregion Meuse-Rhine

Chapter 3 Prevalence and spread of multi drug resistant Escherichia

coli isolates among nursing home residents in the southern part of the Netherlands

Chapter 4 Prevalence and spread of multi drug resistant E. coli including ST131 in different patient populations in the Euregion Meuse-Rhine

Chapter $5 \quad$ Resistance and population structure of Staphylococcus aureus in nursing homes in the border region of the Netherlands and Germany

Chapter 6 Is living in a border region a risk for a high prevalence of resistance?

Chapter 7 A 12 year (1998-2009) antibiotic resistance surveillance of Klebsiella pneumoniae collected from intensive care and urology patients in 14 Dutch hospitals

Chapter $8 \quad$ General discussion, summary and samenvatting

Dankwoord

Curriculum vitae

List of publications 


\section{Abbreviations}

\begin{tabular}{|c|c|}
\hline AMC & amoxicillin-clavulanic acid \\
\hline AMO & amoxicillin \\
\hline ATC & anatomical therapeutic chemical classification system \\
\hline ATCC & American type culture collection \\
\hline AZI & azitromycin \\
\hline B & Belgium \\
\hline BURP & based upon repeat pattern \\
\hline BURST & based upon related sequence types \\
\hline CAZ & ceftazidime \\
\hline CA-MRSA & community-associated MRSA \\
\hline $\mathrm{CC}$ & clonal complex \\
\hline CIP & ciprofloxacin \\
\hline CFA & clonal frame analysis \\
\hline CFM & cefixime \\
\hline CFX & cefotaxime \\
\hline CLI & clindamycin \\
\hline CTX-M & cefotaxime-Munich \\
\hline CXM & cefuroxime \\
\hline DDD & defined daily dosage \\
\hline DI & diversity index \\
\hline ERY & erytromycin \\
\hline ESBL & extended spectrum beta-lactamase \\
\hline EUCAST & European committee on antimicrobial susceptibility testing \\
\hline FDR & false discovery rate \\
\hline FEP & cefepime \\
\hline FUC & fusidic acid \\
\hline G & Germany \\
\hline GEN & gentamicin \\
\hline GP & general practice \\
\hline HA-MRSA & hospital associated MRSA \\
\hline ICU & intensive care unit \\
\hline IMP & imipenemase \\
\hline IPM & imipenem \\
\hline KPC & Klebsiella pneumoniae carbapenemase \\
\hline L & Limburg \\
\hline MDR & multi drug resistant \\
\hline MEM & meropenem \\
\hline MIC & minimal inhibitory concentration \\
\hline MLST & multi locus sequence typing \\
\hline MLVA & multi locus variable number tandem repeat analysis \\
\hline MRSA & methicillin resistance Staphylococcus aureus \\
\hline MSSA & methicillin susceptible Staphylococcus aureus \\
\hline
\end{tabular}




$\begin{array}{ll}\text { MUMC } & \text { Maastricht University Medical Centre } \\ \text { MUP } & \text { mupirocin } \\ \text { NDM } & \text { New Delhi metallo-beta-lactamase } \\ \text { NH } & \text { nursing home } \\ \text { NIT } & \text { nitrofurantoin } \\ \text { NL } & \text { the Netherlands } \\ \text { NOR } & \text { norfloxacin } \\ \text { NT } & \text { not tested } \\ \text { OXA } & \text { oxacillin } \\ \text { OXA } & \text { oxacillinase } \\ \text { PBP } & \text { penicillin binding protein } \\ \text { PCR } & \text { polymerase chain reaction } \\ \text { PEN } & \text { penicillin } \\ \text { PFGE } & \text { pulsed field gel electrophoresis } \\ \text { PIP } & \text { piperacillin } \\ \text { QUI } & \text { quinolones } \\ \text { SCCmec } & \text { Staphylococcal cassette chromosome } \\ \text { SHV } & \text { sulfhydryl variable } \\ \text { SPa } & \text { staphylococcal protein A gene } \\ \text { SPa-CC } & \text { spa clonal complex } \\ \text { ST } & \text { sequence type } \\ \text { SXT } & \text { trimethoprim-sulfamethoxazole } \\ \text { TAZ } & \text { piperacillin-tazobactam } \\ \text { TEM } & \text { Temoneira } \\ \text { TOB } & \text { tobramycin } \\ \text { TRIM } & \text { trimethoprim } \\ \text { UPGMA } & \text { unweighted pair group method with arithmetic averages } \\ \text { URO } & \text { urology services } \\ \text { UPEC } & \text { uropathogenic Escherichia coli } \\ \text { UTI } & \text { urinary tract infection } \\ \text { VIM } & \\ \text { WHO } & \end{array}$



Map of the Euregion Meuse-Rhine

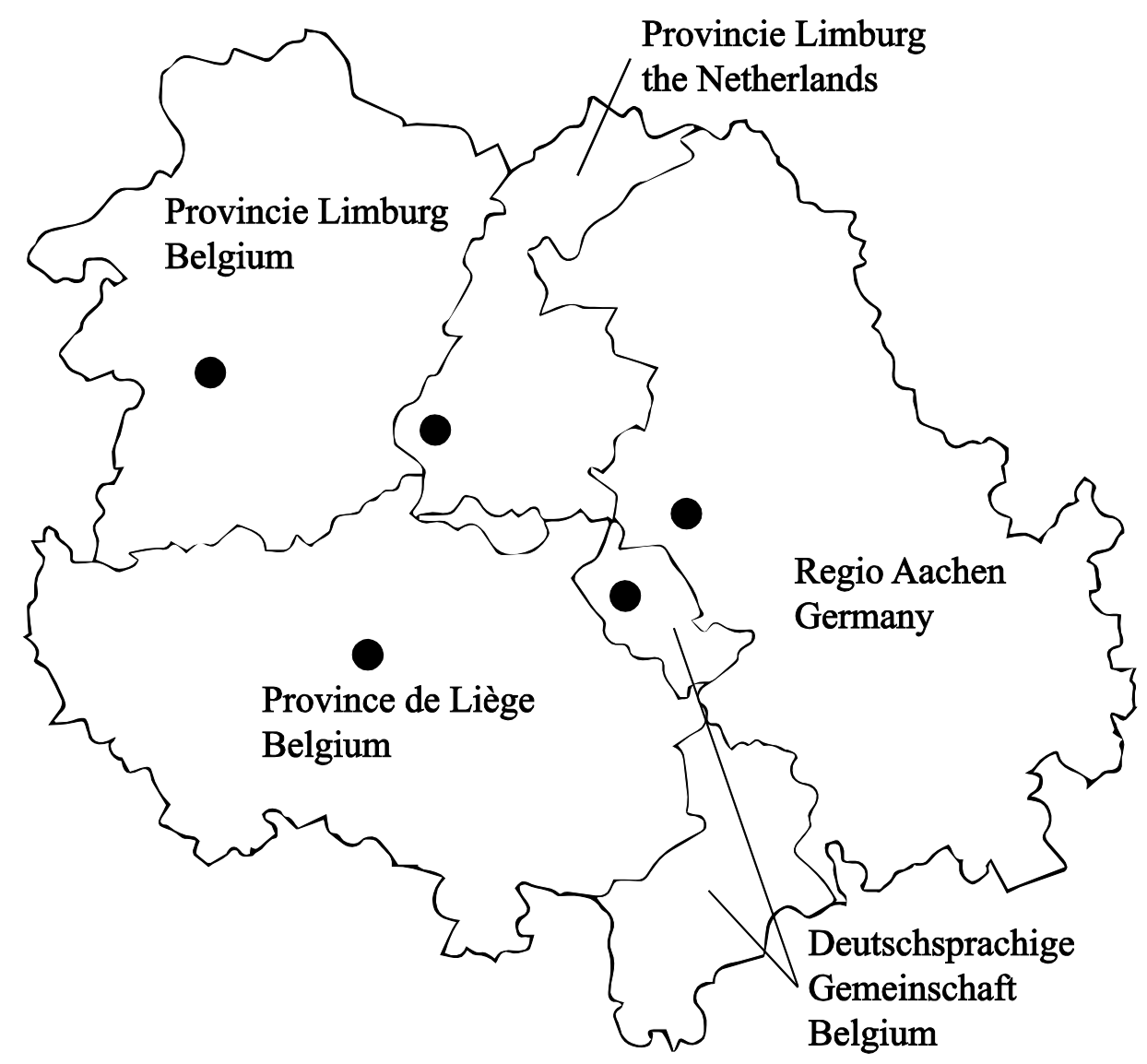



Chapter 1

General introduction Aim \& Outline of the thesis 


\section{Commensal microbiota}

Only when in uterus is every child presumed sterile. This will change at the start of delivery and will never change back again ${ }^{1-3}$. Each human being carries with him or her approximately $10^{14}$ bacteria in the intestines alone, outnumbering our own human cells by at least ten fold ${ }^{1}$. All these bacteria put together are our commensal microbiota or commensal flora but the make up and amount of bacterial species differ per site on the human body. For example the most abundant flora of the skin consists of Staphylococcus epidermidis ${ }^{4}$, while these are Bacteroides spp. in the colon ${ }^{1}$. Moreover, the colon is also the location with the highest number of colonizing bacteria ${ }^{5}$.

Commensalism is a symbiotic relationship between two species in which the symbiont benefits, but the host does neither gain nor lose from the relationship ${ }^{4}$. However, this is not completely true for the human microbiota, since the host does benefit but is sometimes harmed too. By their number commensal microorganisms outcompeed pathogenic microorganisms and many bacteria produce or breakdown nutrients which are vital in maintaining human health. The bacteria are also necessary for priming the host's immune system ${ }^{1,3-6}$.

Although, our commensal microbiota is mostly of value to us, it is also for a small part made up of potentially pathogenic micro-organisms. These include Staphylococcus aureus, Escherichia coli and other Enterobacteriaceae including Klebsiella pneumoniae $^{4,5}$. These micro-organisms are prevalent causes of many infections, nosocomial and community acquired.

\section{Staphylococcus aureus}

Staphylococcus aureus is a potentially pathogenic, facultatively anaerobic, Gram positive commensal of the skin and the mucosa, that was first described in 1880 by Sir Alexander Ogston ${ }^{7}$. Although, these bacteria can be cultured from multiple body sites, the anterior nares are the prime location of colonization ${ }^{8}$. S. aureus can cause community acquired and nosocomial infections ranging from mild skin and soft tissue infections, like erysipelas and cellulitis, to severe and life-threatening infections, such as necrotizing pneumonia, bacteraemia and endocarditis ${ }^{7}$.

Persistent carriers of $S$. aureus (12-30\% of the population) are more at risk for an infection with S. aureus than intermittent carriers (16-70\% of the population) and noncarriers (16-69\%) since S. aureus infections are often caused by the patient's own commensal strains ${ }^{8-10}$.

\section{Escherichia coli}

Escherichia coli is a potentially pathogenic, facultatively anaerobic, Gram negative commensal of the intestinal microbiota ${ }^{5}$ and was first described in 1885 by Theodor Escherich $^{11}$. 
$E$. coli is one of the facultative anaerobic species in the human gut microbiotica, which mainly consists of obligatory anaerobics, such as Bacteroides spp., Clostridium spp., bifido-, eu- and fusobacteria ${ }^{1}$.

$E$. coli is a prevalent causative agent of both intra- and extra intestinal infection. In particular, the extra intestinal infections are mainly caused by the host's own $E$. coli strains $^{12,13}$. Extra intestinal infections with $E$. coli range from mild self-limiting cystitis to severe urosepsis and meningitis ${ }^{14}$. Whether a certain $E$. coli isolate causes an intra or extra intestinal infection is mainly determined by its combination of virulence factors, which are usually encoded for by multiple genes located on pathogenicity islands ${ }^{15-17}$. Extra intestinal $E$. coli bacteria usually express many adhesins and iron acquisition systems to survive outside the intestines, while intra intestinal (diarrheacausing) $E$. coli express specific secretions systems to inject toxins into the host cells $^{17}$.

\section{Klebsiella pneumoniae}

Klebsiella pneumoniae is an opportunistic potentially pathogenic, facultatively anaerobic, Gram negative bacteria and was first described in 1883 by Carl Friedländer and named after the German bacteriologist Edwin Klebs ${ }^{18}$. This bacteria is, unlike $E$. coli, also common in the environment ${ }^{19}$. Infections caused by $K$. pneumoniae include but are not limited to urinary and respiratory tract infections. The type of infection is just as with $E$. coli dependent on the strain's specific virulence factors ${ }^{19}$. In patients with lowered host defense it can also cause severe infections including bacteraemia ${ }^{14}$.

\section{Antibiotic treatment}

The suitability of an antibiotic for the treatment of an infectious disease is determined mostly by the site of infection, the causative bacteria and the resistance of this bacterium to certain antibiotics. For many infections, often treatment is initiated empirically. These include amongst others urinary tract infections (UTIs) and skin and soft tissue infections. Empiric therapy means treatment with antimicrobial agent(s) for an infection for which the causative agent(s) and the antimicrobial resistance are unknown. Therefore, to make an appropriate choice the probable causative agent and the anticipated susceptibility to antimicrobial agents should be taken into account.

For urinary tract infections the most prevalent bacterial agents include E. coli, Enterococcus spp., Proteus mirabilis, Staphylococcus saprophyticus, Klebsiella pneumoniae and Enterobacter cloacae ${ }^{20-22}$. However, distribution of the species differs per patient population. For example: $E$. coli is by far the number one causative agent in every patient population but S. saprophyticus is more often isolated from young and K. pneumoniae from elderly general practice (GP) patients ${ }^{21}$ Bacteria such as Proteus spp. and Enterobacter spp. but also Klebsiella spp. are observed more among hospitalized patients and nursing home residents ${ }^{20,23}$. Urinary tract infections range from mild self-limiting cystitis to prostatitis and pyelonephritis and can lead to 
urosepsis. These infections remain one of the most common indications for antibiotic treatment ${ }^{24,25}$.

For skin and soft tissue infections the most prevalent bacterial agents include $S$. aureus and Streptococcus pyogenes. These infections are generally mild, such as impetigo or cellulitis, but can be more severe (necrotizing fasciitis) and can be accompanied with signs of systemic involvement ${ }^{26}$. If a patient presents with a skin and soft tissue infection with mild symptoms, often the topical application of the antimicrobial agent can be effective ${ }^{27}$.

\section{Antibiotic agents}

Antibiotic is a derivative of a Greek word meaning against life. An antibiotic is a chemical substance produced by one species that is life threatening to another species. Throughout the centuries antimicrobial substances have been used to treat infections but renewed search for such agents started with the acceptance of the germ theory of disease ${ }^{28}$. One of the first agents, still to be used today, was discovered by Sir Alexander Fleming in $1928^{29,30}$. However, it was not until 1942 that this substance, penicillin, could be manufactured in high amount ${ }^{29,} 30$. This was the start of the development of many new agents: the era of antibiotics.

Ideally antibiotics should be specific and only inhibit bacterial cell processes and should not damage the host cells (selective toxicity). However, antibiotics do not differentiate between pathogenic and non-pathogenic bacteria ${ }^{3}, 31$ resulting in a disturbance of the commensal flora, however, the degree of disturbance is dependent on the antibiotic used ${ }^{31}$.

The following antibiotics agents are often but not solely used for the treatment of urinary tract infections (UTIs) and, skin and soft tissue infections. These include nitrofurantoin, fosfomycin, the fluoroquinolones and amoxicillin-clavulanic acid for the UTIs and flucloxacillin, the macrolides, clindamycin and fusidic acid for the treatment of S. aureus infections

\section{Nitrofurantoin}

This antimicrobial agent has been available since 1953. After influx into the bacterial cell, nitrofurantoin first has to be activated by the microbial nitroreductases before it inhibits several bacterial enzymes and thereby interferes in the DNA and RNA synthesis, carbohydrate metabolism and other metabolic processes ${ }^{32}$.

Nitrofurantoin is active against most Gram negative and Gram positive bacteria. However, Pseudomonas spp, Serratia spp. and Proteus spp. are intrinsically resistant ${ }^{32}$, 33. Approximately $40 \%$ of the nitrofurantoin is excreted unchanged via the kidneys. The highest concentration in the urine will be reached after 4-5 hours. This high concentration in the urine and the low tissue penetration deem this agent only suitable for uncomplicated cystitis $^{32,}{ }^{34}$. Potential severe side effects include polyneuropathy among the elderly and those with renal impairment, and lung- or hepatotoxicity ${ }^{32}$. 


\section{Fosfomycin}

Fosfomycin is an antibiotic, which has been available for many years and is mainly used for the treatment of uncomplicated cystitis. Fosfomycin has a broad antibacterial activity including both Gram positive (e.g. S. aureus and E. faecalis) and Gram negative bacteria (e.g. Enterobacteriaceae and Pseudomonas aeruginosa).

Fosfomycin is an agent that interferes in the cell wall synthesis by inhibiting the formation of $\mathrm{N}$-acetylmuramic acid, a precursor of peptidoglycan ${ }^{35}, 36$. It also decreases the adhesion of the bacteria to the bladder epithelium ${ }^{36}$. After a single dose, the urine concentration of this agent is high and may exceed $2000 \mathrm{mg} / \mathrm{L}$. Fosfomycin also has a good tissue penetration and overall adverse effects are minor ${ }^{37}$. Worldwide resistance to fosfomycin has remained $\operatorname{low}^{21}, 38$ and fosfomycin retains activity against ESBL producing strains ${ }^{35,36}$. Unfortunately, the use of fosfomycin is only indicated for the treatment of uncomplicated UTI and thus not used for other infections, despite its promising characteristics.

\section{(Fluoro)quinolones}

Quinolones are broad spectrum antibiotics prescribed both in the hospital ${ }^{23}$ and in the extramural setting, especially in long-term care facilities ${ }^{39-41}$. They are prescribed for a wide range of infections, caused by both Gram positive (for example: the fluoroquinolones levofloxacin and moxifloxacin) and/or Gram negative bacteria (for example: the fluoroquinolones ciprofloxacin and norfloxacin $)^{42}$.

Quinolones have been available since 1962 and lots of analogues have been developed since then including the fluoroquinolones. Their mode of action is the inhibition of DNA gyrase and topoisomerase IV. These enzymes are required for the coiling/uncoiling and (de)catenating of the DNA strand during replication ${ }^{42-44}$.

\section{Amoxicillin-clavulanic acid and flucloxacillin}

These agents are part of the beta-lactam group. Amoxicillin-clavulanic acid is a combination of a beta-lactam antibiotic with a beta-lactamase inhibitor and flucloxacillin is resistant to penicillinase.

Beta-lactam antibiotics inhibit the formation of the peptidoglycan layer by inhibiting the transpeptidase or Penicillin Binding Protein (PBP), which cross links the different peptidoglycan layers of the bacterial cell wall ${ }^{45}$.

Amoxicillin-clavulanic acid is a broad spectrum antibiotic prescribed for various infections, mild and severe and is also used for a complicated UTI ${ }^{46}$. Flucloxacillin, a narrow spectrum antibiotic, is mainly used for the treatment of Staphylococcus aureus infections ${ }^{46}$. Both agents are prescribed in intra- and extramural settings $s^{23}$.

\section{Macrolides and clindamycin}

The macrolides are a group of antibiotics that act by inhibiting the protein synthesis by blocking the attachment of the next tRNA molecule and the ribosomal translocation at the 505 subunit of the bacterial ribosomes ${ }^{47}$. Both the macrolides and clindamycin are mainly used to battle Gram positive infections ${ }^{48}$ but these agents are not active to facultative anaerobic Gram negatives, such as the Enterobacteriaceae $e^{33}$. 


\section{Fusidic acid}

Fusidic acid is an antibiotic that inhibits bacterial growth, mainly bacteriostaticly, by binding to elongation factor $\mathrm{G}$ on the ribosome and thereby preventing the bacterial protein synthesis to continue ${ }^{49}$. Fusidic acid is active against Staphylococci, Corynebacteria and Gram positive anaerobes. The Enterobacteriaceae are resistant and the activity to streptococci and enterococci is limited ${ }^{49}$. Although, fusidic acid is available both in systemic as topical formulation ${ }^{46}$, in the Netherlands the use of systemic fusidic acid is very low ${ }^{50}$ while the topical use is much higher ${ }^{51}$. It is mostly used as a topical agent to treat skin and soft tissue infections ${ }^{51}$. Overall the tolerability of fusidic acid is high with few side effects ${ }^{27}$.

\section{Antibiotic resistance}

There are several mechanisms for bacterial resistance to antibiotic agents. They can be divided in four groups: 1) alteration of the drug target site, 2) inactivation of the drug, 3) decreased permeability or influx to reduce the drug uptake, 4) increased efflux of the drug ${ }^{52}$. The main resistance mechanisms and the genes encoding the mechanisms of resistance for the above mentioned antibiotics are described on the following pages.

\section{Methicillin resistant S. aureus (MRSA)}

MRSA was first described in 1961 only 2 years after the introduction of methicillin ${ }^{53}$, a penicillinase resistant penicillin. The resistance to methicillin is encoded by the mecA gene, which codes for the PBP2a. This is an altered PBP and, therefore, the affinity of the drug to this target is decreased and the peptidoglycan synthesis remains uninterrupted $^{54}$. The mec $A$ gene is located on a mobile genetic element, the staphylococcal cassette chromosome, the $\mathrm{SCCmec}^{55}$, 56, which contains several elements besides the mecA gene. These include amongst others: 1) the $c c r$ gene complexes, responsible for the integration or excision of the cassette from the genome, 2) genes responsible for regulation of mecA transcription (mecl, mecR1), 3) associated insertion sequences and 4 ) the so called junkyard $(\mathrm{J})$ regions ${ }^{54}$. In S. aureus 11 types of SCCmec cassettes have been described so far, each with its own variants ${ }^{57 .}$ ${ }^{59}$. SCCmec I to $\mathrm{V}$ have been observed most often. SCCmec IV and V only encode resistance to methicillin while $\mathrm{SCCmec}$ I, II and III also encode for resistance to several other antibiotic classes including the macrolides, aminoglycosides and fluoroquinolones, due to integrated plasmids or transposons in the cassette $e^{54}$. In the mid nineties MRSAs with SCCmec IV and V were isolated from healthy persons with no apparent risk factors for MRSA acquisition or contact with healthcare and were, therefore, classified as community associated MRSA. This in contrast to the hospital associated MRSAs, which carry mostly SCCmec II and III, and are isolated from patients at healthcare facilities with more risk factors and co morbidities ${ }^{53,54}$. However, during recent years CA-MRSA isolates have also been isolated from hospital admitted patients ${ }^{60}$. Thus, the strict division between the two groups of MRSAs is fading. 


\section{Beta lactamases and extended spectrum beta-lactamases (ESBLs)}

Beta-lactamases are enzymes produced by many bacteria both Gram positive and negative, aerobic and anaerobic ${ }^{61}$. These enzymes hydrolyze the $\mathrm{C}-\mathrm{N}$ bond in the betalactam ring of the beta-lactam antibiotics, which makes them inactive ${ }^{45,52,62}$. The first beta-lactamase was described before the introduction of penicillin ${ }^{63}$. However, since their first discovery the development of new beta-lactam antibiotics and the "development" of new beta-lactamases, especially by Enterobacteriaceae have kept in pace. Nowadays the increasing prevalence of new beta-lactamases, i.e. extended spectrum, AmpC and inhibitor resistant beta-lactamases and carbapenemases, is a point of concern ${ }^{64-66}$.

Beta-lactamase enzymes can be classified based on their molecular or functional characteristics. Based on molecular characteristics the TEM, SHV, CTX-M and Klebsiella pneumoniae carbanemase (KPC) belong to class A, New Delhi metallo-beta-lactamase (NDM), imipenemase (IMP) and Verona integrated metallo-beta-lactamase (VIM) to class $B$, the AmpC to class $C$ and oxacillinase (OXA) to class $D^{65,67}$. The functional classification according to Bush et al. divides beta-lactamases into 3 groups. Group 1 includes the AmpC and group 3 the metallo beta-lactamases including the NDM carbapenemases. Group 2 is subdivided in 12 subgroups (i.e. $2 \mathrm{a}, 2 \mathrm{~b}, 2 \mathrm{be}, 2 \mathrm{ber} 2 \mathrm{br}, 2 \mathrm{c}$, $2 \mathrm{ce}, 2 \mathrm{~d}, 2 \mathrm{de}, 2 \mathrm{df}, 2 \mathrm{e}$ and $2 \mathrm{f}$ ) of which $2 \mathrm{f}$ and $2 \mathrm{df}$ include the other carbapenemases ${ }^{68}$. Resistance genes encoding for beta-lactamases are mostly located on plasmids or some on transposons, but these genes can also be located in the chromosomal DNA ${ }^{69,70}$.

Due to the relatively high prevalence of ESBLs and other beta-lactamases and their impact on treatment outcome it is essential to detect beta-lactamases rapidly to prevent the too long continuation of inappropriate antibiotic therapy ${ }^{71,72}$ and to start infection control measures as soon as possible.

Both phenotypic and genotypic tests for the detection of beta-lactamases have been developed. Phenotypic tests include: a combination disk diffusion test or an Etest with $3^{\text {rd }}$ gen cephalosporines with and without clavulanic acid and micro broth dilution for ESBLs and, a modified Hodge test and carbapenemase inhibition tests for the detection of carbapenemases ${ }^{73}$. However, these tests all require overnight incubation and this means a delay in initiation of the appropriate antibiotic therapy.

Fast and simple tests to determine the presence of a beta-lactamase a day earlier than the described phenotypic tests are available ${ }^{74,75}$. These are biochemical tests based on the in vitro hydrolysis of cefotaxime and imipenem. However, the characterization of the type of ESBL is not possible with these tests. Molecular detection of the different ESBL genes with PCR is an alternative and many PCR assays have been developed ${ }^{76-79}$ but this type of detection is costly and not available in every laboratory. Also, due to the high number of resistance genes it is hard to detect all of them in one assay. New diagnostic tests such as micro-arrays might be able to overcome this problem ${ }^{80}$.

\section{Quinolone resistance}

Due to the wide antibacterial spectrum and oral availability of the quinolones, they have been extensively used over the years ${ }^{81}$. This, together with misuse or unnecessary use, is probably the main reason for increased resistance worldwide ${ }^{50,82,83}$. Resistance 
to quinolones is mediated by alterations in the drug target and decrease of the drug inside the cell due to decreased influx or increased efflux.

Alteration of the drug targets i.e. DNA gyrase (catalyses of the negative supercoiling of DNA) and topoisomerase IV (decatenating of daughter replicons) are encoded by gyrA, gyrB and parC, parE, respectively ${ }^{43}$. These alterations are mostly chromosomally encoded $^{69}$. Although, a comparable mechanism but plasmid-mediated, encoded by the $q n r A, q n r B$ and $q n r S$ genes, has been described ${ }^{69}$. The qnr proteins can bind to the DNA gyrase and this binding protects the bacteria from the activity of the quinolones ${ }^{69}$. Decreased uptake can be accomplished through alterations of the membrane permeability, usually due to decreased expression of porins, mostly OmpF (one of the two major outer membrane porins of $E$. coli $)^{42,43}$. Increased efflux is regulated by overexpression of efflux pump systems ${ }^{42,43}$. Another mechanism of resistance is encoded by the aminoglycoside acetyltransferase (aac('6)-lb-cr), which is capable of acetylating not only the aminoglycosides but also ciprofloxacin and norfloxacin ${ }^{69}$. The prevalence of this mechanism is still low ${ }^{84}$.

\section{Resistance mechanism of the other described antibiotic agents}

Nitrofurantoin: Bacterial resistance to this agent was and still is very low ${ }^{85}$, which is in contrast to the relative high prevalence of resistance to other agents. The mechanism of resistance is probably due to the capacity of bacteria to stop the activation of the nitrofurantoin by nitroreductase ${ }^{86}$. This has a fitness cost for the bacteria ${ }^{86}$ and resistant bacteria are thus easily outcompeted by other susceptible bacteria.

Fosfomycin: Till today several mechanisms of resistance have been described, which include: 1) decreased drug uptake, 2) inactivation of fosfomycin or 3) modification of the target site $^{35}$. These mutations have a biological cost for the bacteria ${ }^{35,36}$ and, therefore, resistant bacteria are not often found.

Macrolides and clindamycin: Resistance to the macrolides is often facilitated through methylation of the drug target (encoded by the erm genes), which also results in (inducible) cross resistance with clindamycin, or alteration of the drug target through mutation ${ }^{48}$. Other mechanisms are efflux of the drug or drug inactivation ${ }^{48}$.

Fusidic acid: The main resistance mechanism for this antibiotic is the alteration of the drug target site, mediated through a mutation in the coding gene e.g. fusA, or the acquisition of the fusB gene (mostly plasmid mediated). However, the underlying mechanism for fusB is still unknown. FusB is the predominate mechanism of resistance in the resistant European clone ${ }^{49,51}$.

\section{Risk factors for resistance}

The number of factors associated with increase of antibiotic resistance or the acquisition of a resistant strain is high. The most important risk factors are antibiotic use, living in a nursing home, contact with husbandry and travelling to endemic countries. However, several other risk factors have been described, which include amongst others the presence of invasive devices or foreign materials such as urinary catheters, co-morbidities such as skin diseases, poor functional status, wounds and diabetes $^{87}$. 


\section{Antibiotic use}

The use of antibiotics is being considered as the main risk factor for the development or increase of antibiotic resistance. In countries with a higher use of antibiotics the prevalence of resistance is higher compared with countries with lower use of antibiotics $^{82}$. Several studies observed a higher, prior use of antibiotics among patients with a resistant strain compared with those without a resistant strain ${ }^{88-90}$. Decrease of antibiotic use and antibiotic stewardship have been described to decrease or control antibiotic resistance ${ }^{91}$.

\section{Nursing homes}

Nursing home $(\mathrm{NH})$ residents are often considered a reservoir for resistance ${ }^{87,92,93}$. In many countries resistance among $\mathrm{NH}$ residents is high ${ }^{93-95}$, due to amongst others the high prevalence of risk factors for acquiring a multi drug resistant strain ${ }^{40,96}$. Also, the enclosed living environment of the residents facilitates the spread of resistant strains.

\section{Husbandry}

Contact with reservoirs of multi resistant microorganism such as husbandry is also a risk factor ${ }^{97}$, since use of antibiotics among those animals is high ${ }^{98}$. Persons who have regular contact with these animals are at risk for acquiring one of their resistant strains $^{99,100}$, but these resistant strains can also potentially spread to other humans via consumption meat ${ }^{101,102}$.

\section{International travel}

Due to international travel the spread of resistant strains is facilitated. Travellers visiting a country with a high prevalence of multi drug resistance have, especially when admitted to a hospital or when visiting a health care facility during their stay, a risk for acquiring a resistant strain ${ }^{103,}{ }^{104}$. Also, visitors from a country with a high prevalence of resistance play a role in the spread of resistant strains in a country with low prevalence of resistance ${ }^{105}$. This potential spread of resistant strains applies not only for travelling to different continents but also to cross border movements in a border region.

\section{Cross border health care}

Everywhere around us the world is becoming more globalized and this definitely includes health care. In the European Union borders start to fade giving the European citizens the opportunity to cross borders at will and to appreciate all that Europe has to offer. This should also include the health care facilities. Therefore, a proposal was made by the European commission to aid and stimulate cross border health care ${ }^{106}$. Patients should be free to seek medical care not only in their own country but also in the other European countries ${ }^{107}$. However, differences between countries, such as variation in prevalence of antibiotic resistance, hamper patient mobility ${ }^{108}$. Patients moving across the border could have negative experiences due to differences in antibiotic resistance and infection control policies, for example: there is a risk of potential over or under treatment, risk of acquisition or spreading of resistant strains 
and possible screening and isolation for (suspected) carriage of a resistant strain ${ }^{109}$. Therefore, after primary problems in cross border health care such as differences in health care, financing and assurance systems have been dealt with by the governments, the other dilemmas, such as the problems caused by differences in antibiotic resistance, have to be addressed ${ }^{110}$. This can be done by improving the cooperation between health care facilities in the different countries regarding infectious diseases, antibiotic policies and infection control policies.

\section{Euregion Meuse-Rhine}

The Euregion Meuse-Rhine consists of five subregions: Provincie Limburg (Midden and Zuid Limburg) in the Netherlands, Provincie Limburg, Province de Liège and Deutschsprachige Gemeinschaft in Belgium and Regio Aachen in Germany. In this region of $10793 \mathrm{~km}^{2}$ live approximately 3.9 million people, which is a population density of approximately 360 people per square kilometer. In this region are approximately 60 general and academic hospitals ${ }^{111}$. The Euregion Meuse-Rhine is also a region with many cross border movements for example for working or educational, recreational and health care purposes ${ }^{110,111}$.

An issue related to cross border healthcare is the potential spread of resistant bacteria, such as E. coli and S. aureus. According to the EARS-net 2010 report the prevalence of MRSA in hospitals was $20.5 \%, 20.9 \%$ and $1.2 \%$ in Belgium, Germany and the Netherlands, respectively ${ }^{83}$. Resistance to third generation cephalosporines among E. coli was $5.2 \%, 8.4 \%$ and $5.1 \%$ and the resistance to the fluoroquinolones was $21.5 \%$, $24.8 \%$ and $13.6 \%$ in Belgium, Germany and the Netherlands, respectively ${ }^{83}$. These differences in prevalence of resistance hamper free access to health care facilities on the other side of the border. For example: the infection control policy of the Netherlands only allows access to health care facilities after negative screening for MRSA $^{109}$.

Previous research has demonstrated that some MRSA clones occur and spread predominantly in a regional health care cluster ${ }^{112,113}$. This suggests that spread of these clones can be interrupted by an intervention at the health care institutions at a regional level. In a cross border region this urges for cross border agreement of infection control policies and increase of cooperation not only nationally but also Euregionally, between the countries. Exchange of knowledge and experience will improve patient care and patient safety in the subregions of this Euregion ${ }^{108}$.

\section{Spread of resistance}

Ever since the introduction of antibiotics, counter mechanism have been developed and adapted by bacteria. Due to globalization and increase of international and intercontinental travel these resistant bacteria spread across the globe ${ }^{105}$.

\section{MRSA}

Just a few years after the introduction of penicillin, the first penicillin resistant strain was isolated. At the introduction of methicillin, in 1959, penicillin resistance was already around $80 \%$ and has remained high until this day ${ }^{54,114,115}$. Shortly, after the 
introduction of methicillin, a resistant S. aureus (MRSA) strain was isolated in Europe. The prevalence of MRSA has increased over the years and spread across the world ${ }^{54}$. The origin of MRSA is not proven but suggested most is that the SCCmec was introduced into several S. aureus lineages (multi clone theory) instead of the SCCmec acquisition of just one strain as the ancestor of all MRSA clones ${ }^{116-118}$. Typing methods have shown that globally several MRSA clones are epidemic and most of those clones have also been isolated in the Netherlands, Belgium and Germany. The most prevalent include: ST45-MRSA-IV (Berlin clone), ST5-MRSA-II (New York/Japan or Rhine Hesse clone), ST5-MRSA-IV (Pediatric clone), ST8-MRSA-IV (EMRSA-2/6 or USA300 if PVLpositive) and ST22-MRSA-IV (EMRSA-15) ${ }^{119-121}$. The overall prevalence of MRSA is variable between and within countries and between patient populations. Overall, the prevalence of MRSA is higher in hospitals and nursing homes compared with the community $^{83,92,122 .}$

\section{Beta-lactamases}

Like the Gram positive S. aureus, the Gram negatives developed resistance mechanisms to combat the antibiotics. The first penicillinase (also a beta-lactamase) producing $E$. coli was already observed before the introduction of penicillin ${ }^{63}$ and this property has rapidly spread to other species. With the introduction of the first cephalosporines treatment options increased but this was also more or less the start of the emergence of more broad spectrum beta-lactamases (TEM and SHV), which were capable of hydrolyzing first generation cephalosporines. These beta-lactamases were already widespread among $E$. coli isolates in the early $1970 s^{62}$. However, with the introduction and increased use of beta-lactamase resistant cephalosporines (third generation cephalosporines) newer beta-lactamases, i.e. the extended spectrum betalactamases $(E S B L)$, were isolated ${ }^{62,123}$. Since then many ESBLs have been detected. One mutation in the DNA sequence of the beta-lactmase gene leads to a new different $\mathrm{ESBL}$, which is amongst others the reason for the explosive increase in prevalence of ESBLs. At present the most prevalent ESBL types belong to the CTX-M class together with TEM and SHV types ${ }^{123}$. The spread of these enzymes is nowadays mostly through transfer of plasmids and other mobile genetic elements ${ }^{69}$.

In the Euregion Meuse-Rhine CTX-M-15, CTX-M-1, CTX-M-14, SHV-12, TEM-52 are common among $E$. coli isolates ${ }^{102,124}$. An example of the global spread of the ESBLs is the UTI causing E. coli $025: \mathrm{H} 4-\mathrm{ST} 131^{125-127}$. This strain has been associated with the increased prevalence of $C T X-M-15^{125}$, is able to pick up new resistance properties easily and has been isolated in most European countries. ST131 strains carry genes encoding for multiple beta-lactamases including ESBLs, fluoroquinolones resistance and recently a carbapenemase gene have been described ${ }^{127,128}$.

Carbapenemases are a more recent problem among antibiotic resistant bacteria. These mostly plasmid mediated beta-lactamases confer resistance to the antibiotics of last resort: the carbapenems. The types most prevalent are: KPC, VIM, IMP, NDM and $\mathrm{OXA}^{65,129}$, which are not yet very frequently found in Western Europe. Infections with carbapenemase producing isolates can often be traced back to hospital admittance in countries where those carbapenemases are endemic, such as India and Pakistan ${ }^{130}$. The production of carbapenemases is a point of concern as: 1) their prevalence is 
increasing, 2) the number of alternative treatment options is limited and 3) the pipeline of new antibiotic drugs is almost empty. If the prevalence of carbapenemase producing isolates increases, this could lead to a situation comparable to the time before the antibiotics, the pre penicillin era.

\section{Typing of Staphylococcus aureus and Escherichia coli}

To analyze a possible outbreak or spread of a certain (antibiotic resistant) strain, several typing techniques (sequence based and band based) have been developed to establish a possible relatedness between the isolates. Some techniques can be used for multiple species, such as pulsed field gel electrophoresis (PFGE), multi locus sequence typing (MLST) and multi locus variable number tandem repeat analysis (MLVA), while others are species specific, such as spa typing (S. aureus) and SCCmec typing (MRSA). The choice of typing method is dependent on 1) the research question (local outbreak or epidemiological study), 2) the discriminatory power, 3) interlaboratory comparability, 4) hands-on time, 5) time-to-results and 6) costs of the method. For an outbreak investigation PFGE, MLVA and spa typing are usefull, but in (large) epidemiological studies MLST and SCCmec and spa typing are more widely used, but also MLVA could be an option.

\section{PFGE}

Pulsed field gel electrophoresis, a band based method, is performed by lysing the bacteria and digesting the bacterial DNA with infrequently cutting restriction enzymes such as Smal for S. aureus and Xbal for E. coli and K. pneumoniae. The DNA fragments are then separated using gel electrophoresis for a "DNA fingerprint"131, 132. This fingerprint can be compared with the fingerprints of other isolates to determine relatedness according to criteria set by Tenover et $\mathrm{al}^{133}$. PFGE is a laborious method with high discriminatory power but the interlaboratory reproducibility is low ${ }^{134}$, also due to the lack of one single protocol. Until now PFGE is still often used, mostly to analyse local outbreaks.

\section{MLST}

Multi locus sequence typing is a sequence based method. For this typing method the DNA sequences of seven or eight house keeping genes are determined. These genes are chosen specifically for each species ${ }^{135,136}$. With these sequences, allelic polymorphism can be determined. The DNA sequences of these seven genes form a sequence type, which can be analysed with the international MLST database and can be clustered into clonal complexes with eBURST. MLST is, like PFGE, a labor intensive and expensive method $^{134}$. However, the MLST results are, due to the use of an international database and a standardized protocol, easily and reliably comparable between laboratories. MLST is considered the gold standard for large epidemiological studies but is not useful to determine hospital outbreaks, due to a slightly lower discriminatory power compared to PFGE and MLVA ${ }^{134}$. 


\section{MLVA}

Multi locus variable number tandem repeat analysis is a newer method and is compared with MLST less expensive and less labor intensive with a higher discriminatory power ${ }^{134}$. For this analysis the number of tandem repeats is determined for seven or eight loci in the genome of the target bacteria. The loci differ per species. This method can be performed with conventional PCR and gel electrophoresis (band based method) ${ }^{137}$, which requires large size of the repeats. Another option includes a real time PCR with fluorescent labeled products after which the product size is determined with an automated DNA sequencer ${ }^{134}$. The accurately determined number of repeats can be entered in a database, which makes interlaboratory comparison and clustering of related strains manageable. Since sequence analysis is not necessary with this method, it is less costly than the MLST method.

\section{Spa typing}

Spa typing is, just as MLST, a DNA sequence based approach. The target is one locus: the polymorphic repeat region of the Staphylococcus protein A gene ${ }^{138}$. This method can be used to determine both hospital outbreaks of S. aureus as well as clonal relatedness in epidemiological studies. Due to the single locus scheme this method is less expensive and laborious. There is also an international database available to compare the spa typing data ${ }^{139}$ and with algorithm Based Upon Repeat Pattern (BURP) it is also possible to cluster these spa data, which has good concordance with MLST and PFGE $^{140}$.

\section{SCCmec typing}

The SCCmec type of a MRSA can be determined with a PCR either by targeting different loci in the different $\mathrm{SCCmec}$ complexes or by determining the structure of the mec complex and de ccr genes. This can be done with a conventional or a real time PCR and with or without a multiplex assay ${ }^{56,141-146}$. However, due to the high number of major and minor SCCmec variants, it is not possible to detect all types and their variants with any of those methods. A method such as a micro-array might be able to resolve this issue. $\mathrm{SCCmec}$ typing is used in epidemiological studies to determine the genetic background of MRSA clones.

\section{Conclusion}

S. aureus and E. coli are both part of the human commensal flora. Infections caused by these bacteria are prevalent in the community, nursing homes and hospitals, and often require antibiotic treatment. The prevalence of antibiotic resistance determines, amongst others, which antibiotics are appropriate as empiric treatment choice for these infections. Since the introduction of antibiotics, bacteria have developed different ways to combat these agents and have become resistance. Some of these mechanisms of resistance have spread between bacteria and across the globe.

In the past especially the multi drug resistant Gram positive bacteria, such as MRSA, have been a point of concern but more recently, the "neglected" Gram negatives have now emerged as a problem. In particular, since new types of beta-lactamases are 
being detected with the ability to resist even the antibiotic agents of last resort. Cross border movements, such as in the Euregion Meuse-Rhine and international travel are important factors in the spread of these resistant strains. Therefore, action should be taken to control the increasing prevalence of antibiotic resistance and to prevent a situation comparable to the time before the antibiotics, when infections could not be treated. 


\section{Aim \& and outline of the thesis}

Differences in prevalence of resistance between and within countries and between different populations affect cross border movement and pose a challenge for medical doctors for appropriate empiric antibiotic treatment. Also, patients crossing the border can potentially carry bacteria with a variety of antibiotic resistance genes and might contribute to the spread of resistant strains.

The prevalence of antibiotic resistance can be determined for a wide range of microorganisms but the main focus of this thesis was to evaluate the antibiotic resistance of two potential pathogenic commensals in a cross border region: 1) $E$. coli, the most prevalent causative agent of UTIs, 2) S. aureus, a primary cause of skin and soft tissue infections. Both types of infections are amongst the most common bacterial infections especially among GP patients and NH residents.

The aims of this thesis were to assess the prevalence and spread of resistance among $S$. aureus and $E$. coli isolated from the community, nursing home residents and hospitalized patients in the border region "the Euregion Meuse-Rhine". Antibiotic resistance surveillance studies provide important information on the prevalence and spread of antibiotic resistance and are necessary for the selection of empirical therapy and infection control policies at a local level.

In Chapter 1, the general introduction, the characteristics of $E$. coli, S. aureus and $K$. pneumoniae will be discussed. Also, several antibiotic agents, resistance mechanisms and spread of resistance are reviewed. The risk factors of resistance and the impact of a cross border region are described. Finally, different typing methods are discussed.

The prevalence of resistance of $E$. coli isolates collected from patients attending the urology services in the Euregion Meuse-Rhine is analyzed and discussed in chapter 2. These are patients, often with recurrent and complicated urinary tract infections. Due to the relatively high use of a small number of antibiotics among those patients, the resistance is expected to be higher than among GP patients.

The nursing home residents are another population where the prevalence of antibiotic resistance is assumed to be relatively high. They are vulnerable and often have several risk factors for the acquisition of a resistant strain. The antibiotic resistance of $E$. coli and the antibiotic use among nursing home residents in Limburg, a province in the Southern part of the Netherlands, are discussed in Chapter 3.

The spread of resistant strains among different populations and across the border is a point of concern. This spread is also a potential threat for acquiring an infection with such a resistant strain. Therefore, the spread of ESBL producing and other multi drug resistant $E$. coli isolates collected from four patient populations (GP patients, NH residents, Urology and ICU patients) in the entire Euregion Meuse-Rhine was investigated with MLST and PFGE (Chapter 4).

Nursing home residents are often regarded a reservoir for MRSA and other multi drug resistant strains, therefore, Chapter 5 describes the resistance of $S$. aureus including the prevalence of MRSA among nursing home residents in the province of Limburg, the Netherlands and the regions of Euskirchen and Daun, Germany. 
Cross border health care and the potential threat of difference in antibiotic resistance for a country with low resistance, such as the Netherlands, is often discussed. In Chapter 6 the potential influence of the higher prevalence of resistance in Belgium and Germany on the border region of Limburg was determined by comparing the antibiotic resistance and population structure of $S$. aureus in the province of Limburg with the other provinces in the Netherlands.

In Chapter 7 the data on the antibiotic resistance, the prevalence of ESBL producing isolates and the implications on empiric treatment for $K$. pneumoniae isolated from urology and ICU patients over a 12 year period are presented. These bacteria are, even more than $E$. coli, known for their multi drug resistance.

In Chapter 8, the results of the previous chapters together with implications for antibiotic treatment, future perspectives and additional recommendations will be discussed. 


\section{References}

1. Berg RD. The indigenous gastrointestinal microflora. Trend Microbiol 1996; 4: 430-5.

2. Fanaro $S$, Chierici R, Guerrini $P$ et al. Intestinal microflora in early infancy: composition and development. Acta Paediatr Suppl 2003; 91: 48-55.

3. Sekirov I, Russell SL, Antunes LC et al. Gut microbiota in health and disease. Phys Rev 2010; 90: 859-904.

4. Cogen AL, Nizet V, Gallo RL. Skin microbiota: a source of disease or defence? $\mathrm{Br} \mathrm{J}$ Dermatol 2008; 158: 442-55.

5. O'Hara AM, Shanahan F. The gut flora as a forgotten organ. EMBO reports 2006; 7: 68893.

6. Allen CA, Torres AG. Host-microbe communication within the Gl tract. Adv Exp Med Biol 2008; 635: 93-101.

7. $\quad$ Lowy FD. Staphylococcus aureus infections. N Eng J Med 1998; 339: 520-32.

8. Wertheim HF, Melles DC, Vos MC et al. The role of nasal carriage in Staphylococcus aureus infections. Lancet Infect Dis 2005; 5: 751-62.

9. Bode LG, Kluytmans JA, Wertheim HF et al. Preventing surgical-site infections in nasal carriers of Staphylococcus aureus. N Eng J Med 2010; 362: 9-17.

10. von Eiff C, Becker K, Machka K et al. Nasal carriage as a source of Staphylococcus aureus bacteremia. Study Group. N Eng J Med 2001; 344: 11-6.

11. Shulman ST, Friedmann HC, Sims RH. Theodor Escherich: the first pediatric infectious diseases physician? Clin Infect Dis 2007; 45: 1025-9.

12. Beerepoot MA, den Heijer CD, Penders J et al. Predictive value of Escherichia coli susceptibility in strains causing asymptomatic bacteriuria for women with recurrent symptomatic urinary tract infections receiving prophylaxis. Clin Microbiol Infect 2012; 18: E84-90.

13. Yamamoto S, Tsukamoto T, Terai A et al. Genetic evidence supporting the fecalperineal-urethral hypothesis in cystitis caused by Escherichia coli. J Urol 1997; 157: 1127-9.

14. Levinson W. Chapter 18: Gram negative rods related to the enteric tract. Review of Medical Microbiology and Immunology, 11th edition, 2010; 122-40.

15. Escobar-Paramo P, Clermont $\mathrm{O}$, Blanc-Potard AB et al. A specific genetic background is required for acquisition and expression of virulence factors in Escherichia coli. Mol Biol Evol 2004; 21: 1085-94.

16. Johnson JR, Owens K, Gajewski A et al. Bacterial characteristics in relation to clinical source of Escherichia coli isolates from women with acute cystitis or pyelonephritis and uninfected women. J Clin Microbiol 2005; 43: 6064-72.

17. Wiles TJ, Kulesus RR, Mulvey MA. Origins and virulence mechanisms of uropathogenic Escherichia coli. Exp Mol Pathol 2008; 85: 11-9.

18. Julius-Maximilians Universität Würzburg. Edwin Klebs, Vorstand van 1872-1873. http://www.pathologie.uni-wuerzburg.de/geschichte/historische_direktoren/edwin_klebs/ (2 August 2012 - Date last accessed).

19. Podschun R, Ullmann U. Klebsiella spp. as nosocomial pathogens: epidemiology, taxonomy, typing methods, and pathogenicity factors. Clin Microbiol Rev 1998; 11: 589-603.

20. Das R, Perrelli E, Towle $V$ et al. Antimicrobial susceptibility of bacteria isolated from urine samples obtained from nursing home residents. Infect Control Hosp Epidemiol 2009; 30: 1116-9.

21. den Heijer CD, Donker GA, Maes $\mathrm{J}$ et al. Antibiotic susceptibility of unselected uropathogenic Escherichia coli from female Dutch general practice patients: a comparison of two surveys with a 5 year interval. J Antimicrob Chemother 2010; 65: 2128-33.

22. Matthews SJ, Lancaster JW. Urinary tract infections in the elderly population. Am J Ger Pharmacother 2011; 9: 286-309. 
23. SWAB. Nethmap 2011 - Consumption of antimicrobial agents and antimicrobial resistance among medically important bacteria in the Netherlands. 2011.

24. Gupta K, Hooton TM, Naber KG et al. International clinical practice guidelines for the treatment of acute uncomplicated cystitis and pyelonephritis in women: A 2010 update by the Infectious Diseases Society of America and the European Society for Microbiology and Infectious Diseases. Clin Infect Dis 2011; 52: e103-20.

25. Nederlandse Vereninging voor Urologie. Bacteriële urineweginfecties bij adolescenten in volwassen: Etiologie, diagnostiek, behandeling en profylaxe., 2009.

26. Stevens DL, Bisno AL, Chambers HF et al. Practice guidelines for the diagnosis and management of skin and soft-tissue infections. Clin Infect Dis 2005; 41: 1373-406.

27. Schofer H, Simonsen L. Fusidic acid in dermatology: an updated review. Eur J Dermatol 2010; 20: 6-15.

28. Smith KA. Louis pasteur, the father of immunology? Front Immunol 2012; 3: 68.

29. Zaffiri L, Gardner J, Toledo-Pereyra LH. History of antibiotics. From salvarsan to cephalosporins. J Invest Surg 2012; 25: 67-77.

30. Dijkshoorn L. Alexander Fleming - De ontdekker van penicilline. Chapter 42: Microcanon - Wat he beslist moet weten over microbiologie, 2001; 159-61.

31. Willing BP, Russell SL, Finlay BB. Shifting the balance: antibiotic effects on hostmicrobiota mutualism. Nature Rev Microbiol 2011; 9: 233-43.

32. Guay DR. An update on the role of nitrofurans in the management of urinary tract infections. Drugs 2001; 61: 353-64.

33. Gilbert DN, Moellering RC, Eliopoulos GM et al. The Sanford guide to antimicrobial therapy - 39th edition, 2009.

34. Charalabopoulos K, Karachalios G, Baltogiannis D et al. Penetration of antimicrobial agents into the prostate. Chemotherapy 2003; 49: 269-79.

35. Karageorgopoulos DE, Wang R, Yu XH et al. Fosfomycin: evaluation of the published evidence on the emergence of antimicrobial resistance in Gram-negative pathogens. J Antimicrob Chemother 2012; 67: 255-68.

36. Garau J. Other antimicrobials of interest in the era of extended-spectrum betalactamases: fosfomycin, nitrofurantoin and tigecycline. Clin Microbiol Infect 2008; 14 Suppl 1: 198-202.

37. Raz R. Fosfomycin: an old-new antibiotic. Clin Microbiol Infect 2012; 18 : 4-7.

38. Naber KG, Schito G, Botto $\mathrm{H}$ et al. Surveillance study in Europe and Brazil on clinical aspects and Antimicrobial Resistance Epidemiology in Females with Cystitis (ARESC): implications for empiric therapy. Eur Urol 2008; 54: 1164-75.

39. Daneman N, Gruneir A, Newman A et al. Antibiotic use in long-term care facilities. $J$ Antimicrob Chemother 2011; 66: 2856-63.

40. McClean $\mathrm{P}$, Hughes $\mathrm{C}$, Tunney $\mathrm{M}$ et al. Antimicrobial prescribing in European nursing homes. J Antimicrob Chemother 2011; 66: 1609-16.

41. Nicolle LE, Bentley DW, Garibaldi R et al. Antimicrobial use in long-term-care facilities. SHEA Long-Term-Care Committee. Infect Control Hosp Epidemiol 2000; 21: 537-45.

42. Ruiz J. Mechanisms of resistance to quinolones: target alterations, decreased accumulation and DNA gyrase protection. $J$ Antimicrob Chemother 2003; 51: 1109-17.

43. Hooper DC. Mechanisms of fluoroquinolone resistance. Drug Resist Updates 1999; 2: 38-

55.

44. Oliphant CM, Green GM. Quinolones: a comprehensive review. Am Fam Physician 2002; 65: 455-64.

45. Levinson W. Chapter 10: Antimicrobial Drugs: Mechanism of Action. Review of Medical Microbiology and Immunology, 11th edition, 2010; 60-74.

46. College voor Zorgverzekeringen. Farmacotherapeutisch Kompas http://www.fk.cvz.nl/ (20 August 2012 - date last accessed). 
47. Roberts MC. Resistance to macrolide, lincosamide, streptogramin, ketolide, and oxazolidinone antibiotics. Mol Biotechnol 2004; 28: 47-62.

48. Leclercq R. Mechanisms of resistance to macrolides and lincosamides: nature of the resistance elements and their clinical implications. Clin Infect Dis 2002; 34: 482-92.

49. Howden BP, Grayson ML. Dumb and dumber--the potential waste of a useful antistaphylococcal agent: emerging fusidic acid resistance in Staphylococcus aureus. Clin Infect Dis 2006; 42: 394-400.

50. SWAB. Nethmap 2012 - Consumption of antimicrobial agents and antimicrobial resistance among medically important bacteria in the Netherlands. 2012.

51. Rijnders MI, Wolffs PF, Hopstaken RM et al. Spread of the epidemic European fusidic acid-resistant impetigo clone (EEFIC) in general practice patients in the south of The Netherlands. J Antimicrob Chemother 2012; 67: 1176-80.

52. Levinson W. Chapter 11: Antimicrobial Drugs: Resistance. Review of Medical Microbiology and Immunology, 11th edition, 2010; 75-82.

53. Enright MC. The evolution of a resistant pathogen--the case of MRSA. Curr Op Pharmacol 2003; 3: 474-9.

54. Deurenberg RH, Stobberingh EE. The evolution of Staphylococcus aureus. Infect Genet Evol 2008; 8: 747-63.

55. Ito T, Katayama Y, Hiramatsu K. Cloning and nucleotide sequence determination of the entire mec DNA of pre-methicillin-resistant Staphylococcus aureus N315. Antimicrob Agents Chemother 1999; 43: 1449-58.

56. Valvatne H, Rijnders Ml, Budimir A et al. A rapid, 2-well, multiplex real-time polymerase chain reaction assay for the detection of $\mathrm{SCCmec}$ types I to $\mathrm{V}$ in methicillin-resistant Staphylococcus aureus. Diagn Microbiol Infect Dis 2009; 65: 384-91.

57. Classification of staphylococcal cassette chromosome mec ( $\mathrm{SCCmec}$ ): guidelines for reporting novel SCCmec elements. Antimicrob Agents Chemother 2009; 53: 4961-7.

58. Li S, Skov RL, Han X et al. Novel types of staphylococcal cassette chromosome mec elements identified in clonal complex 398 methicillin-resistant Staphylococcus aureus strains. Antimicrob Agents Chemother 2011; 55: 3046-50.

59. Shore AC, Deasy EC, Slickers P et al. Detection of staphylococcal cassette chromosome mec type XI carrying highly divergent mecA, mecl, mecR1, blaZ, and ccr genes in human clinical isolates of clonal complex 130 methicillin-resistant Staphylococcus aureus. Antimicrob Agents Chemother 2011; 55: 3765-73.

60. Otter JA, French GL. Nosocomial transmission of community-associated methicillinresistant Staphylococcus aureus: an emerging threat. Lancet Infect Dis 2006; 6: 753-5.

61. Brook I. The role of beta-lactamase-producing-bacteria in mixed infections. $B M C$ infectious diseases 2009; 9: 202.

62. Livermore DM. Defining an extended-spectrum beta-lactamase. Clin Microbiol Infect 2008; 14 Suppl 1: 3-10.

63. Abraham EP, Chain E. An enzyme from bacteria able to destroy penicillin. 1940. Rev Infect Dis 1988; 10: 677-8.

64. Jacoby GA. AmpC beta-lactamases. Clin Microbiol Rev 2009; 22: 161-82.

65. Nordmann P, Naas T, Poirel L. Global spread of Carbapenemase-producing Enterobacteriaceae. Emerg Infect Dis 2011; 17: $1791-8$.

66. Pitout JD, Laupland KB. Extended-spectrum beta-lactamase-producing Enterobacteriaceae: an emerging public-health concern. Lancet Infect Dis 2008; 8: 159-66.

67. Jacoby GA, Munoz-Price LS. The new beta-lactamases. New Engl J Med 2005; 352: 380-

91.

68. Bush K, Jacoby GA. Updated functional classification of beta-lactamases. Antimicrob Agents Chemother 2010; 54: 969-76. 
69. Schultsz C, Geerlings S. Plasmid-mediated resistance in Enterobacteriaceae: changing landscape and implications for therapy. Drugs 2012; 72: 1-16.

70. Carattoli A. Resistance plasmid families in Enterobacteriaceae. Antimicrob Agents Chemother 2009; 53: 2227-38.

71. Lautenbach E, Patel JB, Bilker WB et al. Extended-spectrum beta-lactamase-producing Escherichia coli and Klebsiella pneumoniae: risk factors for infection and impact of resistance on outcomes. Clin Infect Dis 2001; 32: 1162-71.

72. Tumbarello M, Sanguinetti M, Montuori E et al. Predictors of mortality in patients with bloodstream infections caused by extended-spectrum-beta-lactamase-producing Enterobacteriaceae: importance of inadequate initial antimicrobial treatment. Antimicrob Agents Chemother 2007; 51: 1987-94.

73. Drieux L, Brossier F, Sougakoff W et al. Phenotypic detection of extended-spectrum beta-lactamase production in Enterobacteriaceae: review and bench guide. Clin Microbiol Infect 2008; 14 Suppl 1: 90-103.

74. Nordmann P, Dortet L, Poirel L. Rapid detection of extended-spectrum ss-lactamaseproducing Enterobacteriaceae. J Clin Microbiol 2012.

75. Nordmann P, Poirel L, Dortet L. Rapid Detection of Carbapenemase-producing Enterobacteriaceae. Emerg Infect Dis 2012; 18: 1503-7.

76. Pallecchi L, Malossi M, Mantella A et al. Detection of CTX-M-type beta-lactamase genes in fecal Escherichia coli isolates from healthy children in Bolivia and Peru. Antimicrob Agents Chemother 2004; 48: 4556-61.

77. Pitout JD, Hossain A, Hanson ND. Phenotypic and molecular detection of CTX-M-betalactamases produced by Escherichia coli and Klebsiella spp. J Clin Microbiol 2004; 42: 5715-21.

78. Saladin M, Cao VT, Lambert T et al. Diversity of CTX-M beta-lactamases and their promoter regions from Enterobacteriaceae isolated in three Parisian hospitals. FEMS microbiology letters 2002; 209: 161-8.

79. Pagani L, Dell'Amico E, Migliavacca R et al. Multiple CTX-M-type extended-spectrum beta-lactamases in nosocomial isolates of Enterobacteriaceae from a hospital in northern Italy. $J$ Clin Microbiol 2003; 41: 4264-9.

80. Naas T, Cuzon G, Bogaerts $P$ et al. Evaluation of a DNA microarray (Check-MDR CT102) for rapid detection of TEM, SHV, and CTX-M extended-spectrum beta-lactamases and of KPC, OXA-48, VIM, IMP, and NDM-1 carbapenemases. J Clin Microbiol 2011; 49: 1608-13.

81. Adriaenssens N, Coenen S, Versporten A et al. European Surveillance of Antimicrobial Consumption (ESAC): outpatient quinolone use in Europe (1997-2009). J Antimicrob Chemother 2011; 66 Suppl 6: vi47-56.

82. Goossens H, Ferech M, Vander Stichele R et al. Outpatient antibiotic use in Europe and association with resistance: a cross-national database study. Lancet 2005; 365: 579-87.

83. ECDC. Antimicrobial resistance surveillance in Europe 2010. Annual Report of the European Antimicrobial Resistance Surveillance Network (EARS-Net). 2011.

84. Karah N, Poirel $\mathrm{L}$, Bengtsson $\mathrm{S}$ et al. Plasmid-mediated quinolone resistance determinants qnr and aac(6')-lb-cr in Escherichia coli and Klebsiella spp. from Norway and Sweden. Diagn Microbiol Infect Dis 2010; 66: 425-31.

85. Van der Donk CFM, Van de Bovenkamp JHB, De Brauwer ElHB et al. Antimicrobial resistance and spread of multi drug resistant Escherichia coli isolates collected from nine urology services in the Euregion Meuse-Rhine.PLoS ONE 2012; 7(10):e47707.

86. Sandegren $L$, Lindqvist $A$, Kahlmeter $G$ et al. Nitrofurantoin resistance mechanism and fitness cost in Escherichia coli. J Antimicrob Chemother 2008; 62: 495-503.

87. von Baum H, Schmidt C, Svoboda D et al. Risk factors for methicillin-resistant Staphylococcus aureus carriage in residents of German nursing homes. Infect Control Hosp Epidemiol 2002; 23: 511-5. 
88. Brugnaro P, Fedeli U, Pellizzer $G$ et al. Clustering and risk factors of methicillinresistant Staphylococcus aureus carriage in two Italian long-term care facilities. Infection 2009; 37: 216-21.

89. Colodner R, Rock W, Chazan B et al. Risk factors for the development of extendedspectrum beta-lactamase-producing bacteria in nonhospitalized patients. Eur J Clin Microbiol Infect Dis 2004; 23: 163-7.

90. Graffunder EM, Preston KE, Evans $A M$ et al. Risk factors associated with extendedspectrum beta-lactamase-producing organisms at a tertiary care hospital. $J$ Antimicrob Chemother 2005; 56: 139-45.

91. Troughton JA, Millar G, Smyth ET et al. Ciprofloxacin use and susceptibility of Gramnegative organisms to quinolone and non-quinolone antibiotics. J Antimicrob Chemother 2011; 66: 2152-8.

92. Barr B, Wilcox MH, Brady A et al. Prevalence of methicillin-resistant Staphylococcus aureus colonization among older residents of care homes in the United Kingdom. Infect Control Hosp Epidemiol 2007; 28: 853-9.

93. Rooney PJ, O'Leary MC, Loughrey AC et al. Nursing homes as a reservoir of extendedspectrum beta-lactamase (ESBL)-producing ciprofloxacin-resistant Escherichia coli. J Antimicrob Chemother 2009; 64: 635-41.

94. Lautenbach E, Marsicano R, Tolomeo P et al. Epidemiology of antimicrobial resistance among gram-negative organisms recovered from patients in a multistate network of long-term care facilities. Infect Control Hosp Epidemiol 2009; 30: 790-3.

95. Xie C, Taylor DM, Howden BP et al. Comparison of the bacterial isolates and antibiotic resistance patterns of elderly nursing home and general community patients. Intern Med J 2011.

96. Nicolle LE, Strausbaugh LJ, Garibaldi RA. Infections and antibiotic resistance in nursing homes. Clin Microbiol Rev 1996; 9: 1-17.

97. Fluit AC. Livestock-associated Staphylococcus aureus. Clin Microbiol Infect 2012.

98. Grave K, Torren-Edo J, Mackay D. Comparison of the sales of veterinary antibacterial agents between 10 European countries. J Antimicrob Chemother 2010; 65: 2037-40.

99. Bisdorff B, Scholholter JL, Claussen $\mathrm{K}$ et al. MRSA-ST398 in livestock farmers and neighbouring residents in a rural area in Germany. Epidemiol Infect 2011: 1-9.

100. Nijsten R, London N, van den Bogaard A et al. Resistance in faecal Escherichia coli isolated from pigfarmers and abattoir workers. Epidemiol Infect 1994; 113: 45-52.

101. Leverstein-van Hall MA, Dierikx CM, Cohen Stuart J et al. Dutch patients, retail chicken meat and poultry share the same ESBL genes, plasmids and strains. Clin Microbiol Infect 2011; 17: 873-80.

102. Overdevest I, Willemsen I, Rijnsburger $M$ et al. Extended-spectrum beta-lactamase genes of Escherichia coli in chicken meat and humans, The Netherlands. Emerg Infect Dis 2011; 17: 1216-22.

103. Dhanji H, Patel R, Wall R et al. Variation in the genetic environments of bla(CTX-M-15) in Escherichia coli from the faeces of travellers returning to the United Kingdom. $J$ Antimicrob Chemother 2011; 66: 1005-12.

104. Tangden T, Cars O, Melhus A et al. Foreign travel is a major risk factor for colonization with Escherichia coli producing CTX-M-type extended-spectrum beta-lactamases: a prospective study with Swedish volunteers. Antimicrob Agents Chemother 2010; 54: 3564-8.

105. van der Bij AK, Pitout JD. The role of international travel in the worldwide spread of multiresistant Enterobacteriaceae. J Antimicrob Chemother 2012.

106. Communication from the commission - A community framework on the application of patients' rights in cross-border healthcare $\{$ SEC(2008) 2183\} COM/2008/0415 final - http://eurlex.europa.eu/LexUriServ/LexUriServ.do?uri=CELEX:52008DC0415:EN:NOT). Last accessed on 13 October 2011, date last accessed). 
107. Commission of the European Communities. Proposal for a directive of the European parliament and the council on the application of patients' rights in cross-border healthcare. Brussels, 2.7.2008. $\operatorname{COM}(2008) 414$ final.

108. Friedrich AW, Daniels-Haardt I, Kock R et al. EUREGIO MRSA-net Twente/Munsterland--a Dutch-German cross-border network for the prevention and control of infections caused by methicillin-resistant Staphylococcus aureus. Euro Surveill 2008; 13.

109. Infection Prevention Working Party. MRSA Hospital. 2012.

110. Wismar M, Palm W, Figueras J et al. The European Observatory on Health Systems and Policies. Cross-border Health Care in the European Union: Mapping and analysing practices and policies. 2011.

111. EIS. Euregion Meuse-Rhine in figures. 2007.

112. Donker $\mathrm{T}$, Wallinga J, Slack $\mathrm{R}$ et al. Hospital networks and the dispersal of hospitalacquired pathogens by patient transfer. PLoS One 2012; 7: e35002.

113. Grundmann H, Aanensen DM, van den Wijngaard CC et al. Geographic distribution of Staphylococcus aureus causing invasive infections in Europe: a molecular-epidemiological analysis. PLoS medicine 2010; 7: e1000215.

114. Rijnders $M$, Nys $S$, Driessen $C$ et al. Staphylococcus aureus carriage among GPs in The Netherlands. Br J Gen Pract 2010; 60: 902-6.

115. Rijnders MI, Deurenberg RH, Boumans ML et al. Flucloxacillin, still the empirical choice for putative Staphylococcus aureus infections in intensive care units in the Netherlands. $J$ Antimicrob Chemother 2009; 64: 1029-34.

116. Enright $M C$, Robinson DA, Randle $G$ et al. The evolutionary history of methicillinresistant Staphylococcus aureus (MRSA). Proc Natl Acad Sci 2002; 99: 7687-92.

117. Kreiswirth B, Kornblum J, Arbeit RD et al. Evidence for a clonal origin of methicillin resistance in Staphylococcus aureus. Science 1993; 259: 227-30.

118. Nubel $U$, Roumagnac $P$, Feldkamp $M$ et al. Frequent emergence and limited geographic dispersal of methicillin-resistant Staphylococcus aureus. Proc Natl Acad Sci 2008; 105: 14130-5.

119. Robert Koch-Institut. Epidemiologisches Bulletin. 4 July 2011. Nr. 26.

120. Deurenberg RH, Nulens $\mathrm{E}$, Valvatne $\mathrm{H}$ et al. Cross-border dissemination of methicillinresistant Staphylococcus aureus, Euregio Meuse-Rhin region. Emerg Infect Dis 2009; 15: 727-34.

121. Deurenberg RH, Vink C, Oudhuis GJ et al. Different clonal complexes of methicillinresistant Staphylococcus aureus are disseminated in the Euregio Meuse-Rhine region. Antimicrob Agents Chemother 2005; 49: 4263-71.

122. Heijer den CDJ, Bijnen van EME, Paget WJ et al. Prevalence and susceptibility of commensal S. aureus in nine European countries World Organization of Family Doctors Europe Conference, 2012.

123. Canton R, Novais A, Valverde A et al. Prevalence and spread of extended-spectrum beta-lactamase-producing Enterobacteriaceae in Europe. Clin Microbiol Infect 2008; 14 Suppl 1: 144-53.

124. Rodriguez-Villalobos $\mathrm{H}$, Bogaerts $\mathrm{P}$, Berhin $\mathrm{C}$ et al. Trends in production of extendedspectrum beta-lactamases among Enterobacteriaceae of clinical interest: results of a nationwide survey in Belgian hospitals. J Antimicrob Chemother 2011; 66: 37-47.

125. Gibreel TM, Dodgson AR, Cheesbrough J et al. Population structure, virulence potential and antibiotic susceptibility of uropathogenic Escherichia coli from Northwest England. J Antimicrob Chemother 2012; 67: 346-56.

126. Ho PL, Lo WU, Lai EL et al. Escherichia coli O25b-ST131 is an important cause of antimicrobial-resistant infections in women with uncomplicated cystitis. $J$ Antimicrob Chemother 2012.

127. Johnson JR, Johnston B, Clabots C et al. Escherichia coli sequence type ST131 as the major cause of serious multidrug-resistant $\mathrm{E}$. coli infections in the United States. Clin Infect Dis 2010; 51: 286-94. 
128. Peirano G, Schreckenberger PC, Pitout JD. Characteristics of NDM-1-producing Escherichia coli isolates that belong to the successful and virulent clone ST131. Antimicrob Agents Chemother 2011; 55: 2986-8.

129. Canton R, Akova M, Carmeli $Y$ et al. Rapid evolution and spread of carbapenemases among Enterobacteriaceae in Europe. Clin Microbiol Infect 2012; 18: 413-31.

130. Struelens MJ, Monnet DL, Magiorakos AP et al. New Delhi metallo-beta-lactamase 1producing Enterobacteriaceae: emergence and response in Europe. Euro Surveill 2010; 15.

131. Mulvey MR, Chui L, Ismail J et al. Development of a Canadian standardized protocol for subtyping methicillin-resistant Staphylococcus aureus using pulsed-field gel electrophoresis. J Clin Microbiol 2001; 39: 3481-5.

132. Ribot EM, Fair MA, Gautom R et al. Standardization of pulsed-field gel electrophoresis protocols for the subtyping of Escherichia coli 0157:H7, Salmonella, and Shigella for PulseNet. Foodborne Pathog Dis 2006; 3: 59-67.

133. Tenover FC, Arbeit RD, Goering RV et al. Interpreting chromosomal DNA restriction patterns produced by pulsed-field gel electrophoresis: criteria for bacterial strain typing. $J$ Clin Microbiol 1995; 33: 2233-9.

134. Schouls LM, Spalburg EC, van Luit $M$ et al. Multiple-locus variable number tandem repeat analysis of Staphylococcus aureus: comparison with pulsed-field gel electrophoresis and spa-typing. PLoS One 2009; 4: e5082.

135. Enright MC, Day NP, Davies CE et al. Multilocus sequence typing for characterization of methicillin-resistant and methicillin-susceptible clones of Staphylococcus aureus. J Clin Microbiol 2000; 38: 1008-15.

136. Wirth $\mathrm{T}$, Falush $\mathrm{D}$, Lan $\mathrm{R}$ et al. Sex and virulence in Escherichia coli: an evolutionary perspective. Mol Microbiol 2006; 60: 1136-51.

137. Sabat A, Krzyszton-Russjan J, Strzalka W et al. New method for typing Staphylococcus aureus strains: multiple-locus variable-number tandem repeat analysis of polymorphism and genetic relationships of clinical isolates. J Clin Microbiol 2003; 41: 1801-4.

138. Frenay HM, Bunschoten AE, Schouls LM et al. Molecular typing of methicillin-resistant Staphylococcus aureus on the basis of protein A gene polymorphism. Eur J Clin Microbiol Infect Dis 1996; 15: 60-4.

139. Harmsen D, Claus H, Witte W et al. Typing of methicillin-resistant Staphylococcus aureus in a university hospital setting by using novel software for spa repeat determination and database management. J Clin Microbiol 2003; 41: 5442-8.

140. Rijnders MI, Deurenberg RH, Boumans ML et al. Population structure of Staphylococcus aureus strains isolated from intensive care unit patients in the Netherlands over an 11-year period (1996 to 2006). J Clin Microbiol 2009; 47: 4090-5.

141. Boye K, Bartels MD, Andersen IS et al. A new multiplex PCR for easy screening of methicillin-resistant Staphylococcus aureus SCCmec types I-V. Clin Microbiol Infect 2007; 13: 7257.

142. Ito T, Katayama $\mathrm{Y}$, Asada $\mathrm{K}$ et al. Structural comparison of three types of staphylococcal cassette chromosome mec integrated in the chromosome in methicillin-resistant Staphylococcus aureus. Antimicrob Agents Chemother 2001; 45: 1323-36.

143. Kondo $\mathrm{Y}$, Ito $\mathrm{T}, \mathrm{Ma} X X$ et al. Combination of multiplex PCRs for staphylococcal cassette chromosome mec type assignment: rapid identification system for mec, ccr, and major differences in junkyard regions. Antimicrob Agents Chemother 2007; 51: 264-74.

144. Milheirico C, Oliveira DC, de Lencastre H. Update to the multiplex PCR strategy for assignment of mec element types in Staphylococcus aureus. Antimicrob Agents Chemother 2007; 51: 3374-7.

145. Okuma K, Iwakawa K, Turnidge JD et al. Dissemination of new methicillin-resistant Staphylococcus aureus clones in the community. J Clin Microbiol 2002; 40: 4289-94. 


\section{Chapter 1}

146. Zhang K, McClure JA, Elsayed $\mathrm{S}$ et al. Novel multiplex PCR assay for characterization and concomitant subtyping of staphylococcal cassette chromosome mec types $\mathrm{I}$ to $\mathrm{V}$ in methicillin-resistant Staphylococcus aureus. J Clin Microbiol 2005; 43: 5026-33. 


\section{Chapter 2}

\section{Antimicrobial resistance and spread of multi drug resistant Escherichia coli isolates collected from nine urology services in the Euregion Meuse-Rhine}

C.F.M. van der Donk, J.H.B. van de Bovenkamp, E.I.G.B. De Brauwer, P. De Mol, K-H. Feldhoff, W.M. Kalka-Moll, S. Nys, I.Thoelen, T.A.M. Trienekens, E.E. Stobberingh 


\begin{abstract}
We determined the prevalence and spread of antibiotic resistance and the characteristics of ESBL producing and/or multi drug resistant (MDR) Escherichia coli isolates collected from urine samples from urology services in the Euregio MeuseRhine, the border region of the Netherlands $(n=176)$, Belgium $(n=126)$ and Germay $(\mathrm{n}=119)$.

Significant differences in resistance between the three regions were observed. Amoxicillin-clavulanic acid resistance ranged from $24 \%$ in the Netherlands to $39 \%$ in Belgium $(p=0.018)$, from $20 \%$ to $40 \%(p<0.004)$ for the fluoroquinolones and from $20 \%$ to $40 \%(p=0.018)$ for the folate antagonists. Resistance to nitrofurantoin was less than $5 \%$. The prevalence of ESBL producing isolates varied from $2 \%$ among the Dutch isolates to $8 \%$ among the German ones $(p=0.012)$ and were mainly CTX-M 15. The prevalence of MDR isolates among the Dutch, German and Belgian isolates was $11 \%, 17 \%$ and $27 \%$, respectively ( $p<=0.001$ for the Belgian compared with the Dutch isolates). The majority of the MDR and ESBL producing isolates belonged to ST131.

This study indicates that most antibiotics used as first choice oral empiric treatment for UTIs (amoxicillin-clavulanic acid, fluoroquinolones and folate antagonists) are not appropriate for this purpose and that MDR strains such as CTX-M producing ST131 have spread in the entire Euregion. Our data stress the importance of ward specific surveillance to optimize empiric treatment. Also, prudent use of antibiotics and further research to alternative agents are warranted.
\end{abstract}




\section{Introduction}

The increase of antimicrobial resistance is a major concern worldwide. Surveillance studies showed an increase in resistance for both Gram positive and Gram negative bacteria $^{1}$, including Escherichia coli, the most prevalent causative agent of urinary tract infections $(\mathrm{UTIs})^{1-4}$. Moreover, the prevalence of extended spectrum betalactamase $(\mathrm{ESBL})$ and/or carbapenemase producing multi drug resistant $E$. coli clones increased not only in the hospitals but also in the general population ${ }^{1-4}$. For the treatment of UTIs antibiotics are often prescribed empirically. An incorrect empiric choice is, in combination with the high prevalence of UTIs, a serious risk factor for the increase of antibiotic resistance among uropathogenic $E$. coli $i^{5}$ and favors the spread of resistant clones such as $E$. coli ST1316, 7 . Differences in the level of antibiotic resistance and the prevalence of ESBL producing strains exist between health care institutions within and between countries ${ }^{1}, 8,9$. Since micro-organisms do not recognize national borders, cross border spread is likely to occur. This is also the case in the Euregion Meuse-Rhine (EMR), the border region of the Netherlands, Belgium and Germany. This Euregion is a densely populated area with considerable cross-border movement and cooperation between health care institutes ${ }^{10}$. Differences in antibiotic resistance and antibiotic treatment protocols as wel as in infection control policies pose a serious risk for patient transfer between health care institutions within and between countries. Current data of prevalence of antibiotic resistance including the prevalence of ESBL producing $E$. coli strains will guide physicians in their choice of adequate empiric treatment. Since such ward specific resistance data for patients visiting the urology services are hardly available we conducted a surveillance to determine the prevalence of (multi drug) resistant $E$. coli isolates including ESBL producing strains collected from patients visiting a urology service in the Euregion Meuse-Rhine.

\section{Materials and Methods}

\section{Ethics statement}

All bacterial isolates in this study were collected and analysed anonymously. Therefore, consent from the patient was not required and ethical approval was waivered. This is in agreement with the code for proper use of human tissue as formulated by the Dutch Federation of Medical Scientific Societies and the policy of the Medical Ethics Committee of het Maastricht University Medical Centre (MUMC).

\section{Bacterial Isolates}

During a 6 month collection period between 2009 and 2011 unique, unrelated, non duplicate, consecutive isolates from urine samples from patients attending the urology services were collected

A total of 421 E. coli isolates were included in this collection: 176, 126 and 119 from the Dutch, Belgian and German urology services, respectively. The following hospitals participated in the study: MUMC - Maastricht, Atrium Medical Centre - Heerlen and 
Viecuri Medical Centre - Venlo in the Netherlands, General Hospital Vesalius Tongeren, Jessa Hospital - Hasselt and Centre Hospitalier Universitaire - Liège in Belgium, and Hermann-Josef Hospital - Erkelenz, St. Antonius Hospital - Eschweiler and St. Marien Hospital - Düren in Germany. Only one isolate per patient was included. Clinical data were not available. The isolates were collected and identified at the local laboratories according to standard microbiological methods, stored and sent to the MUMC for susceptibility testing.

\section{Antibiotic susceptibility testing}

Quantitative susceptibility testing was performed using a broth microdilution with Mueller-Hinton II cation-adjusted broth (Becton-Dickinson, Sparks, MD, USA) and micro titre plates with freeze-dried antibiotics (MCS Diagnostics BV, Swalmen, the Netherlands). The minimal inhibitory concentration (MIC) was defined as the lowest concentration showing no growth after 18 hours of incubation at $35^{\circ} \mathrm{C}$. E. coli ATCC 35218 and ATCC 25922 were used as control strains. The MIC data were analysed using breakpoints defined by the European Committee on Antimicrobial Susceptibility Testing (EUCAST) ${ }^{11}$. Intermediate results were considered resistant. Multi drug resistance (MDR) was defined as resistance to three or more classes of antibiotics excluding the broad spectrum penicillins without a beta-lactamase inhibitor.

\section{Molecular characterization of beta-lactamases}

Putative ESBL producing isolates (i.e. MIC for cefotaxime or ceftazidime $\geq 2 \mathrm{mg} / \mathrm{L}$ ) were confirmed as an ESBL producer with a combination disk diffusion test ${ }^{12}$ and characterized for the presence of TEM, SHV and/or CTX-M beta-lactamases with a micro-array (Check-points, Wageningen, the Netherlands). Based on these results $b l a_{\mathrm{TEM}}$ or bla $a_{\mathrm{CTX}-\mathrm{M}}$ were amplified with PCR and specific primers ${ }^{13,14}$. After purification (Spin PCRapace, Invitek, Berlin, Germany) automated sequencing was performed with the 3730 DNA analyzer with BigDye Terminator v1.1 (Applied Biosystems, Forster City, CA, USA).

\section{Pulsed field gel electrophoresis (PFGE) and multi locus sequence tying (MLST)}

All MDR isolates and ESBL producing isolates were further analyzed with PFGE ${ }^{15}$. All isolates with a indistinguishable or closely related pulsotype ${ }^{16}$ and all ESBL producing isolates were analyzed with multi locus sequence typing (MLST) using the scheme specified at the University College of Cork $E$. coli MLST web site ${ }^{17}$.

\section{Empiric treatment}

The appropriateness of amoxicillin-clavulanic acid, piperacillin-tazobactam, cefuroxime, ceftazidime, cefixime, ceftibuten, ciprofloxacin, nitrofurantoin, trimethoprim-sulfamethoxazole and gentamicin for empiric treatment was determined. These agents are considered representatives to other antibiotics in their class. As criterion for appropriateness of empiric treatment for complicated UTI, a 10\% resistance cutoff value was used ${ }^{18}$. If the prevalence of resistance for a specific agent was higher than $10 \%$, this agent was considered not appropriate choice for empiric treatment. 


\section{Statistical analysis}

A Pearson's chi square test or Fisher's exact test was performed to determine statistically significant differences of resistance between the three different countries (subregions) of the Euregion Meuse-Rhine (PASW software, version 18.0, IBM, Armonk, NY, USA). A modified false discovery rate (FDR) method developed by Benjamini and Yekutieli was used as correction for multiple testing ${ }^{19}$. A p-value $<0.05$ was considered statistically significant.

\section{Results}

Significant differences in prevalence of antibiotic resistance between the three regions in the Euregion were found for several antimicrobial agents tested including the fluoroquinolones, and folate antagonists (Table 1).

Table 1: Antimicrobial resistance among (\%) E. coli isolates

\begin{tabular}{|c|c|c|c|c|c|c|}
\hline Antibiotic agent & $\begin{array}{c}\mathrm{NL} \\
\mathrm{n}=176\end{array}$ & $\begin{array}{c}B \\
n=126\end{array}$ & $\begin{array}{c}G \\
\mathrm{G}=119\end{array}$ & $\begin{array}{c}\text { NLvsB } \\
\text { p-value }\end{array}$ & $\begin{array}{l}\text { NLvsG } \\
\text { p-value }\end{array}$ & $\begin{array}{c}\text { BvsG } \\
\text { p-value }\end{array}$ \\
\hline Amoxicillin & 48 & 60 & 49 & - & - & - \\
\hline Amoxicillin-clavulanic acid & 24 & 39 & 27 & 0.018 & - & - \\
\hline Piperacillin & 43 & 56 & 50 & - & - & - \\
\hline Piperacillin-tazobactam & 3 & 9 & 1 & - & - & 0.014 \\
\hline Cefuroxime & 5 & 17 & 10 & $<0.004$ & - & - \\
\hline Cefotaxime & 3 & 10 & 8 & - & - & - \\
\hline Ceftazidime & 3 & 10 & 7 & - & - & - \\
\hline Cefixime & 7 & 13 & 8 & - & - & - \\
\hline Ceftibuten & 5 & 8 & 5 & - & - & - \\
\hline Cefepime & 2 & 7 & 5 & - & - & - \\
\hline Ciprofloxacin & 20 & 37 & 29 & 0.007 & - & - \\
\hline Norfloxacin & 24 & 44 & 33 & $<0.004$ & - & - \\
\hline Levofloxacin & 19 & 37 & 29 & $<0.004$ & - & - \\
\hline Moxifloxacin & 20 & 39 & 32 & $<0.004$ & - & - \\
\hline Nitrofurantoin & 5 & 5 & 2 & - & - & - \\
\hline Trimethoprim & 22 & 39 & 32 & 0.011 & - & - \\
\hline $\begin{array}{l}\text { Trimethoprim- } \\
\text { sulfamethoxazole }\end{array}$ & 21 & 36 & 31 & 0.018 & - & - \\
\hline Amikacin & 0 & 4 & 0 & 0.043 & - & - \\
\hline Gentamicin & 5 & 6 & 12 & - & - & - \\
\hline Tobramycin & 6 & 9 & 13 & - & - & - \\
\hline
\end{tabular}

$\mathrm{NL}=$ the Netherlands, $\mathrm{B}=$ Belgium and $\mathrm{G}=$ Germany, - = not significant

Overall, resistance was highest among the Belgian isolates and lowest among the Dutch strains. Amoxicillin-clavulanic acid resistance ranged from $24 \%$ in the Netherlands to $39 \%$ in Belgium $(p=0.018)$. Resistance to piperacillin-tazobactam was still low $(1-9 \%)$ with the highest prevalence of resistance among the Belgian isolates $(p=0.014)$. Among the Belgian isolates resistance to cefuroxime, cefotaxime, ceftazidime was higher compared with resistance among the Dutch isolates $(p<0.004, p=0.097$ and $p=0.097$, respectively). The prevalence of resistance to the fluoroquinolones ranged from $20 \%$ 
among the Dutch isolates to $40 \%$ among the Belgian ones $(p<=0.007)$. Significant difference in resistance between the Dutch isolates (20\%) and Belgian isolates $(40 \%$, $\mathrm{p}=0.018$ ) was observed for the folate antagonists. Resistance to the carbapenems was not demonstrated.

Putative ESBL producing isolates were found in 10, 14 and 9 isolates among the Dutch, Belgian and German isolates, respectively. ESBL production was confirmed for 20 isolates (i.e. 3, 8 and 9) resulting in a prevalence of ESBL producing isolates of $1.7 \%$, $5.5 \%$ and $7.6 \%$ among the Dutch, Belgian and German isolates, respectively $(p=0.043$ for the Dutch and German isolates). The confirmed ESBLs were mainly CTX-M 15 (Table 2).

Table 2: Number and identification of ESBL producing isolates

\begin{tabular}{lccc}
\hline & Netherlands & Belgium & Germany \\
\hline CTX-M 1 & 0 & 2 & 1 \\
CTX-M 14 & 1 & 1 & 0 \\
CTX-M 15 & 2 & 1 & 8 \\
CTX-M 55/79 & 0 & 2 & 0 \\
TEM 52 & 0 & 1 & 0 \\
\hline Total & $\mathbf{3 ( 1 . 7 \% )}$ & $\mathbf{7 ( 5 . 5 \% )}$ & $\mathbf{9 ( 7 . 6 \% )}$ \\
\hline
\end{tabular}

* Significantly higher than among isolates from the Netherlands $(p<0.05)$

MDR was observed in 74 out of 421 isolates. The prevalence of the MDR isolates ranged from $11 \%(n=20)$ in the Dutch subregion to $27 \%(n=34)$ in the Belgian subregion $(p<=0.001)$ (Figure 1).

Figure 1: Prevalence of multi drug resistance of $E$. coli

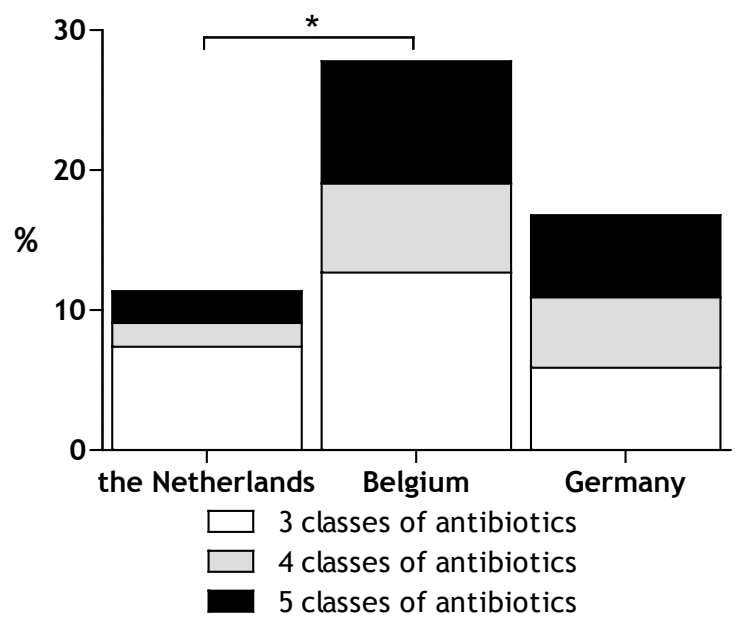

${ }^{*}=p<0.05,{ }^{* *}=p<=0.001$ 
The PFGE pulsotypes of 24 isolates of these 74 MDR isolates were found more than ones. $E$. coli ST 131 strain was the most prevalent one $(63 \%)$ of which $53 \%$ was an ESBL producer divided over 3 different pulsotypes (A, C and D, Table 3). This ST was demonstrated in all three subregions. The second most prevalent pulsotype (B) $(13 \%)$ consisted of 2 STs, where ST1394 is a single nucleotide polymorphism of ST393. Among the ESBL producing isolates ST131 was the also the most prevalent ST (47\%).

Only pulsotype A was demonstrated in all three subregions. The other pulsotypes were only observed in one subregion.

For empiric treatment of a complicated UTI, the prevalence of resistance should not exceed $10 \%$. Taken into account this cutoff value several antibiotic agents are no longer appropriate for (oral) empiric treatment (Figure 2). These include amoxicillinclavulanic acid, the fluoroquinolones and the folate antagonist in all three subregions and also some cephalosporines in the Belgian subregion. However, piperacillintazobactam and several third generation cephalosporines are still appropriate, which applies also for nitrofuratoin, although its pharmacokinetic properties do not support its use for a complicated UTI.

Table 3: Pulsotypes and STs of multi drug resistant and/or ESBL producing isolates

\begin{tabular}{lllcl}
\hline Pulsotype & ST $(\mathrm{CC})$ & $\mathbf{n}$ & $\mathbf{n}$ ESBL & ESBL Types \\
\hline A & 131 & 10 & 5 & CTX-M 14, 15 \\
B & $393(31)$ & 2 & 0 & \\
& 1394 & 1 & 0 & \\
C & 131 & 3 & 1 & CTX-M 15 \\
D & 131 & 2 & 2 & CTX-M 15 \\
E & 624 & 2 & 0 & \\
F & $162(469)$ & 2 & 2 & CTX-M 55/79 \\
G & $88(23)$ & 2 & 0 & \\
ESBL singletons & $10(10)$ & 1 & & CTX-M 1 \\
& $744(10)$ & 1 & & CTX-M 1 \\
& 131 & 1 & & CTX-M 15 \\
& $23(23)$ & 1 & & TEM 52 \\
& $88(23)$ & 1 & & CTX-M 1 \\
& 224 & 1 & & CTX-M 15 \\
& $964(405)$ & 1 & & CTX-M 15 \\
& 2509 & 1 & & CTX-M 14 \\
& 648 & 1 & & CTX-M 15
\end{tabular}

ESBL singletons: ESBL strains with a pulsotype of which no similar type has been demonstrated among the other typed isolates.

$\mathrm{ST}=$ sequence type, $\mathrm{CC}=$ clonal complex, $\mathrm{n}=$ amount 
Figure 2: Antibiotic resistance and suitability of antibiotics for empiric treatment

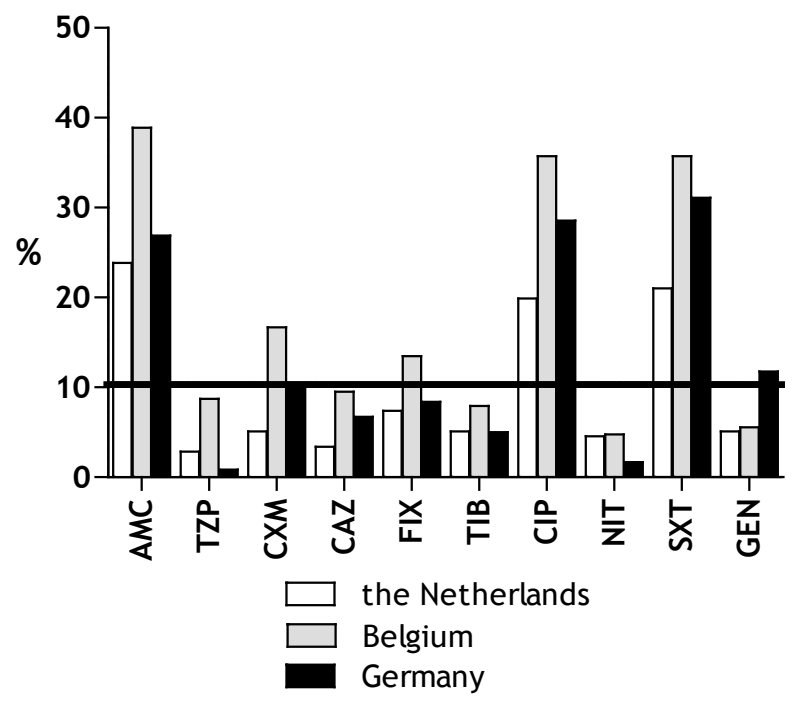

Antibiotic resistance for the different antibiotics among the three groups of isolates compared with a $10 \%$ resistance cutoff to decide whether an antibiotic agent is suitable for empiric treatment. $A M C=$ amoxicillin-clavulanic acid, $T Z P=$ piperacillin-tazobactam, $C X M=$ cefuroxime, $\mathrm{CAZ}=$ ceftazidime, $\mathrm{FIX}$ = cefixime, $\mathrm{TIB}=$ ceftibuten, $\mathrm{CIP}=$ ciprofloxacin, NIT = nitrofurantoin, $\mathrm{SXT}$ $=$ trimethoprim-sulfamethoxazole and GEN = gentamicin

\section{Discussion}

This study provides current data of the antimicrobial resistance of $E$. coli isolates collected from nine urology services in the Euregio Meuse-Rhine. We found significant differences in resistance between the Dutch, Belgian and German isolates. Although, overall the prevalence of resistance was highest among the Belgian isolates and lowest among the Dutch ones, the prevalence of ESBL producing isolates was highest among the German isolates.

More importantly, this study also indicates that most antibiotics used as first choice oral empiric treatment for UTIs (amoxicillin-clavulanic acid, fluoroquinolones, trimethoprim-sulfamethoxazole $)^{20}$ are not appropriate for this purpose since the prevalence of resistance exceeds $10 \%{ }^{18}$. Previously, it has been demonstrated that the prevalence of antimicrobial resistance from invasive clinical isolates was higher in Belgium and Germany than in the Netherlands ${ }^{1}$. but has, to our knowledge, not been described for isolates from the urology services. This study also demonstrates that the globally emerging $E$. coli ST131, 7, 21, 22 was prevalent in this entire population and also frequently produced an ESBL.

The $E$. coli isolates were collected from urine samples from patients of both gender and all ages visiting the urology services in the participating hospitals of this cross border multi centre surveillance study to prevent selection bias. Since all isolates were tested in one centre, the results were not influenced by differences in methodology. 
Unfortunately, additional patient and clinical data were not available. Since we cannot specify the underlying illness of the patients, this should be taken into consideration when initiating empiric treatment.

Comparing the resistance rates of $E$. coli from the EARSS annual report 2009, which consist mainly of isolates from invasive disease ${ }^{1}$, and this study, the prevalence of resistance was comparable, except for resistance to the fluoroquinolones. This was higher among the urology isolates $(11 \%$ vs. $19-20 \%$ for the Dutch isolates, $20 \%$ vs. 37 $45 \%$ for the Belgian isolates and $23 \%$ vs. $29-33 \%$ for the German isolates, Table 1). These differences might be related to the high prescribing rate of fluoroquinolones at the urology services ${ }^{8,23}$

Moreover, differences in antibiotic use ${ }^{24}$ are also the most likely reason for the differences in resistance between the three countries in this study, although, differences in patient population can also play a role.

Compared with prevalence of resistance among general practice (GP) patients ${ }^{2}, 3,9,25$ the resistance in this study was much higher. This is probably due to the more frequent antibiotic use among urology patients compared with GP patients, the higher prevalence of urinary tract comorbidities and the use of catheters, which might select for resistant strains ${ }^{5,26,27}$. Compared to a previous study among urology isolates the Dutch isolates in the present study showed a lower prevalence of resistance for the folic acid antagonists and higher resistance for the quinolones ${ }^{8}$. Taken into account that only antimicrobial agents with a resistance level of $10 \%$ or less are suitable for empiric therapy ${ }^{18}$, fluoroquinolones, broad spectrum penicillins and folate antagonist are not an appropriate choice. This applies for the whole Euregion. Alternatives agents are limited and include nitrofurantoin, which is not used for complicated UTIs because of poor tissue penetration ${ }^{28}$, piperacillin-tazobactam, which cannot be administered orally, and the third generation cephalosporines. However, high use of cephalosporines could increase the selection and persistence of ESBL producers and should be kept to a minimum ${ }^{29}$. Therefore, further research to potential alternatives, such as fosfomycin, is essential.

During the last years (multi drug) resistant strains have become a major healthissue. National and international surveys show an increase in nosocomial and community acquired infections involving ESBL and/or carbapenemase producing isolates ${ }^{1,2}, 30,31$. Also, globally the MDR and often ESBL producing $E$. coli ST131 clone is emerging ${ }^{6,7,21}$, 22. An infection with these isolates can often not be treated with penicillins, cephalosporines, fluoroquinoles and folate antagonists ${ }^{20,32}$. Consequently, adequate antibiotic therapy is delayed because of inadequate empirical therapy, which affects the patient outcome negatively ${ }^{33}$. In this study the percentage of ESBL producing isolates was less than $8 \%$ in all three subregions, with the lowest prevalence of ESBL producers among the Dutch isolates. Most ESBL producers contained the ESBL type CTX-M, which is prevalent ${ }^{21,22,29}$. The high prevalence of ST131 among the tested isolates is a point of concern, since this clone can easily acquire more resistance traits $^{6,7,21}$ and will become a major health risk since it is infesting itself in our population. However, current prevalences of (multi drug) resistance do not justify alteration of the treatment protocols to empiric therapy with carbapenems. Nevertheless, continuous ward specific surveillance is necessary to monitor changes in 
antibiotic resistance MDR strains. Moreover, further research is indicated to find alternative antibiotic agents of which fosfomycin is a possibility. This agent has high tissue penetration, maintains active against ESBL producing isolates ${ }^{34}$, but is until now not registered for complicated UTI. Therefore, further research into the usefullness of fosfomycin for treatment of this type of infection is warranted.

Concluding, ward specific surveillance of antimicrobial resistance is important to monitor resistance over time on a regional, national and international level since we demonstrated significant differences in antibiotic susceptibility between the three subregions in the Euregion Meuse-Rhine. We also found a high prevalence of E.coli ST131 and CTX-M type ESBLs, suggesting a spread of this clone in the entire Euregion. Due to the high prevalence of resistance many antibiotics including amoxicillinclavulanic acid, the fluoroquinolones and the folate antagonists are no longer suitable for empiric treatment of complicated UTI, therefore, further research to other possible agents is needed. 


\section{References}

1. ECDC. Antimicrobial resistance surveillance in Europe 2009. Annual Report of the European Antimicrobial Resistance Surveillance Network (EARS-Net). Stockholm: ECDC, 2010.

2. den Heijer CD, Donker GA, Maes J et al. Antibiotic susceptibility of unselected uropathogenic Escherichia coli from female Dutch general practice patients: a comparison of two surveys with a 5 year interval. J Antimicrob Chemother 2010; 65: 2128-33.

3. Cullen IM, Manecksha RP, McCullagh E et al. The changing pattern of antimicrobial resistance within 42033 Escherichia coli isolates from nosocomial, community and urology patient-specific urinary tract infections, Dublin, 1999-2009. BJU Int 2011.

4. SWAB. Nethmap 2011 - Consumption of antimicrobial agents and antimicrobial resistance among medically important bacteria in the Netherlands. 2011.

5. Goossens H, Ferech M, Vander Stichele R et al. Outpatient antibiotic use in Europe and association with resistance: a cross-national database study. Lancet 2005; 365: 579-87.

6. Gibreel TM, Dodgson AR, Cheesbrough J et al. Population structure, virulence potential and antibiotic susceptibility of uropathogenic Escherichia coli from Northwest England. J Antimicrob Chemother 2012; 67: 346-56.

7. Pitout JD, Gregson DB, Campbell L et al. Molecular characteristics of extendedspectrum-beta-lactamase-producing Escherichia coli isolates causing bacteremia in the Calgary Health Region from 2000 to 2007: emergence of clone ST131 as a cause of community-acquired infections. Antimicrob Agents Chemother 2009; 53: 2846-51.

8. Nys S, Terporten PH, Hoogkamp-Korstanje JA et al. Trends in antimicrobial susceptibility of Escherichia coli isolates from urology services in The Netherlands (1998-2005). J Antimicrob Chemother 2008; 62: 126-32.

9. Naber KG, Schito $\mathrm{G}$, Botto $\mathrm{H}$ et al. Surveillance study in Europe and Brazil on clinical aspects and Antimicrobial Resistance Epidemiology in Females with Cystitis (ARESC): implications for empiric therapy. Eur Urol 2008; 54: 1164-75.

10. EIS. Euregion Meuse-Rhine in figures. 2006.

11. EUCAST. Breakpoint tables for interpretation of MICs and zone diameters - version 1.3, January 2011

12. NVMM Guideline - Laboratory detection of highly resistant microorganisms (HRMO) version 1.0. 2011.

13. Pallecchi L, Malossi M, Mantella A et al. Detection of CTX-M-type beta-lactamase genes in fecal Escherichia coli isolates from healthy children in Bolivia and Peru. Antimicrob Agents Chemother 2004; 48: 4556-61.

14. Saladin M, Cao VT, Lambert $T$ et al. Diversity of CTX-M beta-lactamases and their promoter regions from Enterobacteriaceae isolated in three Parisian hospitals. FEMS microbiology letters 2002; 209: 161-8.

15. Ribot EM, Fair MA, Gautom R et al. Standardization of pulsed-field gel electrophoresis protocols for the subtyping of Escherichia coli 0157:H7, Salmonella, and Shigella for PulseNet. Foodborne Pathog Dis 2006; 3: 59-67.

16. Tenover FC, Arbeit RD, Goering RV et al. Interpreting chromosomal DNA restriction patterns produced by pulsed-field gel electrophoresis: criteria for bacterial strain typing. $J$ Clin Microbiol 1995; 33: 2233-9.

17. UCC. Escherichia coli MLST database http://mlst.ucc.ie/mlst/dbs/Ecoli (6 July 2012 date last accessed ).

18. Gupta K, Hooton TM, Naber KG et al. International clinical practice guidelines for the treatment of acute uncomplicated cystitis and pyelonephritis in women: A 2010 update by the Infectious Diseases Society of America and the European Society for Microbiology and Infectious Diseases. Clin Infect Dis 2011; 52: e103-20. 


\section{Chapter 2}

19. Narum SR. Beyond Bonferroni: Less conservative analyses for conservation genetics. Conservation Genetics 2006; 7: 783-7.

20. SWAB. Antibioticaboekje. http://customid.duhs.duke.edu/NL/Main/Start.asp (date last accesed: 15 August 2012 ).

21. Overdevest I, Willemsen I, Rijnsburger $M$ et al. Extended-spectrum beta-lactamase genes of Escherichia coli in chicken meat and humans, The Netherlands. Emerg Infect Dis 2011; 17: 1216-22.

22. Rodriguez-Villalobos $\mathrm{H}$, Bogaerts $\mathrm{P}$, Berhin $\mathrm{C}$ et al. Trends in production of extendedspectrum beta-lactamases among Enterobacteriaceae of clinical interest: results of a nationwide survey in Belgian hospitals. J Antimicrob Chemother 2011; 66: 37-47.

23. Wagenlehner FM, Niemetz AH, Weidner $\mathrm{W}$ et al. Spectrum and antibiotic resistance of uropathogens from hospitalised patients with urinary tract infections: 1994-2005. Int J Antimicrob Agents 2008; 31 Suppl 1: S25-34.

24. ESAC. European Surveillanc of Antimicrobial Consumption Yearbook 2009.

25. De Backer D, Christiaens $T$, Heytens $S$ et al. Evolution of bacterial susceptibility pattern of Escherichia coli in uncomplicated urinary tract infections in a country with high antibiotic consumption: a comparison of two surveys with a 10 year interval. J Antimicrob Chemother 2008; 62: 364-8.

26. Yagupsky P. Selection of antibiotic-resistant pathogens in the community. Pediatr Infect Dis J 2006; 25: 974-6.

27. Colodner R, Kometiani I, Chazan B et al. Risk factors for community-acquired urinary tract infection due to quinolone-resistant $E$. coli. Infection 2008; 36: 41-5.

28. Charalabopoulos K, Karachalios G, Baltogiannis D et al. Penetration of antimicrobial agents into the prostate. Chemotherapy 2003; 49: 269-79.

29. Coque TM, Baquero F, Canton R. Increasing prevalence of ESBL-producing Enterobacteriaceae in Europe. Euro Surveill 2008; 13.

30. van der Donk CF, Beisser PS, Hoogkamp-Korstanje JA et al. A 12 year (1998-2009) antibiotic resistance surveillance of Klebsiella pneumoniae collected from intensive care and urology patients in 14 Dutch hospitals. J Antimicrob Chemother 2011; 66: 855-8.

31. Jans B, Glupczynski Y. Surveillance van multiresistente kiemen in Belgische ziekenhuizen: Enterobacter aerogenens en cloacae, Escherichia coli, Klebsielle pneumoniae, Acinetobacter baumanii en Pseudomonas aeruginosa Eerste semester 2009. Brussel: Wetenschappelijk Instituut Volksgezondheid.

32. SWAB. Richtlijn antimicrobiële therapie bij gecompliceerde urineweginfecties. 2006.

33. Lee SS, Kim Y, Chung DR. Impact of discordant empirical therapy on outcome of community-acquired bacteremic acute pyelonephritis. J Infect 2011; 62: 159-64.

34. Raz R. Fosfomycin: an old-new antibiotic. Clin Microbiol Infect 2012; 18: 4-7. 
Chapter 3

Prevalence and spread of multi drug resistant Escherichia coli isolates among nursing home residents in the southern part of the Netherlands

C.F.M. van der Donk, J.M.G.A. Schols, C.J.Driessen, R.G.P. Hagenouw, A. Meulendijks,

E.E. Stobberingh

J Am Med Dir Assoc. 2013 Mar;14(3):199-2013. Epub 2012 Nov 7. 


\section{Abstract}

\section{Objectives}

Empiric antibiotic treatment should be based on recent surveillance data. Therefore, we conducted a surveillance of (multi drug) resistance of Escherichia coli and antibiotic use among Dutch nursing home $(\mathrm{NH})$ residents. Pulsed-field gel electrophoresis (PFGE) and multi locus sequence typing (MLST) were used to describe the spread of multi drug resistant strains.

\section{Desgin}

Observational study

\section{Setting}

Five NHs in the southern part of the Netherlands

\section{Participants}

$337 \mathrm{NH}$ residents from both somatic and psycho-geriatric wards

\section{Measurements}

The prevalence and spread of antibiotic resistance and multi drug resistant $E$. coli isolates collected from urine samples and antibiotic use among the $\mathrm{NH}$ residents were investigated.

\section{Results}

A total of $208 \mathrm{E}$. coli isolates were collected from 308 urine samples.

Resistance to amoxicillin-clavulanic acid was $23 \%$ and resistance to ciprofloxacin was $16 \%$. Resistance to trimethoprim-sulfamethoxazole was $19 \%$, while nitrofurantoin resistance was less than $1 \%$. Multi drug resistance was observed in 28 of the 208 isolates (13\%). Several isolates showed a similar PFGE pulsotype and MLST type. ST131 was the most prevalent (48\%) and was demonstrated in all NHs and with four different pulsotypes. Consumption of antibiotics for systemic use was $64.4 \mathrm{DDD} / 1000$ residents/day. Amoxicillin-clavulanic acid was most frequently prescribed (20.92 $\mathrm{DDD} / 1000$ residents/day), followed by the quinolones (14.8 DDD/1000 residents/day).

\section{Conclusion}

We observed a high prevalence of antibiotic resistance and antibiotic use. In particular, the use of and resistance to fluoroquinolones is concerning. Due to the high prevalence of resistance many agents are no longer suitable for empiric treatment. $E$. coli ST131, which has also been demonstrated in this study, poses a potential risk to this vulnerable population.

We have clearly demonstrated that the resistance among $\mathrm{NH}$ residents is different from elderly living at home and hospitalized patients and with the emergence of resistant strains, such as ST131, NHs are a potential reservoir for multi drug resistant bacteria. 


\section{Introduction}

Urinary tract infections (UTIs) are one of the most prevalent bacterial infections among nursing home $(\mathrm{NH})$ residents ${ }^{1}$. This can vary from an asymptomatic or relatively mild cystitis to urosepsis and can have severe consequences for the residents overall condition $^{2,3}$.

UTIs are a common indication for empiric antimicrobial treatment ${ }^{4}$. Approximately 20$60 \%$ of all used systemic antibiotics among NH residents are prescribed for a $\mathrm{UTI}^{5}$. Optimal empiric antibiotic treatment should be based on recent surveillance data. Unfortunately, for nursing homes these data are hardly available and the choice for empiric treatment is usually based on surveillance data from hospitals. This might result in a relatively high use of inappropriately prescribed broad-spectrum antibiotics, of which especially the use of fluoroquinolones is a point of concern ${ }^{4}$. These agents are often used due to their favourable pharmacokinetics and antibacterial spectrum, but resistance can be rapidly acquired, limiting the use of these antimicrobials ${ }^{6}$. Overall, the high use of antibiotics contributes to an increase of antimicrobial resistance and a more prevalent carriage of extended spectrum beta-lactamases (ESBLs) ${ }^{7,8}$, such as the multi drug resistant ESBL producing Escherichia coli sequence type (ST) 1319, 10 . Although, antibiotic use is considered as one of the main risk factors for emergence of and colonization with antibiotic resistant isolates ${ }^{7}$, other risk factors including poor functional status, presence of wounds or foreign materials are also very prevalent among $\mathrm{NH}$ residents ${ }^{5,11,12}$. Infections with (multi drug) resistant pathogens have been associated with higher morbidity, mortality and costs due to delayed adequate antibiotic treatment ${ }^{13,14}$.

UTIs are often caused by the resident's own commensal microorganisms ${ }^{15}{ }^{16}$. Therefore, actual data of resistance of the commensal flora will guide physicians in making an appropriate choice for empiric therapy. Since current resistance data for $E$. coli, a commensal and the most prevalent causative agent of UTIs ${ }^{17,}{ }^{18}$, are not available for $\mathrm{NH}$ residents in the Netherlands, we performed a surveillance in five $\mathrm{NHs}$ in the southern part of the Netherlands. Moreover, spread of multi drug resistant isolates, such as ST131, between and within NHs was investigated with multi locus sequence typing (MLST) and pulsed field gel electrophoresis (PFGE).

\section{Methods}

Five NHs in the province of Limburg in the southern part of the Netherlands agreed to participate in this project. All psycho-geriatric and somatic residents of these NHs were eligible for participation but only those residents who signed a consent form (either by themselves or their legal representative) were included in the study.

This study was approved by the medical ethics committee of the Maastricht University Medical Centre (MUMC). We received a total of 336 consent forms (Table 1). Due to withdrawal of consent, faecal incontinence, moving or death of a resident, 29 residents could not be sampled. In each $\mathrm{NH}$ the samples were collected in one week in the period between February 2010 and June 2011. 


\section{Bacterial isolates}

Urine samples were collected from all included, asymptomatic residents and used to inoculate a uricult (Biomérieux, Marcy l'Etoile, France) A uricult or dipslide is a semi quantitative microbial culture method, which has a two sided paddle in a protective vial with on one side a cystine lactose electrolyte deficient (CLED) agar and on the other side a MacConkey agar.

If a resident suffered from urine incontinence the uricult was inoculated by pressing the paddle onto the incontinence pads. The inoculated uricults were sent to the laboratory at the MUMC and incubated at $35^{\circ} \mathrm{C}$ for 18 hours. The putative $E$. coli colonies were identified using standard microbiological methods. Samples were analysed anonymously, therefore, clinical data were not available.

\section{Quantitative susceptibility testing}

Antimicrobial susceptibility testing was performed using a broth microdilution with Mueller-Hinton II cation-adjusted broth (Becton-Dickinson, Sparks, MD, USA) and micro titre plates with freeze-dried antibiotics (MCS Diagnostics BV, Swalmen, the Netherlands). E. coli ATCC 35218 and ATCC 25922 were used as control strains. The following antimicrobial agents were tested: amoxicillin, amoxicillin-clavulanic acid, ciprofloxacin, gentamicin, nitrofurantoin, norfloxacin, trimethoprim and trimethoprimsulfamethoxazole. The minimal inhibitory concentration (MIC) data were analysed using clinical breakpoints defined by the European Committee on Antimicrobial Susceptibility Testing (EUCAST) ${ }^{19}$. Amoxicillin-clavulanic acid resistant isolates were further tested for resistance to ceftazidime and ESBL production was confirmed for isolates with a ceftazidime MIC $\geq 2 \mathrm{mg} / \mathrm{L}$ using a combination disk diffusion test according to guidelines of the Dutch society for medical microbiology ${ }^{20}$. Multi drug resistance was defined as resistance to three or more of the tested antimicrobial classes.

\section{Molecular characterization}

The ESBL positive isolates were further analyzed for the presence of $b l a_{\mathrm{TEM}}, b l a_{\mathrm{SHV}}$ and bla $a_{\mathrm{CTX}-\mathrm{M}}$ with PCR and specific primers ${ }^{21-24}$. Automated sequencing was performed with the 3730 DNA analyzer with BigDye Terminator v1.1 (Applied Biosystems, Forster City, CA, USA). All multi drug resistant isolates and ESBL producers were analyzed with $\mathrm{PFGE}^{25}$ and $\mathrm{MLST}^{26,27}$.

\section{Use of antimicrobial agents}

Data on the use of antibiotics were collected from each $\mathrm{NH}$ from the in the period of one year prior to the collection of the urine samples. These data were collected anonymously and could not be linked to an individual resident. These data were collected using the ATC/DDD classification protocol as defined by the WHO Collaborating Centre for Drug Statistics Methodology ${ }^{28}$. The defined daily dose (DDD) is the assumed average dose per day for a drug used for its main indication in adults. In this study the DDD are expressed as DDD per 1000 residents per day. The DDD is a unit of measurement and does not necessarily reflect the recommended or prescribed daily dose $^{28}$. 


\section{Statistical analysis}

To determine significant differences in prevalence of resistance, a Pearson's chisquare or Fisher's exact test was performed (PASW-software 18.0, IBM, Armonk, NY, USA). A p-value $<0.05$ was considered statistically significant.

\section{Results}

In total $208 \mathrm{E}$. coli isolates were collected ranging from 20-64 isolates per NH from 308 urine samples from residents of the five NHs (Table 1 ).

Table 1: Overview of included residents and collected samples per nursing home

\begin{tabular}{ccccc}
\hline $\begin{array}{c}\text { Nursing } \\
\text { home }\end{array}$ & $\begin{array}{c}\text { Eligible } \\
\text { residents }\end{array}$ & $\begin{array}{c}\text { Included } \\
\text { residents (\%) }\end{array}$ & $\begin{array}{c}\text { Collected } \\
\text { samples }\end{array}$ & $\begin{array}{c}\text { Number of } \\
\text { E. coli isolates }\end{array}$ \\
\hline 1 & 130 & $40(31)$ & 38 & 33 \\
2 & 180 & $84(47)$ & 70 & 54 \\
3 & 329 & $56(17)$ & 55 & 37 \\
4 & 282 & $109(39)$ & 103 & 64 \\
5 & 104 & $51(49)$ & 42 & 20 \\
\hline Total & $\mathbf{1 0 2 5}$ & $\mathbf{3 3 7 ( 3 3 )}$ & $\mathbf{3 0 8}$ & $\mathbf{2 0 8}$ \\
\hline
\end{tabular}

Figure 1: Antibiotic resistance of $E$. coli in the five nursing homes

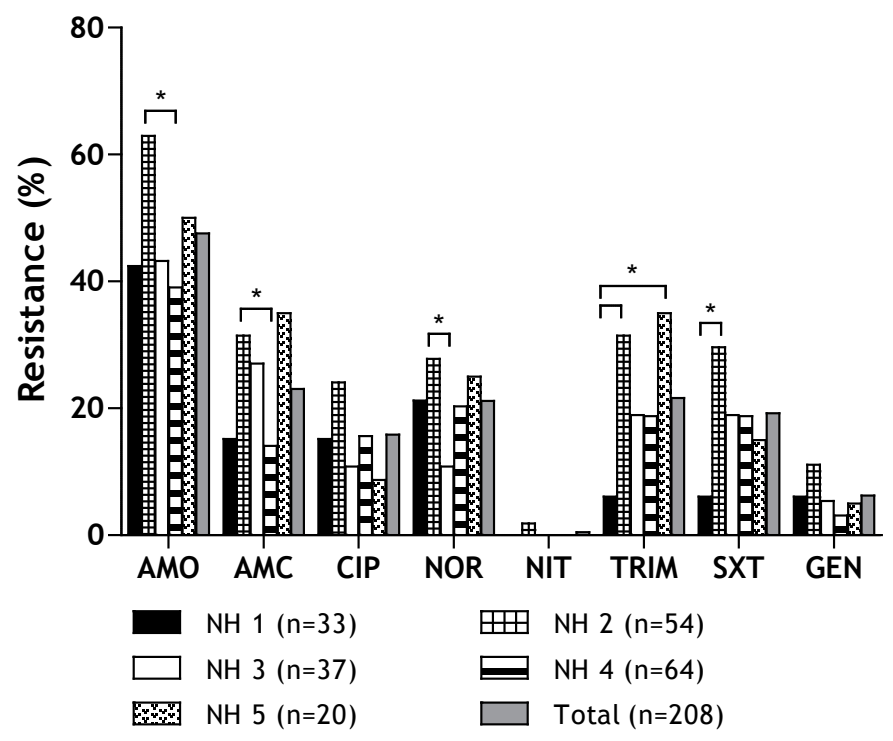

AMO = amoxicillin, $A M C=$ amoxicillin-clavulanic acid, CIP = ciprofloxacin, NOR = norfloxacin, NIT = nitrofurantoin, TRIM = trimethoprim, SXT = trimethoprim-sulfamethoxazole, $\mathrm{GEN}=$ gentamicin, $\mathrm{NH}=$ nursing home, ${ }^{*}=\mathrm{p}<0.05$ 
The prevalence of resistance is shown in Figure 1. Amoxicillin-clavulanic acid resistance varied from $14 \%$ to $31 \%(p=0.023)$. Ciprofloxacin ranged from $9 \%$ to $24 \%$ $(p=0.056)$ and resistance to norfloxacin ranged from $11 \%$ to $28 \%(p=0.042)$. Resistance to trimethoprim ranged from $6 \%$ to $35 \%(p=0.010)$ and from $6 \%$ to $30 \%(p=0.008)$ for trimethoprim-sulfamethoxazole. Nitrofurantoin resistance was less than $1 \%$. Overall resistance was highest among residents from NH2. ESBL production was observed in 1 isolate from $\mathrm{NH} 4(<1 \%)$ which was ST38 and CTX-M 15 positive.

Multi drug resistance was observed in 28 of the 208 isolates (13\%) and ranged from 9\% in $\mathrm{NH} 4$ to $22 \%$ in $\mathrm{NH} 2$. All of these isolates were resistant to norfloxacin and amoxicillin. $68 \%$ was resistant to ciprofloxacin and $43 \%$ to amoxicillin-clavulanic acid and $86 \%$ to the folate antagonists (Table 2). Among these isolates ST131 was the most prevalent ST $(n=14,50 \%)$ and was observed in each $\mathrm{NH}$ but with three different pulsotypes each of which was present in one or three NHs. ST69 (n=5) was demonstrated in three NHs. The other STs had only one pulsotype and were demonstrated in one $\mathrm{NH}$ only (Figure 2).

Table 2: Overview of the multi drug resistant isolates

\begin{tabular}{lc}
\hline Antibiotic resistance combinations & $\mathbf{n}$ \\
\hline AMO/NOR/GEN & 2 \\
AMO/NOR/TRIM/SXT & 2 \\
AMO/NOR/GEN/TRIM/SXT & 2 \\
AMO/CIP/NOR/TRIM/SXT & 4 \\
AMO/CIP/NOR/GEN/TRIM/SXT & 6 \\
AMO/AMC/NOR/TRIM & 1 \\
AMO/AMC/NOR/TRIM/SXT & 2 \\
AMO/AMC/CIP/NOR/GEN & 2 \\
AMO/AMC/CIP/NOR/TRIM/SXT & 6 \\
AMO/AMC/CIP/NOR/GEN/TRIM/SXT & 1 \\
\hline Total & $\mathbf{2 8}$ \\
\hline
\end{tabular}

This table shows to which antibiotics the multi drug resistant isolates were resistant AMO = amoxicillin, $A M C=$ amoxicillin-clavulanic acid, CIP = ciprofloxacin, NOR = norfloxacin, TRIM = trimethoprim, SXT = trimethoprim-sulfamethoxazole, GEN = gentamicin, $\mathrm{n}=$ number of isolates.

The average consumption of antibiotics for systemic use in the five NHs was 64.4 DDD per 1000 residents per day ranging from 52.81 to $81.56 \mathrm{DDD} / 1000$ residents/day (Table 3). Antibiotics in class J01CR were most frequently prescribed (20.92 DDD/1000 residents/day), followed by the quinolones (14.8 DDD/1000 residents/day) and tetracyclines (11.13 DDD/1000 residents/day). Antibiotic use of antimicrobials in class J01C ranged from 21.6 to $41.4 \mathrm{DDD} / 1000$ residents/day, $81 \%$ of antibiotic use in this class could be attributed to the use of amoxicillin-clavulanic acid. Antibiotic use of antimicrobials in class J01E ranged from 1.4 to $5.9 \mathrm{DDD} / 1000$ residents/day. The majority (i.e. $71 \%$ ) could be attributed to the use of trimethoprim, which is solely prescribed for the treatment of UTI. Use of antimicrobials in class J01M, mainly ciprofloxacin and norfloxacin, ranged from 9.8 to $23.4 \mathrm{DDD} / 1000$ residents/day. Antibiotic use of antimicrobials in class J01X ranged from 1.6 to $12.2 \mathrm{DDD} / 1000$ residents/day of which $98 \%$ was nitrofurantoin. 
Figure 2: Spread of isolates with related pulsotype and MLST sequence among the nursing homes

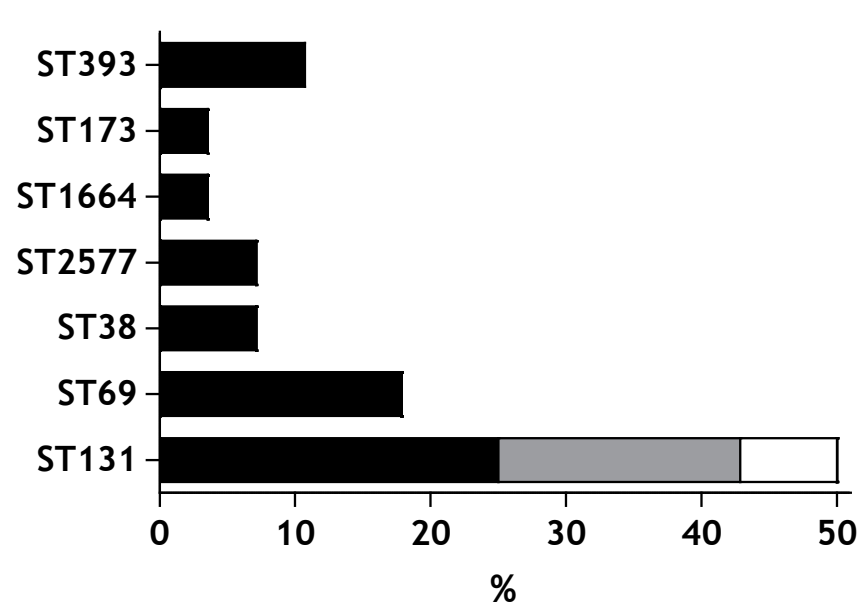

$\begin{array}{ll}\text { Pulsotype } & \text { NH } \\ \text { None } & 2 \\ \text { H } & 5 \\ \text { G } & 2 \\ \text { F } & 2 \\ \text { E } & 1 \\ \text { D } & 2-4 \\ \text { A-C } & 1-5 \\ & \end{array}$

This figure describes the distribution of ST among the multi drug resistant isolates, the number of pulsotypes per ST and in which NHs these STs were observed. ST = sequence type, $\mathrm{NH}=$ nursing home

Table 3: Consumption of antibiotics for systemic use in DDD/1000 residents/day

\begin{tabular}{|c|c|c|c|c|c|c|c|}
\hline $\begin{array}{l}\text { ATC } \\
\text { group }\end{array}$ & Therapeutic group & $\begin{array}{l}\mathrm{NH} 1 \\
\mathrm{n}=130\end{array}$ & $\begin{array}{l}\mathrm{NH} 2 \\
\mathrm{n}=180\end{array}$ & $\begin{array}{l}\mathrm{NH} 3 \\
\mathrm{n}=329\end{array}$ & $\begin{array}{l}\mathrm{NH} \mathrm{4} \\
\mathrm{n}=282\end{array}$ & $\begin{array}{l}\text { NH } 5 \\
n=104\end{array}$ & Total \\
\hline J01AA & Tetracyclines & 4.87 & 6.74 & 11.08 & 20.97 & 0.08 & 11.13 \\
\hline J01CA & $\begin{array}{l}\text { Penicillins with extended } \\
\text { spectrum }\end{array}$ & 0.94 & 0.34 & 3.93 & 0.14 & 2.06 & 1.69 \\
\hline J01CE & $\begin{array}{l}\text { Beta-lactamase sensitive } \\
\text { penicillins }\end{array}$ & 4.68 & 2.99 & 0.12 & 0.00 & 0.33 & 1.19 \\
\hline J01CF & $\begin{array}{l}\text { Beta-lactamase resistant } \\
\text { penicillins }\end{array}$ & 6.94 & 1.07 & 2.27 & 0.51 & 0.70 & 2.01 \\
\hline J01CR & $\begin{array}{l}\text { Combination of penicillins } \\
\text { incl. beta-lactamase inhibitors }\end{array}$ & 19.86 & 17.50 & 18.01 & 20.59 & 38.28 & 20.92 \\
\hline J01DC & $2^{\text {nd }}$ gen. cephalosporines & 3.31 & 2.05 & 0.00 & 0.00 & 0.00 & 0.78 \\
\hline J01DD & $3^{\text {rd }}$ gen. cephalosporines & 0.00 & 0.00 & 0.12 & 1.84 & 1.52 & 0.67 \\
\hline J01EA & $\begin{array}{l}\text { Trimethoprim and derivates } \\
\text { Combinations of sulfonamides }\end{array}$ & 1.98 & 0.10 & 3.24 & 0.09 & 11.74 & 2.53 \\
\hline J01EE & $\begin{array}{c}\text { and trimethoprim incl } \\
\text { derivates }\end{array}$ & 3.90 & 1.61 & 0.83 & 1.28 & 0.00 & 1.40 \\
\hline J01FA & Macrolides & 0.00 & 0.34 & 0.23 & 1.38 & 0.49 & 0.56 \\
\hline J01FF & Lincosamides & 0.20 & 1.48 & 0.67 & 3.06 & 2.13 & 1.56 \\
\hline J01MA & Fluoroquinolones & 9.83 & 14.25 & 10.61 & 23.37 & 12.00 & 14.80 \\
\hline J01XE & Nitrofuran derivates & 2.50 & 9.82 & 1.59 & 4.47 & 12.22 & 5.02 \\
\hline $\mathrm{J} 01$ & Antibacterials for systemic use & 59.02 & 58.94 & 52.81 & 77.60 & 81.56 & 64.41 \\
\hline
\end{tabular}




\section{Discussion}

This study provides the current situation of antibiotic resistance and spread of multi drug resistant $E$. coli isolates in NHs in the southern part of the Netherlands. Resistance to the folate antagonists, amoxicillin-clavulanic acid and fluoroquinolones was mostly more than $20 \%$, and these agents are, therefore, no longer suitable for empiric treatment of $\mathrm{UTI}^{29}$. The only exception is nitrofurantoin since resistance was only sporadically observed. Multi drug resistance was demonstrated among $13 \%$ of the isolates of which ST131 was the most prevalent type. This ST was observed in all NHs. The antibiotics most often prescribed were penicillins in combination with a betalactamase inhibitor and fluoroquinolones, which is in line with the high prevalence of resistance to these agents.

Bias of the results between the nursing homes due to differences in methodology was prevented by applying the same method of sampling and analysis of the urine samples for all NHs. Unfortunately, this study was performed anonymously and, therefore, detailed clinical data were not available and linkage of the antibiotic use to an individual resident was not possible.

An up to date overview of antibiotic resistance is necessary for a suitable empiric antibiotic treatment policy. However, if such an overview is not available other inappropriate data are used. Resistance data from (elderly) general practice (GP) patients were different from the data presented here and are, therefore, not suitable as basis for empiric antibiotic choice for NH residents. The prevalence of resistance to amoxicillin, amoxicillin-clavulanic acid and the quinolones was lower among elderly GP patients ${ }^{30}$. This suggests that age alone is not a risk factor for antibiotic resistance but that other factors contribute to increase of resistance. So, the difference in resistance between NH residents and GP patients might be due to the high use of antibiotics among the $\mathrm{NH}$ residents ${ }^{31}$. In particular, the high use of quinolones among $\mathrm{NH}$ residents compared with the GP patients ${ }^{31}$, which is due to this agent's oral availability, favourable pharmacokinetics and the broad spectrum antibacterial activity. On the other hand, quinolone resistance was higher among the $\mathrm{NH}$ residents compared with hospitalized patients ${ }^{31}$ while antibiotic use was higher among the hospitalized patients ${ }^{31}$. This suggests that other factors are also playing a role in the observed differences in resistance between the elderly GP patients and hospitalized patients, and the $\mathrm{NH}$ residents. Factors such as a chronic, worse physical status of the $\mathrm{NH}$ residents are also of importance. In turn, this could also explain the differences in antibiotic resistance between the participating $\mathrm{NHs}$ that cannot be attributed to differences in antibiotic use. Overall antibiotic use among the participating $\mathrm{NH}$ residents in this study could be ranked average/high compared with $\mathrm{NH}$ residents in other European countries ${ }^{32}$.

With regard to initiation of empiric treatment with a specific antimicrobial agent, resistance should not exceed $20 \%$ for an uncomplicated UTI and should not exceed $10 \%$ for a complicated $\mathrm{UTI}^{29}$. Based on the resistance data, nitrofurantoin could be an appropriate agent for both uncomplicated and complicated UTI. However, since the tissue penetration of nitrofurantoin is very $l_{0} w^{33}$, this agent is not suitable for the treatment of complicated UTI. Taken into account the $20 \%$ and $10 \%$ cutoff value, 
amoxicillin-clavulanic acid, ciprofloxacin, norfloxacin, trimethoprim and trimethoprimsulfamethoxazole are not appropriate anymore for treatment of complicated UTI but some agents might be appropriate for empiric treatment of uncomplicated UTI. This was, however, $\mathrm{NH}$ dependent. An alternative option for oral empiric treatment includes fosfomycin which, up till now, is not registered for the treatment of complicated UTI despite promising characteristics i.e. low resistance ${ }^{30}$, high tissue penetration and activity against ESBL producing isolates ${ }^{34}$.

Another point of concern is the global increase of resistance and spread of multi drug resistant, ESBL and/or carbapenemase producing strains. Infections with these bacteria are more difficult to treat as the number of adequate antimicrobial treatment options is limited. Globally, the E. coli ST131 strains are often multi drug resistant, produce ESBLs, have many virulence traits and cause infections such as, UTIs and bacteraemia $9,10,35$. The same applies for ST69 ${ }^{35,36}$. Both ST131 and ST69 strains were found among the $\mathrm{NH}$ residents in all participating NHs, as was ST405, another previously reported resistant $\mathrm{ST}^{36}$. A concerning property of these strains, especially $\mathrm{ST} 131^{9}$, is the high prevalence of resistance to the often prescribed fluoroquinolones, which was also demonstrated in this study. Fortunately, the resistant isolates observed in our population were no ESBL producers and they were also resistant to fewer antibiotics than other previously reported multi drug resistant strains ${ }^{9}$. We did demonstrate, however, that especially ST131 has spread into the NH population. This ST can also easily pick up plasmids with resistance traits and the number of plasmid relicons carrying resistance genes is high as is the number of antibiotic gene combinations on those plasmids ${ }^{37}$.

Continuous surveillance to monitor this potential upcoming problem is important, as are prudent infection control measures and antibiotic use to prevent and control the spread of these antibiotic resistant strains. Maybe, the preventive use of cranberry tablets or lactobacilli could decrease empiric antibiotic use ${ }^{38,39}$.

\section{Conclusion}

In this study we observed a high prevalence of antibiotic resistance but a low prevalence of ESBL production among $E$. coli isolates collected from urine samples from $\mathrm{NH}$ residents. Antibiotic use was also relatively high. Especially the use of and the resistance to fluoroquinolones is a point of concern. Due to this prevalence of resistance many antibiotics including amoxicillin-clavulanic acid, the folate antagonists and the fluoroquinolones, are no longer suitable for empiric treatment and, therefore, oral treatment options have become limited. Moreover, E. coli STs globally emerging as multi drug resistant strains have also been demonstrated in this study and pose a potential risk to this vulnerable population, since the risk of treatment faillure would increase. We clearly demonstrated that the resistance among $\mathrm{NH}$ residents is different from elderly living at home and hospitalized patients and that with the emergence of multi drug resistant strains worldwide, such as ST131, NHs are a potential reservoir for antibiotic (multi drug) resistance. Therefore, continuous surveillance of antimicrobial resistance in nursing homes is needed to monitor resistance overtime and the increase 
Chapter 3

of multi drug resistant strains and should be continued to be able to adapt treatment protocol if necesary. Also, antibiotic treatment should be iniated with care and adequate infection control measures should be applied.

\section{Acknowledgements}

The authors would like to thank all the participants for their participation in this study and the nursing staff in the participating nursing homes for their aid and assistance with the collection of the samples. 


\section{References}

1. Nicolle LE, Strausbaugh LJ, Garibaldi RA. Infections and antibiotic resistance in nursing homes. Clin Microbiol Rev 1996; 9: 1-17.

2. Tal S, Guller V, Levi $S$ et al. Profile and prognosis of febrile elderly patients with bacteremic urinary tract infection. $J$ Infect 2005; 50: 296-305.

3. Koch AM, Eriksen HM, Elstrom $P$ et al. Severe consequences of healthcare-associated infections among residents of nursing homes: a cohort study. $J$ Hosp Infect 2009; 71: 269-74.

4. Nicolle LE, Bentley DW, Garibaldi R et al. Antimicrobial use in long-term-care facilities. SHEA Long-Term-Care Committee. Infect Control Hosp Epidemiol 2000; 21: 537-45.

5. Nicolle LE. Resistant pathogens in urinary tract infections. J Am Ger Soc 2002; 50: S230-

5.

6. Oliphant CM, Green GM. Quinolones: a comprehensive review. Am Fam Physician 2002; 65: 455-64.

7. Goossens $\mathrm{H}$, Ferech $\mathrm{M}$, Vander Stichele $\mathrm{R}$ et al. Outpatient antibiotic use in Europe and association with resistance: a cross-national database study. Lancet 2005; 365: 579-87.

8. Rooney PJ, O'Leary MC, Loughrey AC et al. Nursing homes as a reservoir of extendedspectrum beta-lactamase (ESBL)-producing ciprofloxacin-resistant Escherichia coli. J Antimicrob Chemother 2009; 64: 635-41.

9. Johnson JR, Johnston B, Clabots C et al. Escherichia coli sequence type ST131 as the major cause of serious multidrug-resistant $E$. coli infections in the United States. Clin Infect Dis 2010; 51: 286-94.

10. Croxall G, Hale J, Weston $\mathrm{V}$ et al. Molecular epidemiology of extraintestinal pathogenic Escherichia coli isolates from a regional cohort of elderly patients highlights the prevalence of ST131 strains with increased antimicrobial resistance in both community and hospital care settings. J Antimicrob Chemother 2011; 66: 2501-8.

11. Matthews SJ, Lancaster JW. Urinary tract infections in the elderly population. Am J Ger Pharmacother 2011; 9: 286-309.

12. Chami K, Gavazzi G, Carrat F et al. Burden of infections among 44,869 elderly in nursing homes: a cross-sectional cluster nationwide survey. J Hosp Infect 2011; 79: 254-9.

13. Lee SS, Kim Y, Chung DR. Impact of discordant empirical therapy on outcome of community-acquired bacteremic acute pyelonephritis. J Infect 2011; 62: 159-64.

14. Hounsom L, Grayson K, Melzer M. Mortality and associated risk factors in consecutive patients admitted to a UK NHS trust with community acquired bacteraemia. Postgrad Med J 2011; 87: 757-62.

15. Yamamoto S, Tsukamoto T, Terai A et al. Genetic evidence supporting the fecalperineal-urethral hypothesis in cystitis caused by Escherichia coli. J Urol 1997; 157: 1127-9.

16. Beerepoot MA, den Heijer CD, Penders J et al. Predictive value of Escherichia coli susceptibility in strains causing asymptomatic bacteriuria for women with recurrent symptomatic urinary tract infections receiving prophylaxis. Clin Microbiol Infect 2012; 18: E84-90.

17. Xie C, Taylor DM, Howden BP et al. Comparison of the bacterial isolates and antibiotic resistance patterns of elderly nursing home and general community patients. Intern Med J 2011.

18. Nys S, van Merode $\mathrm{T}$, Bartelds $\mathrm{Al}$ et al. Antibiotic treatment and resistance of unselected uropathogens in the elderly. Int J Antimicrob Agents 2006; 27: 236-41.

19. EUCAST. Breakpoint tables for interpretation of MICs and zone diameters - version 1.3, January 2011

20. NVMM Guideline - Laboratory detection of highly resistant microorganisms (HRMO) version 1.0. 2011. 
21. Saladin M, Cao VT, Lambert $T$ et al. Diversity of CTX-M beta-lactamases and their promoter regions from Enterobacteriaceae isolated in three Parisian hospitals. FEMS microbiol lett 2002; 209: 161-8.

22. Pitout JD, Hossain A, Hanson ND. Phenotypic and molecular detection of CTX-M-betalactamases produced by Escherichia coli and Klebsiella spp. J Clin Microbiol 2004; 42: 5715-21.

23. Pallecchi L, Malossi M, Mantella A et al. Detection of CTX-M-type beta-lactamase genes in fecal Escherichia coli isolates from healthy children in Bolivia and Peru. Antimicrob Agents Chemother 2004; 48: 4556-61.

24. Meex C, Melin P, Docquier JD et al. Presence of extended-spectrum beta-lactamaseproducing Enterobacteriaceae in fecal flora of patients from general practice. ECCMID. Barcelona, 2008.

25. Ribot EM, Fair MA, Gautom R et al. Standardization of pulsed-field gel electrophoresis protocols for the subtyping of Escherichia coli 0157:H7, Salmonella, and Shigella for PulseNet. Foodborne Pathog Dis 2006; 3: 59-67.

26. Wirth $\mathrm{T}$, Falush $\mathrm{D}$, Lan $\mathrm{R}$ et al. Sex and virulence in Escherichia coli: an evolutionary perspective. Mol Microbiol 2006; 60: 1136-51.

27. UCC. Escherichia coli MLST database http://mlst.ucc.ie/mlst/dbs/Ecoli (6 July 2012 date last accessed ).

28. WHO Collaborating Centre for Drug Statistics Methodology. ATC/DDD Index 2012 http://www.whocc.no/atc_ddd_index/ (25 June 2012 - date last accesed).

29. Gupta K, Hooton TM, Naber KG et al. International clinical practice guidelines for the treatment of acute uncomplicated cystitis and pyelonephritis in women: A 2010 update by the Infectious Diseases Society of America and the European Society for Microbiology and Infectious Diseases. Clin Infect Dis 2011; 52: e103-20.

30. den Heijer CD, Donker GA, Maes J et al. Antibiotic susceptibility of unselected uropathogenic Escherichia coli from female Dutch general practice patients: a comparison of two surveys with a 5 year interval. $J$ Antimicrob Chemother 2010; 65: 2128-33.

31. SWAB. Nethmap 2011 - Consumption of antimicrobial agents and antimicrobial resistance among medically important bacteria in the Netherlands. 2011.

32. McClean $P$, Hughes $C$, Tunney $M$ et al. Antimicrobial prescribing in European nursing homes. J Antimicrob Chemother 2011; 66: 1609-16.

33. Charalabopoulos K, Karachalios G, Baltogiannis D et al. Penetration of antimicrobial agents into the prostate. Chemotherapy 2003; 49: $269-79$.

34. Raz R. Fosfomycin: an old-new antibiotic. Clin Microbiol Infect 2012; 18 : 4-7.

35. Tartof SY, Solberg OD, Manges AR et al. Analysis of a uropathogenic Escherichia coli clonal group by multilocus sequence typing. J Clin Microbiol 2005; 43: 5860-4.

36. Gibreel TM, Dodgson AR, Cheesbrough J et al. Population structure, virulence potential and antibiotic susceptibility of uropathogenic Escherichia coli from Northwest England. $J$ Antimicrob Chemother 2012; 67: 346-56.

37. Lindsey RL, Frye JG, Thitaram SN et al. Characterization of multidrug-resistant Escherichia coli by antimicrobial resistance profiles, plasmid replicon typing, and pulsed-field gel electrophoresis. Microb Drug Resist 2011; 17: 157-63.

38. Jepson RG, Craig JC. Cranberries for preventing urinary tract infections. Cochrane Database Syst Rev 2008: CD001321.

39. Beerepoot MAJ, Ter Riet G, Nys $S$ et al. Lactobacilli vs Antibiotics to Prevent Urinary Tract Infections: A Randomized, Double-blind, Noninferiority Trial in Postmenopausal Women. Arch Intern Med 2012; 172: 704-12. 


\section{Chapter 4 Prevalence and spread of multi drug resistant E. coli including ST131 in different patient populations in the Euregion Meuse-Rhine}

C.F.M. van der Donk, C.C. Driessen, H. Bamelis, J.H.B. van de Bovenkamp, K-H. Feldhoff, W.A. Kalka-Moll, K. Magerman, E.E. Stobberingh 


\section{Abstract}

\section{Objective}

To determine the prevalence and genetic background of resistant $E$. coli isolates collected from general practice patients, and nursing home residents, intensive care unit (ICU) and urology services patients in the Euregion Meuse-Rhine.

\section{Methods}

A total of $1651 \mathrm{E}$. coli isolates were collected from residents of the Euregion. Susceptibility testing was performed with broth microdilution. The genetic background was determined using PFGE and MLST, and analyzed with eBURST and clonal frame analysis.

\section{Results}

The prevalence of resistance varied significantly between the four populations. Amoxicillin-clavulanic acid resistance was highest among the ICU isolates (40\%). Ciprofloxacin resistance was highest among the urology isolates (27\%). Approximately $10 \%$ of the $E$. coli isolates was multi drug resistant and/or an ESBL producer. The most prevalent ESBL type was CTX-M 15. In total, 47 different STs were observed and ST131 was the most prevalent one. PFGE analysis of the ST131, 393 and 88 isolates suggested the spread of isolates belonging to the same PFGE group in the entire Euregion.

\section{Conclusion}

$E$. coli ST131 was the most prevalent ST in our Euregional study. The emergence of resistant strains might be a precursor for an increasing prevalence of resistance. To control the spread of these resistant strains adherence to infection control policies and implementation of an antibiotic stewardship program, based on the results of antibiotic resistance surveillance, is essential. In this way we could observe a shift in the prevalence of resistance and the genetic structure of the $E$. coli population and act accordingly. 


\section{Introduction}

Since the introduction of antibiotics bacteria have developed ways to resist these agents, which urged for the development of new antibiotics. Now we have come to a time were there are even bacteria resistant to our last resort agents ${ }^{1,2}$. The prevalence of these multi, extensively or pan drug resistant bacteria is increasing and they are spreading across the globe ${ }^{3-6}$.

Previous research has shown that the spread of resistant bacteria is mostly within one health care network ${ }^{7}$ and that health care institutions should not be considered as an individual centre but as parts of a network ${ }^{8}$. In a border region, such as the Euregion Meuse-Rhine, the region between Belgium, Germany and the Netherlands, we are confronted not only with the spread of resistant bacteria within the three countries, but also with cross border movement, including for health care purposes ${ }^{9,10}$. This will facilitate the spread between the three countries and prevalence of resistant bacteria, since bacteria can potentially spread from one country to another.

Escherichia coli is part of the commensal gut microbiota and a prevalent cause of infections, in particular, urinary tract infections (UTI) ${ }^{11}$. It is well known that $E$. coli can carry a range of mobile genetic elements such as plasmids with different antibiotic resistance genes ${ }^{12}$, such as $E$. coli with sequence type (ST) 131 . This is a globally spreading clone often with many resistance and virulence genes ${ }^{6}$ (including genes encoding for extended spectrum beta-lactamases (ESBL)).

UTI infections are often treated empirically. The first step for optimal empiric treatment is to make the right antibiotic choice: the right drug, dose, duration and minimize development of resistance ${ }^{13}$. This choice needs to be based on actual antibiotic resistance data phenotypically and preferably also genotypically. As the current situation in terms of genetic background of $E$. coli isolates and the potential spread of specific $E$. coli clones in the Euregion Meuse-Rhine is still unknown while this was investigated for other bacteria, such as $S$. aureus ${ }^{14}$, we performed the present study. We determined the prevalence of (multi drug) resistant E. coli and the genetic background of these isolates collected from general practice (GP) patients, and nursing home $(\mathrm{NH})$ residents, intensive care unit (ICU) and urology services (URO) patients in the Euregion. The isolates were characterized with quantitative susceptibility testing, multi locus sequence typing (MLST) and pulsed field gel electrophoresis (PFGE). The obtained data will enable us to investigate the prevalence and spread of multi drug resistant $(M D R)$ and/or extended spectrum beta-lactamase (ESBL) producing $E$. coli strains in the border region, the Euregion Meuse-Rhine.

\section{Materials and Methods}

\section{Bacterial isolates and susceptibility testing}

Between March 2009 and May 2012 a total of 1651 E. coli isolates were collected (Table 1) from urine samples from patients attending the URO services, GP patients and $\mathrm{NH}$ residents (colonization only for $\mathrm{NH}$ residents), and from various clinical samples from ICU patients. The samples were collected from 10 hospitals, 17 nursing 
homes and 54 GPs in the Euregion Meuse-Rhine (i.e. in the Province of Limburg and the Province of Liège in Belgium, the Province of Limburg in the Netherlands and the Regions Aachen, Düren, Euskirchen, Heinsberg and Vulkaneifel in Germany).

The hospital samples and German GP samples were analyzed at the local laboratory, stored and sent to the Maastricht University Medical Centre (MUMC). The samples from the $\mathrm{NH}$ residents and the other GP samples were used to inoculate a dipslide (Biomérieux, Marcy l'Etoile, France) and were sent to the MUMC for isolation and identification. Quantitative susceptibility testing was performed in the MUMC using a broth microdilution with Mueller-Hinton II cation-adjusted broth (Becton-Dickinson, Sparks, MD, USA) and micro titre plates with freeze-dried antibiotics (MCS Diagnostics BV, Swalmen, the Netherlands). E. coli ATCC 35218 and ATCC 25922 were used as control strains. The minimal inhibitory concentration (MIC) breakpoints were defined by the European Committee on Antimicrobial Susceptibility Testing (EUCAST) ${ }^{15}$. MDR was defined as resistance to three or more of the tested antimicrobial classes: amoxicillin-clavulanic acid, fluoroquinolones, folate pathway antagonists, nitrofurantoin and gentamicin.

ESBL production among the URO and ICU isolates was confirmed for isolates with a ceftazidime and or cefotaxime MIC $\geq 2 \mathrm{mg} / \mathrm{L}$ using a combination disk diffusion test according to the guidelines of the Dutch society for medical microbiology ${ }^{16}$ and for the $\mathrm{NH}$ and GP isolates ESBL production was confirmed for isolates with an amoxicillinclavulanic acid $\mathrm{MIC} \geq 8 \mathrm{mg} / \mathrm{L}$.

\section{ESBL characterization}

The ESBL positive isolates were characterized for the presence of TEM, SHV and/or CTX-M beta-lactamases with a micro-array (Check-points, Wageningen, the Netherlands). Based on these results bla $a_{\mathrm{TEM}}, b l a_{\mathrm{SHV}}$ or bla $a_{\mathrm{CTX}-\mathrm{M}}$ were amplified with PCR and specific primers ${ }^{17-20}$.

Automated sequencing was performed with the 3730 DNA analyzer with BigDye Terminator v1.1 (Applied Biosystems, Forster City, CA, USA).

\section{MLST}

The MDR isolates and ESBL producers were analyzed with MLST using the scheme by Wirth et al. ${ }^{21}$ specified at the University College of Cork $E$. coli MLST web site ${ }^{22}$.

The Based Upon Related Sequence Types (eBURST) algorithm was used to analyse the allelic profiles and define clonal complexes ${ }^{23}$. The default settings of the eBURST V3 software (http: / /eburst.mlst.net/) were used.

Clonal frame analysis (CFA) software (version 1.1$)^{24}$ was used to construct a majority rule consensus tree. Ten runs were computed with the default settings $(-x=50000,-y$ $50000,-z 100)$ after which a 50\% consensus tree and network representations were constructed with the graphical user interface.

\section{PFGE}

Based upon the MLST results and the antibiotic resistance pattern, isolates belonging to ST393 and ST88, and a selection of the isolates belonging to ST131 were further analyzed with PFGE using the Xbal restriction enzyme ${ }^{25}$. For the ST131, at least $50 \%$ of 
the isolates per population per country with one of three resistance patterns were selected for PFGE, which were: resistance to amoxicillin-clavulanic acid and ciprofloxacin combined with resistance to gentamicin and/or trimethoprimsulfamethoxazole.

The PFGE profiles were analyzed with BioNumerics v.6.0 (Applied Maths, Sint-MartensLatem, Belgium). A dendrogram was generated from the cluster analysis of Dice similarity indices with 0.5 optimization and $2.0 \%$ tolerance based on the unweighted pair group method with arithmetic averages (UPGMA). Isolates were considered to belong to the same PFGE group if their Dice similarity index was $\geq 85 \%{ }^{26}$.

\section{Statistical analysis}

A Pearson's chi square test or Fisher's exact test was performed to determine statistically significant differences of resistance between the three different countries of the Euregion Meuse-Rhine and between the four different populations in this study (PASW-software, version 18.0, IBM, Armonk, NY, USA). A modified false discovery rate (FDR) method developed by Benjamini and Yekutieli was used as correction for multiple testing ${ }^{27}$. A p-value $<0.05$ was considered statistically significant. Diversity of the groups of isolates regarding the STs was determined with Simpson's Index of diversity $^{28}$.

\section{Results}

\section{Bacterial isolates and antibiotic resistance}

A total of $1651 \mathrm{E}$. coli isolate were collected (Table 1). The number of isolates per countries ranged from 488 to 639 isolates and the number of isolates per population category from 421-597 isolates except for the ICU isolates with a total of 180 . Approximately $20 \%$ of those ICU isolates were collected from urine samples.

Table 1: The collected isolates per patient population and country

\begin{tabular}{lllll}
\hline Unit & NL & B & G & Total \\
\hline GP & 184 & 194 & 75 & 453 \\
NH & 209 & 152 & 236 & 597 \\
ICU & 70 & 52 & 5 & 180 \\
URO & 176 & 126 & 119 & 421 \\
\hline Total & 639 & 524 & 488 & 1651 \\
\hline
\end{tabular}

$\mathrm{NL}=$ the Netherlands, $\mathrm{B}=$ Belgium, $\mathrm{G}=$ Germany, $\mathrm{GP}=$ general practice, $\mathrm{NH}=$ nursing home, $\mathrm{ICU}$ $=$ intensive care unit, URO = urology services.

The prevalence of antibiotic resistance of the collected isolates is shown in Table 2 . The prevalence of resistance was comparable for the three countries. Only for amoxicillin-clavulanic acid and ciprofloxacin the prevalence of resistance was significantly higher in Belgium than in the Netherlands i.e. $27 \%$ and $23 \%$ versus $21 \%$ and $16 \%$, respectively. However, the prevalence of resistance varied significantly between the different populations. Overall the GP isolates showed the lowest prevalence of resistance. The ICU isolates had the highest prevalence of resistance for amoxicillin, 
both alone and in combination with clavulanic acid (61\% and $40 \%$, respectively). Norfloxacin and ciprofloxacin resistance was significantly higher among the $\mathrm{NH}(27 \%$ and $22 \%$ ), ICU (21\% and $18 \%$ ) and URO isolates (32\% and $27 \%$ ) compared with the GP isolates $(12 \%$ and $8 \%)$. The prevalence of resistance to both folate pathway inhibitors was comparable among the GP (23\% and $22 \%)$ and $\mathrm{NH}(22 \%$ and $20 \%)$ isolates and significantly higher among the ICU (33\% and 30\%) and URO (29\% and $28 \%)$ isolates. The resistance to gentamicin and nitrofurantoin was low, the highest prevalence of resistance to these antibiotics was observed among the URO isolates, $7 \%$ and $4 \%$, respectively.

Table 2: Prevalence of resistance in \% among all collected isolates

\begin{tabular}{llll|llll}
\hline Unit & NL & B & G & GP & NH & ICU & URO \\
\hline AMO & 46 & 50 & 43 & 39 & 43 & $61^{+\dagger}$ & $49^{+\dagger}$ \\
AMC & 21 & $27^{*}$ & 26 & 17 & 22 & $40^{+\dagger}$ & $29^{+\dagger}$ \\
CIP & 16 & $23^{*}$ & 20 & 8 & $22^{+}$ & $18^{+}$ & $27^{+}$ \\
NOR & 20 & 26 & 25 & 12 & $27^{+}$ & $21^{+}$ & $32^{+\ddagger}$ \\
TRIM & 24 & 27 & 24 & 23 & 22 & $33^{+\dagger}$ & $29^{\dagger}$ \\
SXT & 22 & 26 & 23 & 22 & 20 & $30^{\dagger}$ & $28^{\dagger}$ \\
GEN & 5 & 6 & 8 & 4 & 6 & 6 & 7 \\
NIT & 2 & 1 & 0 & 0 & 0 & 0 & $4^{+\dagger}$ \\
\hline Total (n) & 639 & 524 & 488 & 453 & 597 & 180 & 421 \\
\hline
\end{tabular}

$\mathrm{NL}=$ the Netherlands, $\mathrm{B}=$ Belgium, $\mathrm{G}=$ Germany, $\mathrm{GP}=$ general practice, $\mathrm{NH}=$ nursing home, $\mathrm{ICU}$ = intensive care unit, $U R O=$ urology services, $A M O=$ amoxicillin, $A M C=$ amoxicillin-clavulanic acid, $\mathrm{CIP}=$ ciprofloxacin, $\mathrm{NOR}=$ norfloxacin, $\mathrm{GEN}=$ gentamicin, $\mathrm{TRIM}=$ trimethoprim, $\mathrm{SXT}=$ trimethoprim-sulfamethoxazole, NIT = nitrofurantoin.

* = significantly higher compared with NL

${ }^{+}=$significantly higher compared with $\mathrm{GP},{ }^{\dagger}=$ significantly higher compared with $\mathrm{NH}$

${ }^{\ddagger}=$ significantly higher compared with ICU, ${ }^{\S}=$ significantly higher compared with URO

\section{MDR and/or ESBL producing isolates}

The overall prevalence of MDR and/or ESBL producing isolates was comparable for the three countries with the highest prevalence among the Belgian isolates $(14 \%)$. Comparing the different populations the URO isolates showed the highest prevalence of MDR (14\%) and the GP isolates (6\%) the lowest. The prevalence was for the $\mathrm{NH}$ $(11 \%)$ and ICU $(14 \%$, range from $2 \%$ to $21 \%)$ isolates.

Table 3: The multi drug resistant and/or ESBL producing isolates per patient population and country

\begin{tabular}{lllll}
\hline Unit & NL & B & G & Total \\
\hline GP & $5(3)$ & $12(6)$ & $8(11)$ & $25(6)$ \\
NH & $21(10)$ & $16(11)$ & $26(11)$ & $63(11)$ \\
ICU & $10(11)$ & $12(21)$ & $4(2)$ & $26(14)$ \\
URO & $18(10)$ & $31(21)$ & $19(13)$ & $68(16)$ \\
\hline Total & $54(8)$ & $71(14)$ & $57(12)$ & $182(11)$ \\
\hline
\end{tabular}

$\mathrm{NL}=$ the Netherlands, $\mathrm{B}=$ Belgium, $\mathrm{G}=$ Germany, $\mathrm{GP}=$ general practice, $\mathrm{NH}=$ nursing home, $\mathrm{ICU}$ $=$ intensive care unit, URO = urology services. The percentage of all collected isolates (Table 1$)$ is indicated between the parentheses. 
Table 4: Different antibiotic resistance patterns per country and per patient population among the multi drug resistant and/or ESBL producing isolates

\begin{tabular}{ll|lll|llll}
\hline AB resistance & Total & NL & B & G & GP & NH & ICU & URO \\
\hline AMC/QUI/GEN/SXT/NIT T & 1 & 0 & 0 & 1 & 0 & 0 & 0 & 1 \\
AMC/QUI/SXT/GEN & $38(12)$ & $7(3)$ & $17(4)$ & $14(5)$ & 6 & $12(4)$ & $5(3)$ & $15(5)$ \\
AMC/QUI/SXT/NIT & 4 & 0 & 4 & 0 & 0 & 0 & 0 & 4 \\
AMC/QUI/SXT & $72(8)$ & $24(1)$ & $31(3)$ & $17(4)$ & 7 & $27(2)$ & $11(3)$ & $27(3)$ \\
AMC/QUI/GEN & $21(3)$ & 3 & $7(2)$ & $11(1)$ & 6 & $10(2)$ & $1(1)$ & 4 \\
AMC/QUI/NIT & 2 & 2 & 0 & 0 & 0 & 0 & 0 & 2 \\
AMC/SXT/GEN & 3 & 2 & 1 & 0 & 1 & 0 & 1 & 1 \\
AMC/SXT/NIT & 1 & 0 & 1 & 0 & 0 & 0 & 0 & 1 \\
QUI/SXT/GEN & $14(1)$ & $10(1)$ & 1 & 3 & 2 & 8 & 1 & $3(1)$ \\
QUI/SXT/NIT & 2 & 1 & 0 & 1 & 0 & 0 & 1 & 1 \\
QUI/GEN/NIT & $1(1)$ & $1(1)$ & 0 & 0 & 0 & 0 & 0 & $1(1)$ \\
AMC/QUI & $3(3)$ & $2(2)$ & $1(1)$ & 0 & 0 & $1(1)$ & $1(1)$ & $1(1)$ \\
AMC/SXT & $3(3)$ & $1(1)$ & $1(1)$ & $1(1)$ & 0 & $1(1)$ & $2(2)$ & 0 \\
QUI/SXT & $7(7)$ & 0 & $1(1)$ & $6(6)$ & 0 & $3(3)$ & $1(1)$ & $3(3)$ \\
SXT/GEN & $1(1)$ & 0 & 0 & $1(1)$ & 0 & 0 & 0 & $1(1)$ \\
AMC & $1(1)$ & 0 & $1(1)$ & 0 & 0 & 0 & 0 & $1(1)$ \\
QUI & $6(6)$ & $1(1)$ & $4(4)$ & $1(1)$ & $1(1)$ & $1(1)$ & $2(2)$ & $2(2)$ \\
SXT & $2(2)$ & 0 & $1(1)$ & $1(1)$ & $2(2)$ & 0 & 0 & 0 \\
\hline \multirow{2}{*}{ Total } & 182 & 54 & 71 & 57 & 25 & 63 & 26 & 68 \\
& $(48)$ & $(10)$ & $(18)$ & $(20)$ & $(3)$ & $(14)$ & $(13)$ & $(18)$ \\
\hline
\end{tabular}

$\mathrm{AB}=$ antibiotic, $\mathrm{NL}=$ the Netherlands, $\mathrm{B}=$ Belgium, $\mathrm{G}=$ Germany, $\mathrm{GP}=$ general practice, $\mathrm{NH}=$ nursing home, ICU = intensive care unit, $U R O=$ urology services, $A M C=$ amoxicillin-clavulanic acid, QUI = fluoroquinolones, GEN = gentamicin, SXT = folate pathway antagonists, NIT = nitrofurantoin. The amount of ESBLs is indicated between the parentheses.

A total of 182 isolates (Table 3) were included for MLST of which 48 were ESBL producers. 23 of those ESBLs were not MDR.

The most prevalent patterns were resistance to: 1) amoxicillin-clavulanic acid, the fluoroquinolones and folate pathway inhibitors ( $n=72), 2)$ amoxicillin-clavulanic acid, the fluoroquinolones, folate pathway inhibitors and gentamicin $(n=38)$, and 3$)$ amoxicillin-clavulanic acid, the fluoroquinolones, and gentamicin ( $n=21)$. Only $11(6 \%)$ isolates were resistant to nitrofurantoin, most of them were from the URO except for one ICU isolate (Table 4).

The most prevalent ESBL type was CTX-M $15(n=34)$. Other ESBL types were CTX-M 1 $(n=5)$, CTX-M $2(n=1)$, CTX-M $14(n=2)$, CTX-M 55/79 $(n=2)$, TEM $52(n=2)$ and SHV 12 $(n=1)$. ESBL producing isolates were mostly found most among the ICU isolates $(n=13$ out of 180$)$ and URO ( $n=18$ out of 427$)$. One isolate $(\mathrm{NH})$ carried two ESBL genes i.e. CTX-M 15 and SHV 12. 


\section{MLST}

Among the 182 MDR and/or ESBL producing isolates 47 different STs were found (Table 5). ST131 was observed in 74 out of 182 samples $(41 \%)$ and in 10 out of the 12 groups of isolates (Table 5) and was overall the most prevalent ST followed by ST393 $(n=10)$ and ST88 $(n=9)$. The other STs were demonstrated one to seven times. Among them was one new ST (ST3088) and 2 new alleles i.e. fumC430 (ST3186) and gyrB316 (ST3187) were found.

All but one of the ST131 isolates were resistant to the fluoroquinolones and 54 were resistant to the folate pathway antagonists.

Nitrofurantoin resistant isolates had 10 different STs from 9 clonal complexes (CCs). Only one isolate (ST964) was an ESBL producer (CTX-M 15). The other ESBL producing isolates belonged in $53 \%$ of the cases to ST131 ( $n=25)$ of which 23 were CTX-M 15. The other ESBLs were found mostly among isolates with CC88 $(n=6)$, CC58 $(n=4)$ and CC10 $(n=3$, Table 6).

The diversity of the STs was highest among the GP and ICU samples compared with the NH samples (Table 5).

Table 5: Overview of the observed STs per patient population and country

\begin{tabular}{lllll}
\hline & NL (56) & B (70) & G (54) & $\begin{array}{l}\text { DI } \\
(95 \% \mathrm{Cl})\end{array}$ \\
\hline GP & $69,393,405,428$, & $10,73,131(6), 156$, & $34,69,88,131(2)$, & 0.944 \\
$(22)$ & 1642 & $167,405,2538$ & $167(2), 1914$ & $(0.884-$ \\
& & & & $1)$ \\
NH & $23,38,69(2), 73$, & $88,131(15)$ & $46,56,58,73,80$, & 0.717 \\
$(60)$ & $131(11), 393(2)$, & & $131(14), 354,398$, & $(0,596-$ \\
& $1664,2577(2)$ & & $453(2), 648,744$, & $0.838)$ \\
ICU & $23,99,131(2)$, & $93,131(2), 354$, & 1411 & \\
$(25)$ & $393(2), 399(2)$, & $393(2), 410(2), 685$, & & 0.977 \\
& 1642,3187 & $1011,1394,3186$ & & $(0.949-$ \\
URO & $58,69,88,131(4)$, & $10,23,58(2), 69(2)$, & $10(2), 131(9)$, & 0.912 \\
$(68)$ & $162,167,410,453$, & $88(6), 95,101,131(9)$, & $393(3), 533$, & $(0.860-$ \\
& $603,648(3), 964$, & $162(2), 167,453$, & $624(2), 1011,1394$ & $0.963)$ \\
& 2509,3088 & $617(2), 648(2), 744$ & & \\
\hline
\end{tabular}

$\mathrm{NL}=$ the Netherlands, $\mathrm{B}=$ Belgium, $\mathrm{G}=$ Germany, $\mathrm{DI}=$ diversity index, $\mathrm{Cl}=$ confidence interval, $\mathrm{GP}=$ general practice, $\mathrm{NH}=$ nursing home, $\mathrm{ICU}=$ intensive care unit, URO = urology. The number of isolates is indicated between parentheses, if not indicated the ST was detected only once.

\section{eBURST and CFA analysis}

eBURST analysis of the isolates showed 7 groups and 27 singletons (Figure 1). The largest group with predicted founder ST10 contained 6 different STs. ST131 could not be assigned to any group. We also performed an eBURST analysis of the entire E. coli MLST database (up to ST3190) to investigate the clonal complex the isolates in our study population belonged to (Table 6).

Most of the STs belonged to CC10 and CC58 (former CC15522), two isolates (ST1914 and 2538) could not be assigned to a CC. 
Table 6: STs per CC

\begin{tabular}{llll}
\hline CC & ST & CC & ST \\
\hline 10 & $10(2), 34,46,93,167,398,617,685(1), 3088$ & 156 & 156 \\
14 & 1411 & 354 & 354,3186 \\
38 & $38(1)$ & 399 & $399(2)$ \\
58 & $56,58(1), 162(2), 533,603,1642,2509(1)$ & 405 & $405,964(1), 2577$ \\
69 & $69,393,1394$ & 428 & 428 \\
73 & 73 & 641 & $453(1)$ \\
80 & 80 & 648 & $624,648(2)$ \\
88 & $23(2), 88(1), 410(3), 1664$ & 1011 & 1011 \\
95 & 95 & 1611 & $99(1)$ \\
101 & 101,3187 & - & 1914,2538 \\
131 & $131(21)$ & & \\
\hline
\end{tabular}

The number of ESBL producing isolates is indicated between the parentheses.

The results of the eBURST clustering and the clonal frame analysis were quite similar (Figure 2). STs that were clustered into one CC with eBURST were also quite closely related according to the CFA. The main exception was ST162, which was in CC58 according to eBURST, but according to the clonal frame analysis this ST was more distantly related to the other STs in CC58. Also, in CC58, ST162 was also far removed from the founder ST58 (eBURST). ST131 could according to the eBURST analysis not be clustered to any of the other demonstrated STs and was not placed as a node in the consensus tree with the CFA.

Figure 1: eBURST

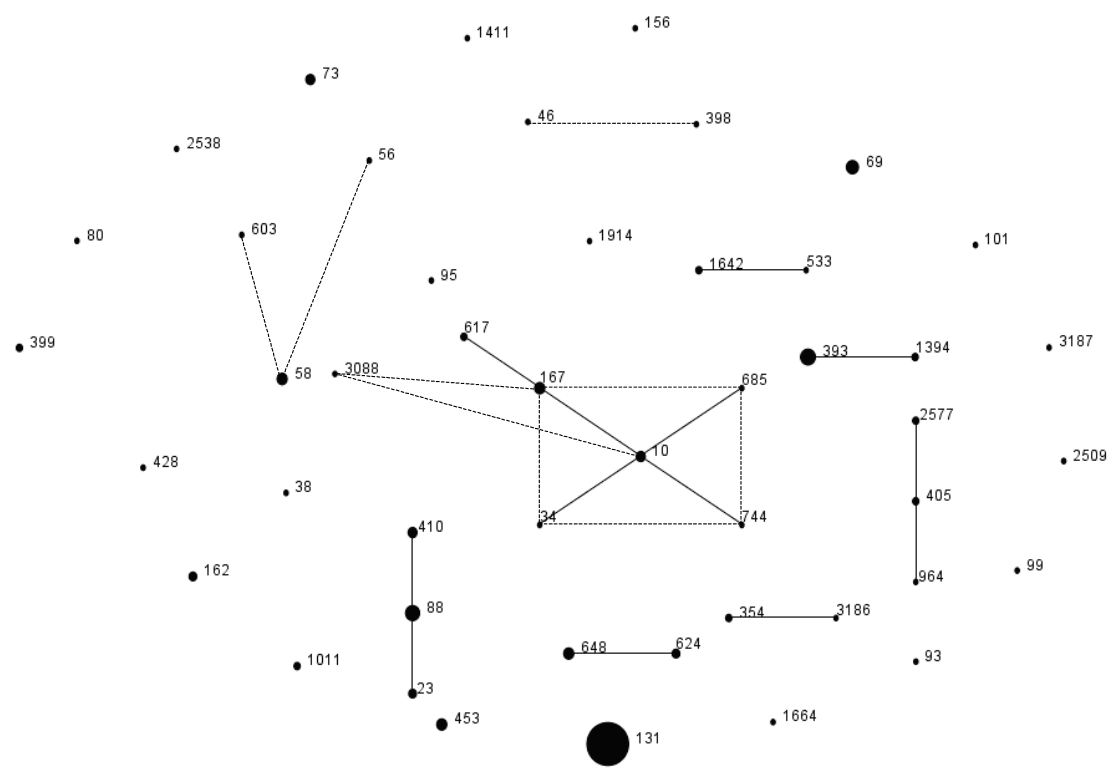

eBURST diagram: Each dot represents a ST and the size of the dot correlates with the frequency this ST was found. The single locus variants and double locus variants are represented by the normal and dotted lines, respectively. The distance between the different dots does not reflect their relatedness 
Figure 2: Clonal frame analysis

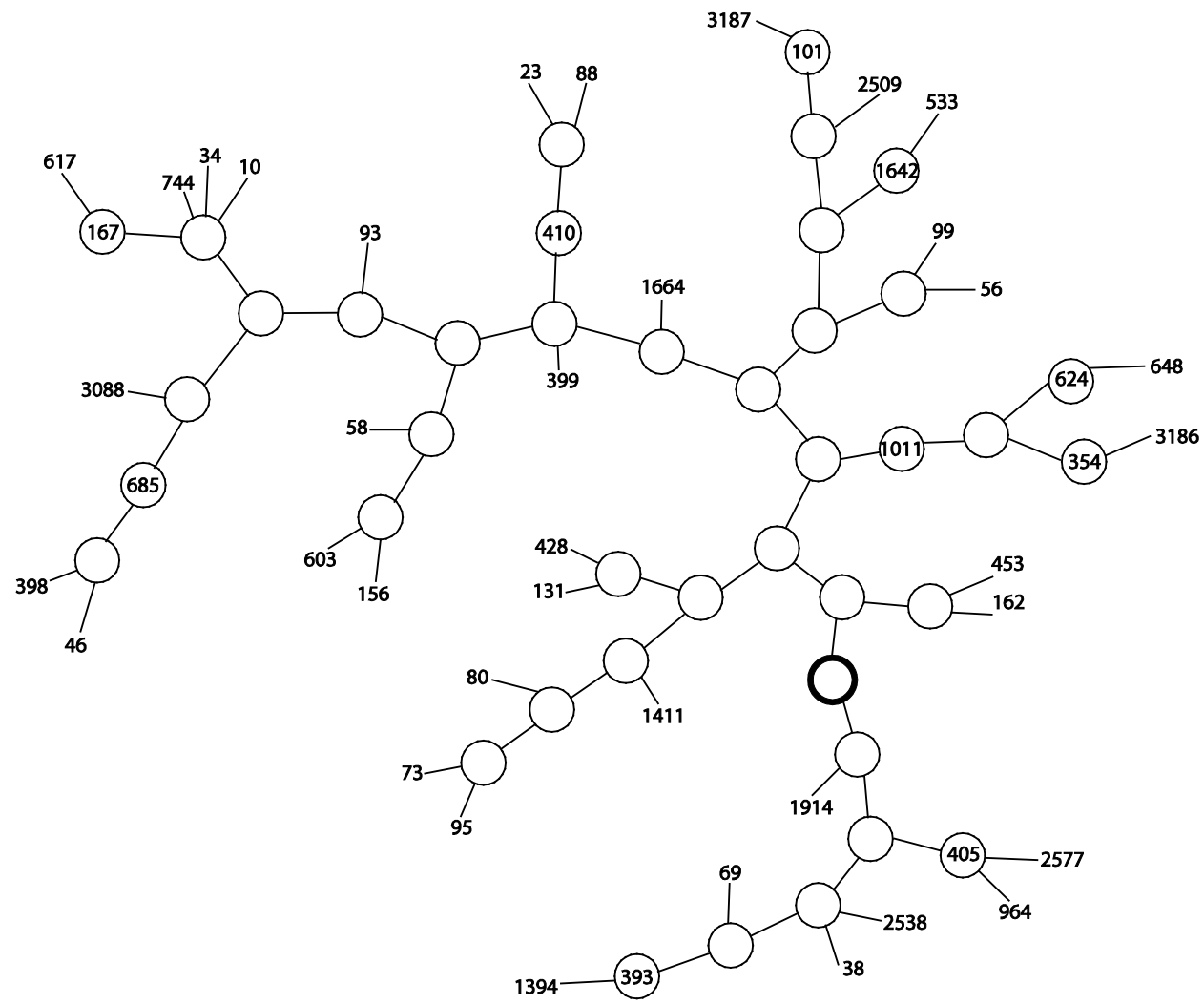

Network representation of ten $50 \%$ consensus trees. The analysis included all demonstrated STs $(n=47)$. The ancestral node (unknown) is demonstrated with a bold border.

\section{PFGE}

All isolates belonging to ST393 and ST88 were further typed with PFGE. The isolates with ST393 had comparable PFGE pulsotypes (Dice $\geq 92 \%$, Figure 3 ). The ST88 isolates had more diverse pulsotypes (Dice $\geq 68 \%$, Figure 4 ).

PFGE analysis demonstrated that among the ST131 isolates, several groups of isolates with a comparable pulsotype were found in the entire Euregion. Among these isolates a group of 13 (Figure 5: lane 17-29) was found with a high similarity (>84\%), which were mostly isolates collected from the NHs in all three countries. A second group of 12 isolates (Figure 5: lane 1-12, Dice >82\%) was demonstrated among the four population in the three countries. 
Figure 3: PFGE dendrogram ST393

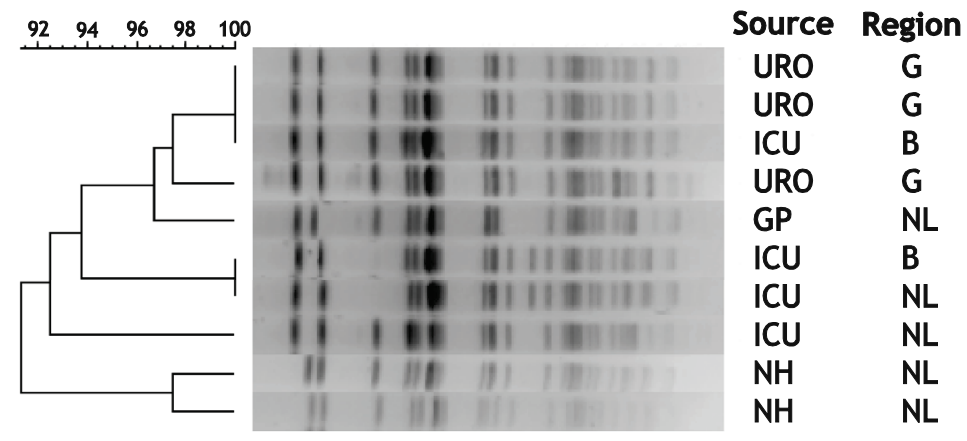

UPGMA tree of PFGE ST393 E. coli isolates

Figure 4: PFGE dendrogram ST88

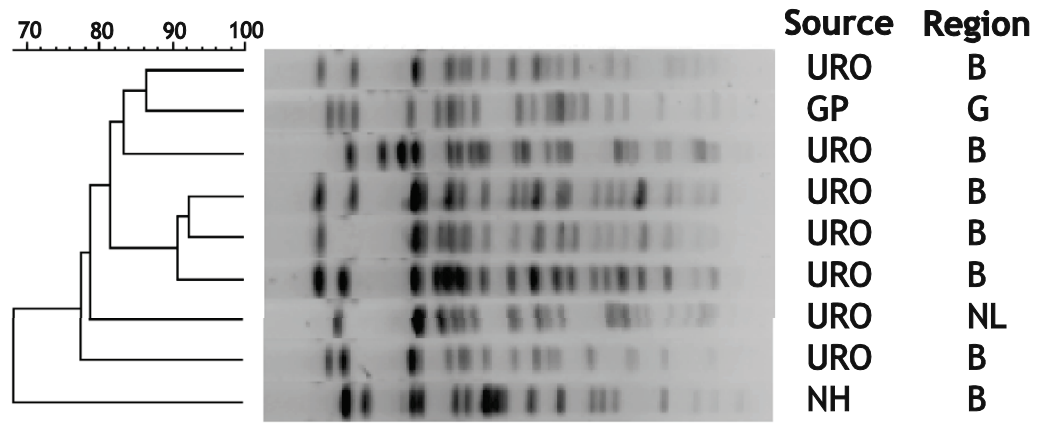

UPGMA tree of PFGE ST88 E. coli isolates 
Figure 5: PFGE dendrogram ST131

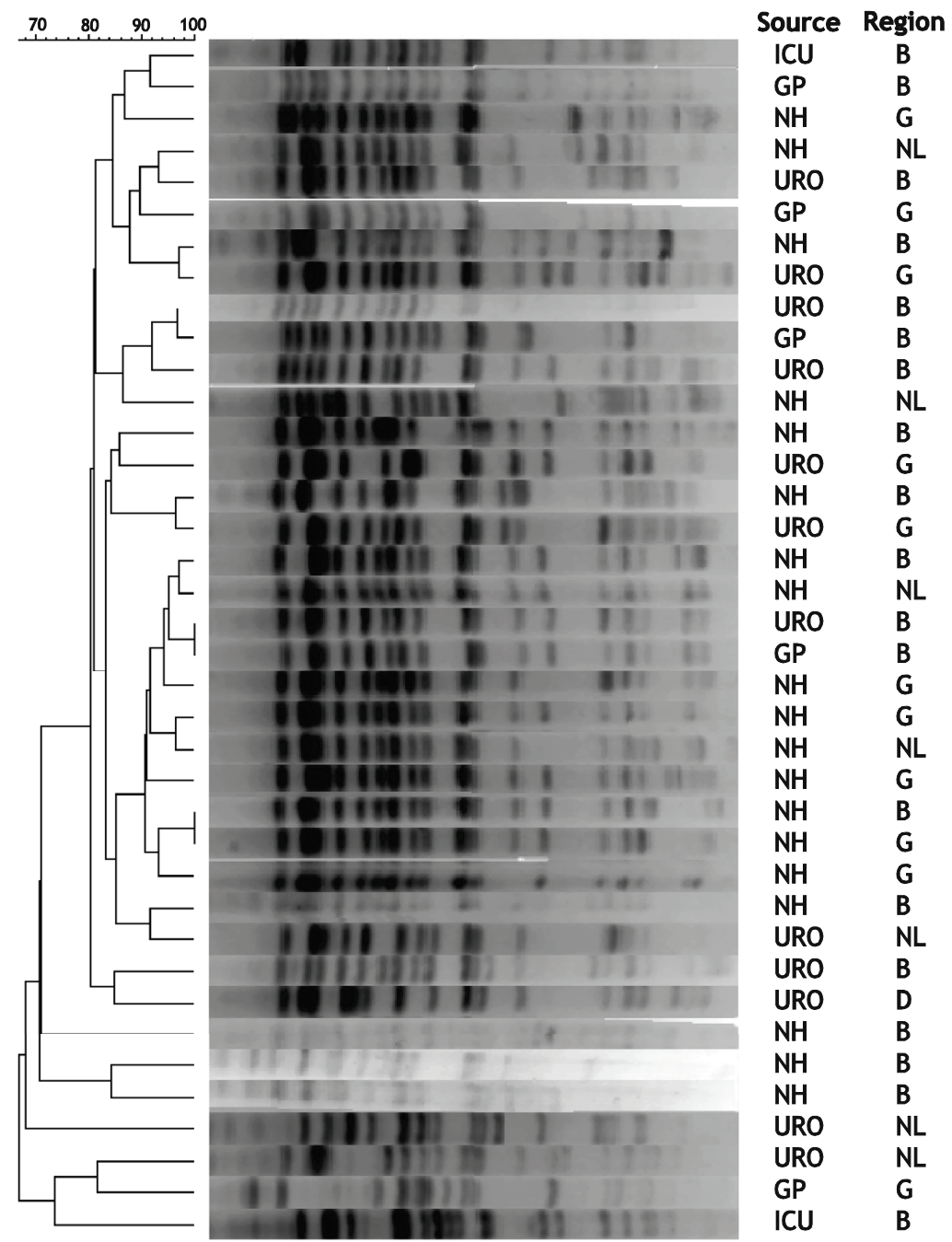

UPGMA tree of PFGE ST131 E. coli isolates 


\section{Discussion}

This study shows that in the Euregion Meuse-Rhine among all the collected $E$. coli isolates from GP patients, NH residents, ICU and URO patients the prevalence of resistance was in the same order of magnitude in the three countries, but varied significantly between the four populations. Approximately $10 \%$ of the $E$. coli isolates was MDR with the highest prevalence among the URO isolates. In total, we observed 47 different STs of which ST131 was the most prevalent one. PFGE analysis of isolates belonging to the top three (ST131, 393 and 88) suggested the spread of isolates belonging to the same PFGE group in the entire Euregion. The results of the clustering via eBURST and CFA of all typed isolates were similar.

The strengths of this study were that isolates were collected from four populations in three different countries and to our are knowledge this is the first study to address the issue of cross border spread among $E$. coli The quantitative susceptibility of all isolates, MLST and PFGE was performed in the same laboratory to prevent bias because of difference in methodology. Weaknesses of the study were that only resistant isolates were included for MLST typing. Therefore, this study does not reflect the entire E. coli population. For ICU patients it was difficult to collect sufficient samples. Therefore, other clinical samples besides urine samples were included. This could give a higher diversity in genetic background of the collected isolates.

Overall there were only significant differences in prevalence of resistance between the three countries in this study for amoxicillin-clavulanic acid and ciprofloxacin. These results are not in line with the higher prevalence of resistance in Belgium and Germany compared with the Netherlands as described by EARS-Net ${ }^{29}$. The difference might be explained by the inclusion of GP and $\mathrm{NH}$ isolates in our study, since EARS-Net only included invasive clinical isolates from hospitalized patients. Similar observations were described for S. aureus isolates i.e. the prevalence of resistance of S. aureus from nasal carriers among GP patients in nine European countries was comparable ${ }^{30}$ whereas among hospitalized patients the resistance differed significantly ${ }^{29}$. In our study we did observe significant differences in resistance between the URO isolates of the three countries (data not shown), which have been described previously ${ }^{31}$.

There were significant differences in prevalence of resistance between the four populations included in this study, which were comparable with previous reports. Cullen et al. described a lower prevalence of resistance among community samples compared to urology and nosocomial samples and a higher resistance to ciprofloxacin among urology compared to nosocomial samples ${ }^{32}$. Xie et al. described a higher prevalence of MDR E. coli among nursing home residents compared with elderly in the community $^{33}$. These differences in prevalence of resistance between the populations were probably caused by differences in the overall antibiotic use, which is low among GP patients compared with the other groups, and the use of specific antibiotics, such as the fluoroquinolones among the nursing home residents ${ }^{34-37}$.

Although we demonstrated $E$. coli isolates with a variable genetic background, the high prevalence of $E$. coli ST131 (39\%) is undeniable. The emerging prevalence of ST131 has 
already been described before ${ }^{38}$, but with this study we demonstrate a high prevalence of this ST in different populations both in the hospitals and in the community in the entire Euregion Meuse-Rhine, with the highest prevalence among NH residents and URO patients. An explanation for this might be the high use of fluoroquinolones among these populations. Van der $\mathrm{Bij}$ et al. described a potential influence of the restricted empirical use of ciprofloxacin on a decreased prevalence of ST131 ${ }^{39}$. We hypothesize that a high use of this agent might increase the prevalence of ST131.

PFGE analysis demonstrated that among the ST131 isolates, several groups of isolates with a comparable pulsotype were found in the entire Euregion. Worrying was the occurrence of comparable ST131 isolates in the NHs. This suggested the emergence, spread and endurance of resistant bacteria among $\mathrm{NH}$ residents. The second group of isolates, with a high similarity demonstrated among the four populations in the three countries, supported a spread of ST131 clones throughout the entire Euregion. The same results were found for ST393 and to a lesser extend ST88. Thus, also, other nonST131 clones have spread among our study populations in the Euregion.

The ST393 isolates, according to our PFGE results, were very similar (Dice $292 \%$ ) and seemed to have pulsotypes comparable to those reported by Blanco et $\mathrm{al}^{40}$. Maybe this group is another emerging clone in the Euregion, though still less prevalent than ST131 and less diverse, based on the high similarity index.

The success in terms of spread of the ST131 clone in comparison to other STs might be the acquisition of multiple resistance genes and the presence of specific virulence factors $^{38}$.

The presence of ST131 isolates with different pulsotypes might suggest that this ST is diversifying and evolving, but this was not supported with MLST. We did not find any single locus variants (SLVs) of ST131 among the MDR isolates, although, the E. coli MLST database ${ }^{22}$ already contains SLVs of ST131.

Overall, the MDR E. coli population in this study showed a high number of different STs but lower than among non-selected uropathogenic $E$. coli (UPEC) isolates ${ }^{26,41}$. This suggests that only a limited number of STs have acquired multiple antibiotic resistance genes, while other STs did not and are still susceptible.

In our study the diversity of STs was highest among the ICU isolates, which could be due to the inclusion of various clinical samples, only $20 \%$ was collected from a urine sample. The higher diversity among the GP patients might be attributed to the low prevalence of MDR E. coli.

Most ESBL producing isolates, both ST131 and non-ST131, were CTX-M 15, which is in line with previous studies ${ }^{26,41,42}$. Reason for the dissemination is the location of bla $a_{\text {CTX-M } 15}$ on very efficient mobile genetic elements, which are encoded on frequently encountered plasmids ${ }^{38}$. The other ESBL producers had a very diverse genetic background and were not associated to one CC.

Overall, the increasing prevalence of (MDR) resistant and/or ESBL producing bacteria is worrisome. As was suggested by $\mathrm{Van}$ der $\mathrm{Bij}$ et al. restrictions in the use of antibiotic seem to have an effect on the genetic background of the $E$. coli population ${ }^{39}$ and a 
meta-analysis by Davey et al. supports the theory that limiting antibiotic use reduces the prevalence of resistant Gram negatives ${ }^{43}$. Therefore, it is essential to implement antibiotic stewardship programs to optimize the use of antibiotics and thereby contribute to control the prevalence of resistance, and subsequently improve patient outcome $^{13}$.

\section{Conclusions}

We described the genetic background of resistant E. coli strains in the Euregion MeuseRhine. ST131 was most prevalent the three countries and in all four included populations, especially in the nursing homes. The emergence of resistant strains, such as E. coli ST131 and to a lesser extent ST393, might be a precursor for a further increasing prevalence of resistance. It is, therefore, essential to prevent and control the spread of these resistant strains by adherence to empiric antibiotic treatment protocols, infection control policies and antibiotic stewardship programs, which are based on the results of antibiotic resistance surveillance studies and mapping of the genetic background of $\mathrm{E}$. coli. In this way it is possible to observe a shift in the prevalence of resistance and the genetic structure of the E. coli population and act accordingly. 


\section{References}

1. Kontopidou F, Plachouras D, Papadomichelakis E et al. Colonization and infection by colistin-resistant Gram-negative bacteria in a cohort of critically ill patients. Clin Microbiol Infect 2011; 17: E9-E11.

2. Landman D, Babu $\mathrm{E}$, Shah $\mathrm{N}$ et al. Transmission of carbapenem-resistant pathogens in New York City hospitals: progress and frustration. J Antimicrob Chemother 2012; 67: 1427-31.

3. Livermore DM, Canton R, Gniadkowski $M$ et al. CTX-M: changing the face of ESBLs in Europe. J Antimicrob Chemother 2007; 59: 165-74.

4. Nordmann P, Naas T, Poirel L. Global spread of Carbapenemase-producing Enterobacteriaceae. Emerg Infect Dis 2011; 17: 1791-8.

5. Pitout JD, Laupland KB. Extended-spectrum beta-lactamase-producing Enterobacteriaceae: an emerging public-health concern. Lancet Infect Dis 2008; 8: 159-66.

6. Woodford N, Turton JF, Livermore DM. Multiresistant Gram-negative bacteria: the role of high-risk clones in the dissemination of antibiotic resistance. FEMS Microbiol Rev 2011; 35: 736-55.

7. Grundmann H, Aanensen DM, van den Wijngaard CC et al. Geographic distribution of Staphylococcus aureus causing invasive infections in Europe: a molecular-epidemiological analysis. PLoS Med 2010; 7: e1000215.

8. Donker T, Wallinga J, Slack R et al. Hospital networks and the dispersal of hospitalacquired pathogens by patient transfer. PLoS One 2012; 7: e35002.

9. $\quad$ EIS. Euregion Meuse-Rhine in figures. 2007.

10. Wismar M, Palm W, Figueras J et al. The European Observatory on Health Systems and Policies. Cross-border Health Care in the European Union: Mapping and analysing practices and policies. 2011.

11. den Heijer CD, Donker GA, Maes J et al. Antibiotic susceptibility of unselected uropathogenic Escherichia coli from female Dutch general practice patients: a comparison of two surveys with a 5 year interval. J Antimicrob Chemother 2010; 65: 2128-33.

12. Carattoli A. Resistance plasmid families in Enterobacteriaceae. Antimicrob Agents Chemother 2009; 53: 2227-38.

13. Doron S, Davidson LE. Antimicrobial stewardship. Mayo Clinic proceedings Mayo Clinic 2011; 86: 1113-23.

14. Deurenberg RH, Nulens $\mathrm{E}$, Valvatne $\mathrm{H}$ et al. Cross-border dissemination of methicillinresistant Staphylococcus aureus, Euregio Meuse-Rhin region. Emerg Infect Dis 2009; 15: 727-34.

15. EUCAST. Breakpoint tables for interpretation of MICs and zone diameters - version 1.3, January 2011

16. NVMM Guideline - Laboratory detection of highly resistant microorganisms (HRMO) version 1.0. 2011.

17. Pallecchi L, Malossi M, Mantella A et al. Detection of CTX-M-type beta-lactamase genes in fecal Escherichia coli isolates from healthy children in Bolivia and Peru. Antimicrob Agents Chemother 2004; 48: 4556-61.

18. Saladin M, Cao VT, Lambert $T$ et al. Diversity of CTX-M beta-lactamases and their promoter regions from Enterobacteriaceae isolated in three Parisian hospitals. FEMS microbiology letters 2002; 209: 161-8.

19. Meex C, Melin P, Docquier JD et al. Presence of extended-spectrum beta-lactamaseproducing Enterobacteriaceae in fecal flora of patients from general practice. ECCMID. Barcelona, 2008.

20. Pitout JD, Hossain A, Hanson ND. Phenotypic and molecular detection of CTX-M-betalactamases produced by Escherichia coli and Klebsiella spp. J Clin Microbiol 2004; 42: 5715-21. 
21. Wirth $\mathrm{T}$, Falush D, Lan R et al. Sex and virulence in Escherichia coli: an evolutionary perspective. Mol Microbiol 2006; 60: 1136-51.

22. UCC. Escherichia coli MLST database http://mlst.ucc.ie/mlst/dbs/Ecoli (6 July 2012 date last accessed ).

23. Spratt BG, Hanage WP, Li B et al. Displaying the relatedness among isolates of bacterial species -- the eBURST approach. FEMS Microbiol Lett 2004; 241: 129-34.

24. Didelot $X$, Falush $D$. Inference of bacterial microevolution using multilocus sequence data. Genetics 2007; 175: 1251-66.

25. Ribot EM, Fair MA, Gautom R et al. Standardization of pulsed-field gel electrophoresis protocols for the subtyping of Escherichia coli 0157:H7, Salmonella, and Shigella for PulseNet. Foodborne Pathog Dis 2006; 3: 59-67.

26. Gibreel TM, Dodgson AR, Cheesbrough J et al. Population structure, virulence potential and antibiotic susceptibility of uropathogenic Escherichia coli from Northwest England. J Antimicrob Chemother 2012; 67: 346-56.

27. Narum SR. Beyond Bonferroni: Less conservative analyses for conservation genetics. Conservation Genetics 2006; 7: 783-7.

28. Grundmann H, Hori S, Tanner G. Determining confidence intervals when measuring genetic diversity and the discriminatory abilities of typing methods for microorganisms. $J$ Clin Microbiol 2001; 39: 4190-2.

29. ECDC. Antimicrobial resistance surveillance in Europe 2010. Annual Report of the European Antimicrobial Resistance Surveillance Network (EARS-Net). 2011.

30. Heijer den CDJ, Bijnen van EME, Paget WJ et al. Prevalence and susceptibility of commensal S. aureus in nine European countries World Organization of Family Doctors Europe Conference, 2012.

31. van der Donk CF, van de Bovenkamp JH, De Brauwer El et al. Antimicrobial Resistance and Spread of Multi Drug Resistant Escherichia coli Isolates Collected from Nine Urology Services in the Euregion Meuse-Rhine. PLoS One 2012; 7: e47707.

32. Cullen IM, Manecksha RP, McCullagh E et al. The changing pattern of antimicrobial resistance within 42033 Escherichia coli isolates from nosocomial, community and urology patient-specific urinary tract infections, Dublin, 1999-2009. BJU Int 2011.

33. Xie C, Taylor DM, Howden BP et al. Comparison of the bacterial isolates and antibiotic resistance patterns of elderly nursing home and general community patients. Intern Med J 2011.

34. Adriaenssens N, Coenen S, Versporten A et al. European Surveillance of Antimicrobial Consumption (ESAC): outpatient antibiotic use in Europe (1997-2009). J Antimicrob Chemother 2011; 66 Suppl 6: vi3-12.

35. McClean $\mathrm{P}$, Hughes $\mathrm{C}$, Tunney $\mathrm{M}$ et al. Antimicrobial prescribing in European nursing homes. J Antimicrob Chemother 2011; 66: 1609-16.

36. SWAB. Nethmap 2011 - Consumption of antimicrobial agents and antimicrobial resistance among medically important bacteria in the Netherlands. 2011.

37. Donk van der CFM, Schols JMGA, Driessen CJ et al. Prevalence and spread of multi drug resistant Escherichia coli isolates among nursing home residents in the southern part of the Netherlands.J Am Med Dir Assoc 2012; Nov 6.

38. Peirano G, Pitout JD. Molecular epidemiology of Escherichia coli producing CTX-M betalactamases: the worldwide emergence of clone ST131 O25:H4. Int J Antimicrob Agents 2010; 35: 316-21.

39. van der Bij AK, Peirano G, Goessens WH et al. Clinical and molecular characteristics of extended-spectrum-beta-lactamase-producing Escherichia coli causing bacteremia in the Rotterdam Area, Netherlands. Antimicrob Agents Chemother 2011; 55: 3576-8.

40. Blanco J, Mora A, Mamani R et al. National survey of Escherichia coli causing extraintestinal infections reveals the spread of drug-resistant clonal groups 025b:H4-B2-ST131, 


\section{Chapter 4}

015:H1-D-ST393 and CGA-D-ST69 with high virulence gene content in Spain. J Antimicrob Chemother 2011; 66: 2011-21.

41. Xu L, Shabir S, Bodah T et al. Regional survey of CTX-M-type extended-spectrum betalactamases among Enterobacteriaceae reveals marked heterogeneity in the distribution of the ST131 clone. J Antimicrob Chemother 2011; 66: 505-11.

42. Rogers BA, Sidjabat HE, Paterson DL. Escherichia coli O25b-ST131: a pandemic, multiresistant, community-associated strain. J Antimicrob Chemother 2011; 66: 1-14.

43. Croxall $\mathrm{G}$, Hale J, Weston $\mathrm{V}$ et al. Molecular epidemiology of extraintestinal pathogenic Escherichia coli isolates from a regional cohort of elderly patients highlights the prevalence of ST131 strains with increased antimicrobial resistance in both community and hospital care settings. J Antimicrob Chemother 2011; 66: 2501-8.

44. Smet A, Martel A, Persoons D et al. Characterization of extended-spectrum betalactamases produced by Escherichia coli isolated from hospitalized and nonhospitalized patients: emergence of CTX-M-15-producing strains causing urinary tract infections. Microb Drug Resist 2010; 16: 129-34.

45. Davey P, Brown E, Fenelon $L$ et al. Systematic review of antimicrobial drug prescribing in hospitals. Emerg Infect Dis 2006; 12: 211-6. 


\section{Chapter 5}

Antibiotic resistance, population structure and spread of Staphylococcus aureus in nursing homes in the Euregion Meuse-Rhine 


\section{Abstract}

\section{Objective}

To determine the spread of Staphylococcus aureus within and between nursing home (NH) residents in the Euregion Meuse-Rhine, a cross border region of the Netherlands and Germany, we investigated the prevalence of antibiotic resistance, genetic background and population structure of both methicillin susceptible $S$. aureus (MSSA) and methicillin resistant $S$. aureus (MRSA) isolates.

\section{Methods}

A total of $245 \mathrm{~S}$. aureus isolates were collected from $\mathrm{NH}$ residents in the Euregion. Susceptibility testing was performed with broth microdilution. The genetic background was determined using spa typing, SCCmec typing, PFGE and MLST.

\section{Results}

Differences in prevalence of resistance between the German and Dutch $\mathrm{NH}$ isolates were observerd for the macrolides $(15 \%$ versus $2 \%, p=0.003)$, clindamycin $(15 \%$ versus $0 \%, p=0.003$ ) and ciprofloxacin (34\% versus $25 \%$ ). The macrolide and ciprofloxacin resistance varied between the $\mathrm{NHs}$ in both countries.

The MRSA prevalence was $3.5 \%$ and $<1 \%$ among the German and Dutch NH residents $(p=0.005)$. The German MRSAs, isolated in 7 out of $10 \mathrm{NHs}$, belonged to ST22-MRSA-IV or ST225-MRSA-II.

Spa-CCs 015 and 002 were most prevalent among the German MSSAs and spa-CCs 024 and 1716 among the Dutch ones.

\section{Conclusions}

The antibiotic resistance of MSSA and the MRSA prevalence were significantly higher among the German NH residents. Spread of two MRSA clones was observed within and between the German NHs, but not between the Dutch and German NHs. Differences in prevalence of resistance and prevalence of MRSA between NHs on both sides of the border warrant continuation of surveillance at a local level. 


\section{Introduction}

Staphylococcus aureus is a commensal and potential pathogenic microorganism, which causes infections ranging from mild skin and soft tissue infections to severe necrotizing pneumonia, endocarditis and sepsis ${ }^{1}$. Since the introduction of penicillin and methicillin, S. aureus isolates resistant to these antibiotics have been isolated ${ }^{2}$. Resistance to methicillin among $\mathrm{S}$. aureus is mediated by the presence of the staphylococcal cassette chromosome mec $(\mathrm{SCCmec})$. This includes the mecA or mecC gene, encoding for a substitute penicillin-binding-protein (PBP), namely PBP2a for which beta-lactam antibiotics have a lower affinity compared with the native PBP2. Infections with a methicillin resistant S. aureus (MRSA) are, therefore, more difficult to treat and cause higher morbidity, mortality and have higher healthcare costs ${ }^{3,4}$.

Nursing home $(\mathrm{NH})$ residents have a high risk for colonization and infection with antibiotic resistant bacteria including MRSA due to a relatively high prevalence of risk factors (e.g. wounds, co morbidities, use of medical devices and antibiotics, and previous hospital admission ${ }^{5-7}$ ). Therefore, $\mathrm{NH}$ residents are often considered a reservoir for MRSA, which could lead to outbreaks in $\mathrm{NHs}^{8,9}$ and spread from the NHs to hospitals and to the general population.

The spread, genetic background and population structure of MRSA and MSSA isolates within and between NHs has not often been investigated especially not in a cross border region.

In Germany the prevalence of MRSA is higher than in the Netherlands ${ }^{10}$ and this difference in prevalence might pose a risk to the population of the border region (the Euregion Meuse-Rhine) and especially to a frail population such as the $\mathrm{NH}$ residents. Resistant bacteria might spread within and between NHs and cross the border. The spread of resistance in a cross border region has already been investigated for hospitals in the Euregion, but not for the $\mathrm{NHs}^{11,12}$ and also little is known about the population structure of MSSA isolates among NH residents on both sites of the border. Therefore, this study investigated the prevalence of antibiotic resistance, genetic background, population structure and potential spread of S. aureus including MRSA among $\mathrm{NH}$ residents in the Dutch-German border region.

\section{Methods}

\section{Residents and bacterial isolates}

Six NHs in the province of Limburg in the southern part of the Netherlands and ten NHs in the regions of Euskirchen (in North Rhine-Westphalia) and Daun (in RhinelandPalatinate) in Germany participated in this study. All psycho-geriatric and somatic residents of these NHs were eligible for participation but only those residents (or their legal representatives) who signed a consent form were included. This study was approved by the medical ethics committee of the Maastricht University Medical Centre. We received 727 signed consent forms (Table 1) but due to withdrawal of consent, transfer to a hospital or other $\mathrm{NH}$ or passing away, 34 residents were 
excluded, resulting in a final $\mathrm{NH}$ population of 693 residents. In each $\mathrm{NH}$ the swabs were collected on one day in the period July 2009 to June 2011.

Nasal swabs (Copan Diagnostics, Brescia, Italy) were taken from the anterior nostrils and analyzed for the presence of S. aureus in one laboratory (Maastricht University Medical Centre) using: 1. Culture on a colistin nalidixic acid agar plate (Becton Dickinson, Sparks, MD, USA) and 2. enrichment in nutrient broth (Oxoid, Hampshire, UK) with $6.5 \% \mathrm{NaCl}$ followed by culture on oxacillin resistance screening agar (Oxoid). The enrichtment method was included to increase the detection of MRSA isolates. Putative $S$. aureus isolates were identified using a catalase and coagulase (tube) test.

\section{Quantitative susceptibility testing}

Quantitative susceptibility testing was performed using broth microdilution with Mueller-Hinton II cation-adjusted broth (Becton-Dickinson, Sparks, MD, USA) and microtitre plates with freeze-dried antibiotics (MCS Diagnostics BV, Swalmen, the Netherlands). Antibiotic susceptibility testing for fusidic acid and mupirocin was performed with a disk diffusion test on Mueller Hinton II agar plates (BD) and antibiotics tablets (fusidic acid 10 $\mathrm{gg}$ and mupirocin $10 \mu \mathrm{g}$, (Rosco, Taastrup, Denmark). Zone diameters of $>20 \mathrm{~mm}$ for fusidic and $>15 \mathrm{~mm}$ for mupirocin were considered susceptible ${ }^{13,14}$. S. aureus ATCC 29213 was the control strain for the susceptibility testing. The clinical breakpoints defined by the European Committee on Antimicrobial Susceptibility Testing (EUCAST) $)^{13}$ were used. A disk-diffusion test was performed on all macrolide resistant but clindamycin susceptible isolates to test for inducible macrolide, lincosamide and streptogramin B (MLS-B) type resistance to clindamycin ${ }^{15}$.

\section{Genetic characterization}

Oxacillin resistant $S$. aureus isolates were analyzed for the presence of the mecA gene using a real-time PCR assay as described previously ${ }^{16}$. Amplification of the spa locus, followed by sequencing, was performed on all MSSA and MRSA isolates ${ }^{17,18}$. The spa types were clustered into spa-clonal complexes (spa-CCs) using the algorithm based upon repeat pattern (BURP) with the Ridom StaphType version 2.2.1. software package (http://www.ridom.de). The spa types with $<6$ repeats were excluded from the analysis and spa types were clustered if the cost was $<5$, to prevent the formation of too large and non specific spa clusters. After applying the BURP algorithm the associated MLST clonal complexes (CCS), were allocated through the Ridom SpaServer (http://spaserver.ridom.de) ${ }^{19}$. MRSA isolates were typed with MLST with primers as described by Enright et al. $^{20}$ and modified by Deurenberg et $\mathrm{al}^{12}$. The allelic profiles were allocated through the database on http://s.aureus.mlst.net. SCCmec typing and pulsed field gel electrophoresis (PFGE) was performed on all MRSA isolates as described previously ${ }^{21,22}$. The PFGE profiles were analyzed according to the criteria by Tenover et al. ${ }^{23}$

\section{Statistical analysis}

Significant differences in antibiotic resistance and population structure between the Dutch and German isolates were calculated using the Pearson's chi-square test or Fisher's exact test (PASW-software, version 18.0, IBM, Armonk, NY, USA). A modified 
false discovery rate (FDR) method developed by Benjamini and Yekutieli was used as correction for multiple testing ${ }^{24}$. A p-value of $<0.05$ was considered statistically significant. The diversity of the spa types was calculated with Simpson's index of diversity $^{25}$.

\section{Results}

\section{S. aureus carriage}

In total 245 (range: 1-33 per $\mathrm{NH}$ ) S. aureus isolates were collected from 693 (range: 11-95 per $\mathrm{NH}$ ) nasal swabs from residents of the 16 participating $\mathrm{NHs}$ (Table 1). The prevalence of $\mathrm{S}$. aureus carriage was $30 \%$ and $39 \%(p=0.032)$ among the Dutch and German NH residents, respectively.

Table 1: Overview of included residents and collected samples per nursing home

\begin{tabular}{llllll}
\hline NH & $\begin{array}{l}\text { Eligible } \\
\text { residents }\end{array}$ & $\begin{array}{l}\text { Included } \\
\text { residents (\%) }\end{array}$ & $\begin{array}{l}\text { Collected } \\
\text { samples }\end{array}$ & $\begin{array}{l}\text { Collected } \\
\text { isolates }\end{array}$ & $\begin{array}{l}\text { Prevalence } \\
\text { in \% }\end{array}$ \\
\hline NL 1 & 130 & $40(31)$ & 39 & 10 & 26 \\
NL 2 & 180 & $84(47)$ & 75 & 29 & 35 \\
NL 3 & 329 & $56(17)$ & 50 & 13 & 26 \\
NL 4 & 282 & $103(37)$ & 94 & 33 & 32 \\
NL 5 & 104 & $53(51)$ & 53 & 18 & 30 \\
NL 6 & 50 & $25(50)$ & 21 & 6 & 29 \\
\hline NL total & 1075 & $361(34)$ & 332 & 109 & 30 \\
\hline G 1 & 118 & $39(33)$ & 33 & 11 & 33 \\
G 2 & 74 & $19(26)$ & 17 & 7 & 41 \\
G 3 & 110 & $30(27)$ & 24 & 15 & 63 \\
G 4 & 134 & $63(47)$ & 54 & 31 & 52 \\
G 5 & 44 & $24(55)$ & 23 & 6 & 26 \\
G 6 & 112 & $51(46)$ & 46 & 21 & 41 \\
G 7 & 139 & $78(56)$ & 77 & 29 & 36 \\
G 8 & 182 & $31(17)$ & 28 & 9 & 32 \\
G 9 & 79 & $11(14)$ & 11 & 1 & 9 \\
G 10 & 103 & $21(20)$ & 20 & 6 & 30 \\
\hline G total & 1095 & $367(34)$ & 333 & 136 & 39 \\
\hline Total & 2170 & $728(34)$ & 665 & 245 & 35 \\
\hline
\end{tabular}

$\mathrm{NL}=$ the Netherlands, $\mathrm{G}=$ Germany

\section{Antibiotic resistance of the MSSA isolates}

Differences in prevalence of resistance among the MSSA isolates from the NHs in the Netherlands (NH-NL) and the NHs in Germany (NH-G) were observed (Figure 1). Resistance to erythromycin was higher among NH-G (15\%) compared with NH-NL (2\%, $\mathrm{p}=0.003)$, as was resistance to clindamycin $(7 \%)$, which was absent among $\mathrm{NH}-\mathrm{NL}(0 \%$, $\mathrm{p}=0.097$ ). Ten NH-G isolates were inducible MLS-B type resistant to clindamycin, which resulted in a total prevalence of clindamycin resistance of $15 \%$ (versus $0 \%$ among $\mathrm{NH}$ $\mathrm{NL}, \mathrm{p}=0.003$ ). Differences in resistance, although not significantly, were demonstrated for ciprofloxacin: $25 \%$ versus 35\%, and fusidic acid: $6 \%$ versus $3 \%$, for the Dutch and German isolates, respectively. The prevalence of resistance to the other tested 
antibiotics was either low $(<5 \%)$ (i.e. gentamicin, tetracycline, daptomycin and mupirocin) or not observed (i.e. vancomycin, linezolid and co-trimoxazole) among both $\mathrm{NH}-\mathrm{NL}$ and NH-G. For erythromycin and ciprofloxacin the prevalence of resistance varied between $\mathrm{NH}-\mathrm{NL}$ and $\mathrm{NH}-\mathrm{G}$ but also between the different $\mathrm{NH}$ in each country (Figure 2).

Figure 1: Antibiotic resistance of the MSSA isolates

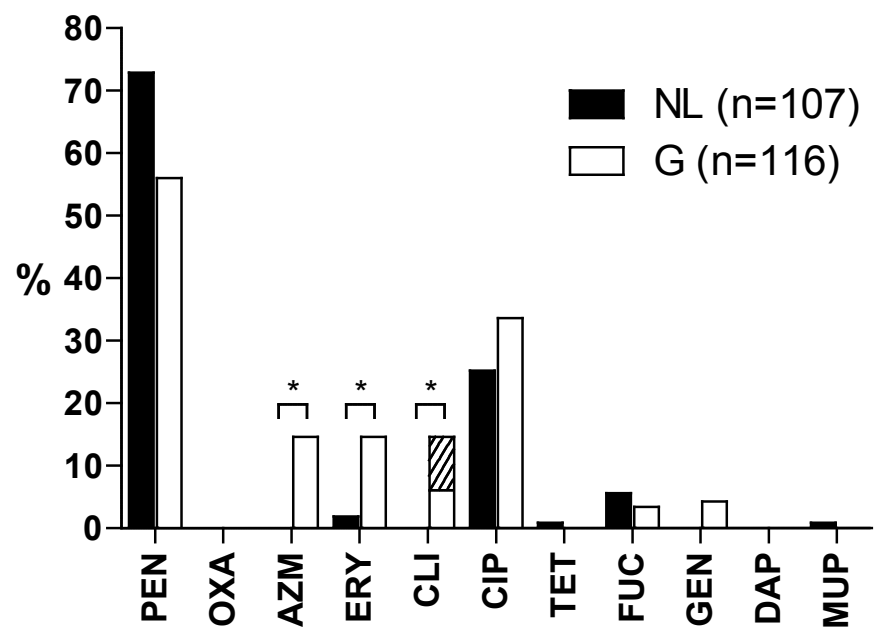

$\mathrm{NL}=$ the Netherlands, $\mathrm{G}=$ Germany, $\mathrm{PEN}=$ penicillin, $\mathrm{OXA}=$ oxacillin, $\mathrm{AZM}=$ azithromycin, $\mathrm{ERY}=$ erythromycin, $\mathrm{CLI}=$ clindamycin, $\mathrm{CIP}=$ ciprofloxacin, $\mathrm{TET}=$ tetracyclin, FUC = fusidic acid, GEN = gentamicin, DAP = daptomycin, MUP = mupirocin. The marked bar is inducible MLS-B type resistance to clindamycin, ${ }^{*} p<0.05$.

\section{MRSA prevalence and genetic background}

The prevalence of MRSA was higher among the German NH residents $(6 \%, 19$ out of 333 residents) compared with the Dutch $\mathrm{NH}$ ones $(<1 \%, 2$ out of 332 residents, $\mathrm{p}<0.001)$. One German NH resident carried two MRSA strains. The MRSA isolates were isolated in 7 out of 10 German NHs, but $50 \%$ of the MRSA isolates were found in one NH (G7). The prevalence of MRSA among the remaining German NHs was 3.9\% (10 out of 256 swabs), which was compared with $\mathrm{NH}-\mathrm{NL}$ still significantly higher $(p=0.005)$. All but one of the German MRSA isolates were resistant to the macrolides, clindamycin (including four isolates of the inducible MLS-B type) and ciprofloxacin, while the Dutch MRSA isolates were only resistant to beta-lactam antibiotics. 
Figure 2: Differences in antibiotic resistance among the participating nursing homes

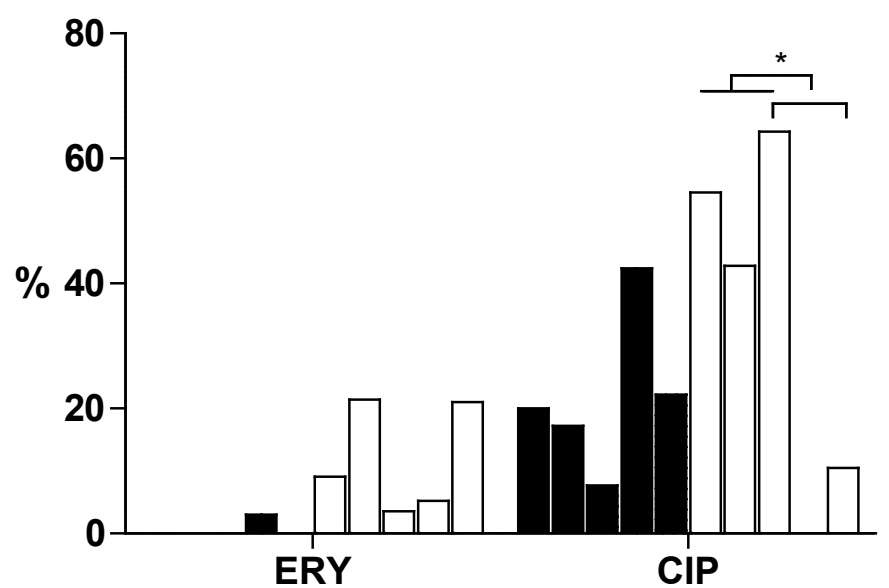

Variation in antibiotic resistance among the MSSA isolates. Each bar represents one $\mathrm{NH}$, the black bars the Dutch NHs and the white bars the German NHs. Only NHs with 10 or more collected isolates were included in the figure. ERY $=$ erythromycin, CIP $=$ ciprofloxacin, ${ }^{*} \mathrm{p}<0.05$.

The German MRSA isolates consisted of two clones i.e. ST22-MRSA-IV (EMRSA-15 or Barnim clone, $n=4$ ), found in 3 out of $10 \mathrm{NHs,} \mathrm{and} \mathrm{ST225-MRSA-II} \mathrm{(Rhine-Hesse} \mathrm{or} \mathrm{New}$ York/Japan clone, $\mathrm{n}=16$ ), observed in 6 out of $10 \mathrm{NHs}$. In two NHs (G4 and G6) both clones were present (Table 2). The ST22-MRSA-IV isolates had spa type t032, while the ST225-MRSA-II isolates had spa type t003 $(n=13)$ and t151 $(n=3)$. The four ST22-MRSA-IV isolates were indistinguishable or closely related using PFGE, which also applied for the 16 ST225-MRSA-II isolates (Figure 3). The two Dutch isolates were ST22-MRSA-IV with spa type t223 and ST7-MRSA-IV with spa type t097 (Table 2).

Table 2: Genetic background of the MRSA isolates

\begin{tabular}{|c|c|c|c|c|c|}
\hline $\mathrm{n}$ & $\mathrm{NL/G}$ & ST & SCCmec & spa type & NHs \\
\hline 16 & G & 225 & II & t003, t151 & $\mathrm{G} 3, \underline{4}, 5, \underline{6}, 7,10$ \\
\hline 4 & G & 22 & IV & t032 & G $2, \underline{4,6}$ \\
\hline 1 & $\mathrm{NL}$ & 22 & IV & t223 & NL 2 \\
\hline 1 & $\mathrm{NL}$ & 7 & IV & t097 & NL 3 \\
\hline
\end{tabular}

The column NHs indicates the NHs in which the MRSA were isolated.

$\mathrm{NL}=$ the Netherlands, $\mathrm{G}=$ Germany

\section{Spa typing and BURP}

A total of 83 spa types were demonstrated among the 237 MRSA and MSSA isolates (8 isolates were not typable). A total of five spa types were demonstrated among the 22 MRSA isolates (Table 2) and among the 215 MSSA isolates a total of 82 spa types were detected (Table 3). Two of these spa types were not described previously (i.e. t10475 and t10476). The most prevalent spa types were t008 $(n=22)$, t091 $(n=10)$ among the 
Figure 3: PFGE profiles of the German MRSA isolates

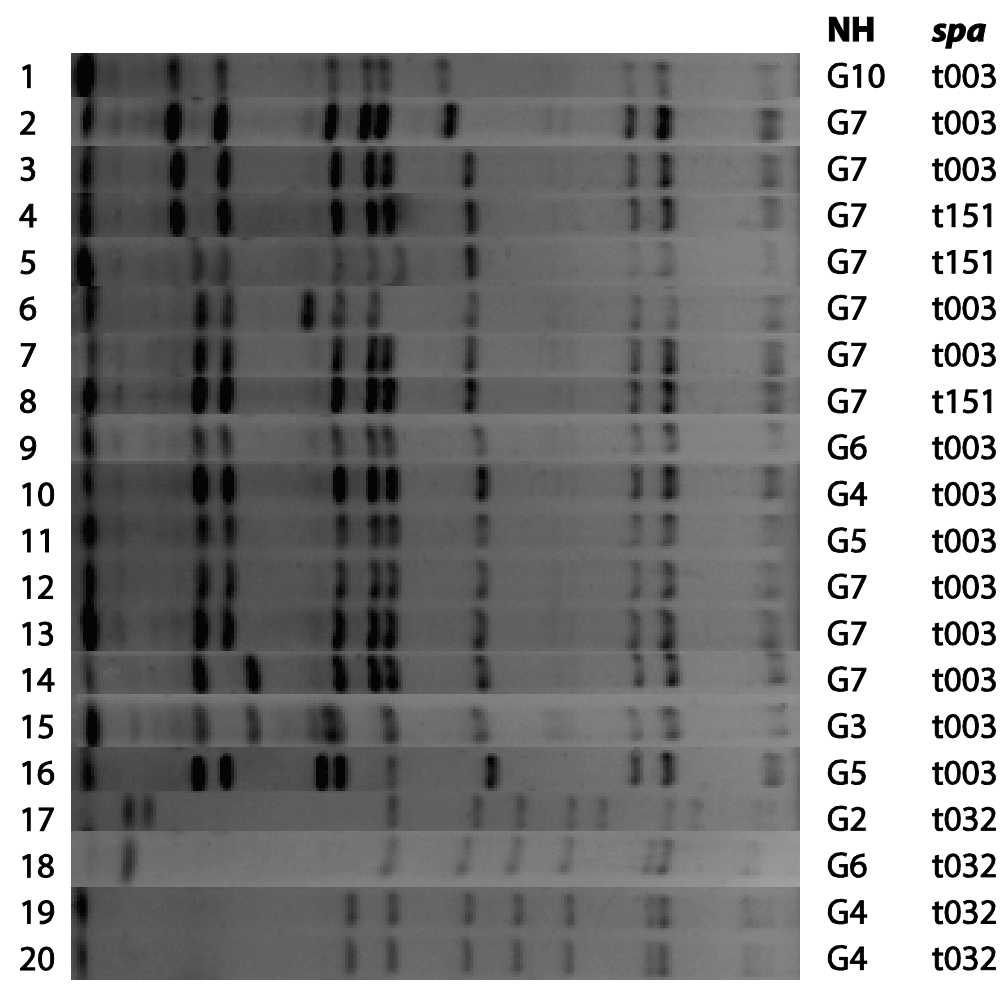

The pulsotypes in lane 1-16 belong to the ST225-MRSA-II clone and in lane 17-20 to the ST22MRSA-IV clone.

Dutch isolates and t003 $(n=14)$ among the German ones. The diversity of the spa types was not significantly lower among the Dutch $\mathrm{NH}$ isolates $(0.939,95 \% \mathrm{Cl} 0.910-0.970)$ compared with those from Germany $(0.968,0.954-0.983)$.

The 82 spa types among the MSSA isolates were clustered into 11 clusters of which four had no founder. Spa-CCs $015(p=0.017)$ and $002(p=0.045)$ were most prevalent among the German MSSA isolates while among the Dutch MSSA isolates spa-CCs $024(p<0.003)$ and 1716 were most prevalent (Table 3). Of all MSSA isolates, 146 isolates contained a spa type which could be associated to a MLST ST or CC using the Ridom SpaServer. There was no significant difference in the number of isolates with a spa type associated to a MRSA or MSSA related CC between the German and Dutch isolates, being $69 \%$ and $68 \%$, respectively. 
S. aureus resistance in nursing homes

Table 3: Composition of spaCCs from the nursing home MSSA isolates per country

\begin{tabular}{|c|c|c|c|c|c|}
\hline spaCC & spa types & $\begin{array}{l}\text { associated } \\
\text { ST }(C C)^{*}\end{array}$ & $\begin{array}{l}\mathrm{n} \mathrm{( \% )} \mathrm{NL} \\
\text { isolates }\end{array}$ & $\begin{array}{l}\mathrm{n}(\%) \mathrm{G} \\
\text { isolates }\end{array}$ & $\mathrm{p}$ \\
\hline 015 & $\begin{array}{l}\text { t015, t031, t050, t095, } \\
\text { t157, t230, t302, t583, } \\
\text { t589, t630, t861, t1238, } \\
\text { t1460, t5529, t8223, } \\
\text { t9070 }\end{array}$ & 30,45 & $12(11)$ & $29(26)$ & 0.017 \\
\hline 1716 & $\begin{array}{l}\text { t084, t091, t254, t279, } \\
\text { t393, t796, t1119, t1204, } \\
\text { t1716, t2119 }\end{array}$ & $7,15,18$ & $18(17)$ & $15(14)$ & - \\
\hline $021 / 012$ & $\begin{array}{l}\text { t012, t021, t122, t276, } \\
\text { t2864, t7576 }\end{array}$ & 30 & $9(9)$ & $9(8)$ & - \\
\hline 002 & $\begin{array}{l}\text { t002, t003, t010, t509, } \\
\text { t548, t1227 }\end{array}$ & $\begin{array}{l}5,225,231 \\
(5)\end{array}$ & $6(6)$ & $18(16)$ & 0.045 \\
\hline 040 & $\begin{array}{l}\text { t040, t065, t130, t266, } \\
\text { t1281, t5834 }\end{array}$ & 45,46 & $7(7)$ & $3(3)$ & - \\
\hline 005 & $\begin{array}{l}\text { t005, t032, t449, t1862, } \\
\text { t1863 }\end{array}$ & $\begin{array}{l}22,23,60 \\
(22)\end{array}$ & $1(1)$ & $8(7)$ & - \\
\hline 024 & t008, t024, t701 & $\begin{array}{l}8,247,250 \\
254(8)\end{array}$ & $24(23)$ & $4(4)$ & $<0.003$ \\
\hline $\begin{array}{l}\text { No } \\
\text { founder }\end{array}$ & t127, t177 & 1,3 & $6(6)$ & $0(0)$ & 0.038 \\
\hline $\begin{array}{l}\text { No } \\
\text { founder }\end{array}$ & t056, t087 & 101 & $3(3)$ & $2(2)$ & - \\
\hline $\begin{array}{l}\text { No } \\
\text { founder }\end{array}$ & $\mathrm{t} 100, \mathrm{t} 10475$ & 9 & $1(1)$ & $1(1)$ & - \\
\hline $\begin{array}{l}\text { No } \\
\text { founder }\end{array}$ & $\mathrm{t} 476, \mathrm{t} 608$ & - & $0(0)$ & $4(4)$ & - \\
\hline \multirow[t]{4}{*}{ Singletons } & $\begin{array}{l}\text { t011, t151, t689, t1312, } \\
\text { t1705, t1827, t2050, } \\
\text { t9557, t9647, t10476 }\end{array}$ & - & 7 (7) & $7(6)$ & - \\
\hline & $\mathrm{t} 156$ & 12 & $0(0)$ & $1(1)$ & - \\
\hline & $\mathrm{t} 209$ & $109(9)$ & $0(0)$ & $1(1)$ & - \\
\hline & $\mathrm{t} 216$ & 59 & $1(1)$ & $1(1)$ & - \\
\hline \multirow[t]{2}{*}{ Excluded } & $\begin{array}{l}\text { t111, t457, t643, t929, } \\
\text { t1011, t2207, t2614, } \\
\text { t4384 }\end{array}$ & - & $6(6)$ & $3(3)$ & - \\
\hline & t026 & $45,47(45)$ & $4(4)$ & $4(4)$ & - \\
\hline Total & & & 105 & 110 & \\
\hline
\end{tabular}

$\mathrm{NL}=$ the Netherlands, $\mathrm{G}=$ Germany, ${ }^{*}=$ associated via the Ridom SpaServer 


\section{Discussion}

In this study we demonstrated a significantly higher prevalence of $S$. aureus among the $\mathrm{NH}-\mathrm{G}$ compared with NH-NL as was the prevalence of MSSA isolates resistant the macrolides, clindamycin and ciprofloxacin $(p<0.05)$. Between the $\mathrm{NHs}$ in both regions we also observed variations in prevalence of resistance. The prevalence of MRSA was significantly higher among NH-G compared with NH-NL. The German MRSA isolates belonged to two major globally spread clones $^{2}$, suggesting spread of isolates within the German NHs. The population structure of the MSSA isolates was significantly different between $\mathrm{NH}-\mathrm{NL}$ and $\mathrm{NH}-\mathrm{G}$, but the prevalence of isolates with a spa type associated to a MRSA related CC was comparable.

The strength of the study was that the same method of sampling and analysis was applied for all samples from all NHs. The results were, therefore, not influenced by differences in methodology. The weakness was that in this study $30 \%(14-56 \%)$ of all eligible residents were included and additional clinical data were not available. However, due to the unselected inclusion of residents this study still provides useful data on prevalence and spread of antibiotic resistance of S.aureus, population structure and genetic background. Although, this study was performed in a period of two years, we do believe that this timedifference does not explain the significant differences in prevalence of resistance between $\mathrm{NH}-\mathrm{NL}$ and $\mathrm{NH}-\mathrm{G}$.

Previous studies have reported a wide range of $S$. aureus carriage among NH residents $(23.9-43 \%)^{26-28}$. Although we observed a significant difference in carriage between the Dutch and German $\mathrm{NH}$ residents, the percentages were within the range mentioned in those studies.

For several antibiotics (the macrolides, clindamycin and ciprofloxacin) the prevalence of resistance among the MSSA isolates was higher among the German NH isolates compared with the Dutch ones. Flucloxacillin and clindamycin are often used as oral empiric treatment for a $S$. aureus infection ${ }^{29}$. Due to the high prevalence of resistance for clindamycin (including the inducible MLS-B type, 15\%) among the German NHs the appropriateness of this agent for empiric treatment is debatable but flucloxacillin remains an appropriate choice. The prevalence of resistance among MSSA isolates and the prevalence of MRSA varied between the NHs (Figure 2), which might imply that there were differences in 1) antibiotic policies by the NHs, 2) prevalence of risk factors among the $\mathrm{NH}$ residents and/or 3) adherence to infection control policies by the NH staff. Therefore, it is very important that local resistance data should be made available and be used as a guiding tool for the choice of empiric treatment.

Several oral agents still had a low prevalence of resistance. These include fusidic acid, although resistance for this agent has also increased and was already $6 \%$ among the Dutch NH isolates. These isolates were probably not related to the epidemic European fusidic acid-resistant impetigo clone (EEFIC), which was prevalent among general practice patients, since their spa types were different from those reported for the $\mathrm{EEFIC}^{30}$. Other alternatives are trimethoprim-sulfamethoxazole and tetracycline ${ }^{31}$, 
since (almost) no resistance was detected. Another potential agent may be fosfomycin ${ }^{32}$, since animal experiments have demonstrated the efficacy of this agent in S. aureus infection ${ }^{33}$. However, more research on humans regarding the systemic concentration and clinical efficacy is warranted.

MRSA is a point of attention due to, amongst others, the differences in prevalence ${ }^{34}$. The prevalence of MRSA among hospital patients has been demonstrated to be much lower in the Netherlands compared with Germany ${ }^{10}$. Our study confirmed that this difference also applies for NHs. Due to a possible outbreak of MRSA in one German NH (9 out of 77 swabs all with the same MRSA clone, 12\%) we hypothesize that the prevalence of $3.5 \%$ that was demonstrated in the remaining $\mathrm{NHs}$ is a better reflection of the MRSA prevalence among German NH residents in a non-outbreak situation. This outbreak, however, does confirm the spread of MRSA within German NHs.

The prevalence of MRSA in the NHs in both countries was in agreement with previous reports ${ }^{35-37}$, and was low in both countries compared to $\mathrm{NH}$ residents in other countries $(22 \% \text { in the UK and } 16 \% \text { in the USA })^{5,38}$. Since the source of infection is mostly the resident's own commensal (nasal) flora ${ }^{39,} 40$, the German NH residents are likely more at risk for an infection with MRSA than the Dutch NH residents. The MRSA prevalence among the German $\mathrm{NH}$ residents was high compared with the general German population, where prevalence of MRSA was much lower $(<1 \%)^{41}$.

The high prevalence of two MRSA clones in the German NHs compared with the Dutch $\mathrm{NHs}$, demonstrated spread of these clones within the German NHs and suggested spread between NHs. Spread directly from one NH to another seems unlikely since few residents transfer between NHs, but a common factor might be the hospitals. Although we do not have data concerning previous hospital admissions spread via the hospitals to the NHs and vice versa could be considered a revolving door mechanism.

The MRSA isolates that were observed in this study were, all but one, globally reported including in the Netherlands and Germany ${ }^{2,11,42,43}$. Both MRSA clones found among the German NH residents had an antibiotic resistance pattern which was in accordance with previous reports from the Robert Koch institute (i.e. co-resistance to the macrolides and fluoroquinolones) and are frequently found in Germany ${ }^{42}$, 44 . However, among the Dutch isolates, we observed one MRSA with ST7. This is an unexpected finding since MRSAs usually have a ST belonging to the MRSA associated CCs (e.g. CC1, CC5, CC8, CC22, CC30 and CC45) ${ }^{2}$. There are only sporadic reports of MRSA isolates belonging to a MSSA associated $\mathrm{CC}^{45}{ }^{46}$, which could be explained by the fact that mainly $S$. aureus lineages associated to the abovementioned CCs have the ability to attain and maintain a SCCmec.

Both the German and Dutch NH populations of MSSA showed a variety of spa types, but there were some significant differences in the distribution of the spaCCs. This does not apply to the number of isolates with a spa type associated to a MRSA related CC. The current data suggest a higher prevalence of MSSA isolates with CC1 and 8 in the Netherlands and with CC5, 22, 30 and 45 in Germany. . 
Previous research has demonstrated that bacteria spread mostly within one health care cluster $^{47}$. The differences in spa-CCs between the Dutch and German nursing homes suggest that there is no spread between those groups of $\mathrm{NH}$ residents.

The prevalence of MSSA isolates with a MRSA associated CC spa type (68\% and 69\%) was higher than among isolates collected from GP patients $(52 \%)^{16}$ but comparable to those from the ICU patients $(62 \%)^{19}$. The relatively high antibiotic use ${ }^{48-50}$ and the living environment of the residents might be responsible at least in part for this finding.

\section{Conclusion}

The prevalence of antibiotic resistance among MSSA isolates and the prevalence of MRSA was significantly higher among German NH residents compared with Dutch NH residents. Our results demonstrated a spread of two MRSA clones, each with several comparable pulsotypes, within and between German nursing homes. The population structure of the MSSA isolates, determined with spa typing, was significantly different between the Dutch and German NH isolates suggesting an absence of spread cross the border between these two groups of isolates in the two countries. Due to the increasing prevalence of resistance, the differences in resistance between $\mathrm{NHs}$ and the spread of MRSA isolates continuation of surveillance and implementation of infection control measures at a local NH level are important.

\section{Acknowledgements}

The authors would like to thank all the participants and the nursing staff in the participating nursing homes for their aid and assistance with the collection of the samples. 


\section{References}

1. Lowy FD. Staphylococcus aureus infections. N Engl J Med 1998; 339: 520-32.

2. Deurenberg RH, Stobberingh EE. The evolution of Staphylococcus aureus. Infect Genet Evol 2008; 8: 747-63.

3. Cosgrove SE, Qi Y, Kaye KS et al. The impact of methicillin resistance in Staphylococcus aureus bacteremia on patient outcomes: mortality, length of stay, and hospital charges. Infect Control Hosp Epidemiol 2005; 26: 166-74.

4. Cosgrove SE, Sakoulas G, Perencevich EN et al. Comparison of mortality associated with methicillin-resistant and methicillin-susceptible Staphylococcus aureus bacteremia: a metaanalysis. Clin Infect Dis 2003; 36: 53-9.

5. Barr B, Wilcox MH, Brady A et al. Prevalence of methicillin-resistant Staphylococcus aureus colonization among older residents of care homes in the United Kingdom. Infect Control Hosp Epidemiol 2007; 28: 853-9.

6. Brugnaro P, Fedeli $U$, Pellizzer $G$ et al. Clustering and risk factors of methicillinresistant Staphylococcus aureus carriage in two Italian long-term care facilities. Infection 2009; 37: 216-21.

7. von Baum H, Schmidt C, Svoboda D et al. Risk factors for methicillin-resistant Staphylococcus aureus carriage in residents of German nursing homes. Infect Control Hosp Epidemiol 2002; 23: 511-5.

8. Melles DC, Hendriks WD, Ott A et al. [Outbreak of methicillin-resistant Staphylococcus aureus (MRSA) in the Rijnmond region: the largest outbreak in the Netherlands]. Ned Tijdschr Geneesk 2004; 148: 1038-43.

9. Verkade E, Bosch T, Hendriks $\mathrm{Y}$ et al. Outbreak of Methicillin-Resistant Staphylococcus aureus ST398 in a Dutch Nursing Home. Infect Control Hosp Epidemiol 2012; 33: 624-6.

10. ECDC. Antimicrobial resistance surveillance in Europe 2009. Annual Report of the European Antimicrobial Resistance Surveillance Network (EARS-Net). Stockholm: ECDC, 2010.

11. Deurenberg $\mathrm{RH}$, Nulens $\mathrm{E}$, Valvatne $\mathrm{H}$ et al. Cross-border dissemination of methicillinresistant Staphylococcus aureus, Euregio Meuse-Rhin region. Emerg Infect Dis 2009; 15: 727-34.

12. Deurenberg RH, Vink C, Oudhuis GJ et al. Different clonal complexes of methicillinresistant Staphylococcus aureus are disseminated in the Euregio Meuse-Rhine region. Antimicrob Agents Chemother 2005; 49: 4263-71.

13. EUCAST. Breakpoint tables for interpretation of MICs and zone diameters - version 1.3, January 2011

14. Fuchs PC, Jones RN, Barry AL. Interpretive criteria for disk diffusion susceptibility testing of mupirocin, a topical antibiotic. J Clin Microbiol 1990; 28: 608-9.

15. Jorgensen JH, Crawford SA, McElmeel ML et al. Detection of inducible clindamycin resistance of staphylococci in conjunction with performance of automated broth susceptibility testing. J Clin Microbiol 2004; 42: 1800-2.

16. Donker GA, Deurenberg RH, Driessen C et al. The population structure of Staphylococcus aureus among general practice patients from The Netherlands. Clin Microbiol Infect 2009; 15: 137-43.

17. Frenay HM, Bunschoten AE, Schouls LM et al. Molecular typing of methicillin-resistant Staphylococcus aureus on the basis of protein A gene polymorphism. Eur J Clin Microbiol Infect Dis 1996; 15: 60-4.

18. Schouls LM, Spalburg EC, van Luit $M$ et al. Multiple-locus variable number tandem repeat analysis of Staphylococcus aureus: comparison with pulsed-field gel electrophoresis and spa-typing. PLoS One 2009; 4: e5082. 
19. Rijnders MI, Deurenberg RH, Boumans ML et al. Population structure of Staphylococcus aureus strains isolated from intensive care unit patients in the netherlands over an 11-year period (1996 to 2006). J Clin Microbiol 2009; 47: 4090-5.

20. Enright MC, Day NP, Davies CE et al. Multilocus sequence typing for characterization of methicillin-resistant and methicillin-susceptible clones of Staphylococcus aureus. J Clin Microbiol 2000; 38: 1008-15.

21. Valvatne $\mathrm{H}$, Rijnders MI, Budimir A et al. A rapid, 2-well, multiplex real-time polymerase chain reaction assay for the detection of SCCmec types I to $\mathrm{V}$ in methicillin-resistant Staphylococcus aureus. Diagn Microbiol Infect Dis 2009; 65: 384-91.

22. Mulvey MR, Chui L, Ismail J et al. Development of a Canadian standardized protocol for subtyping methicillin-resistant Staphylococcus aureus using pulsed-field gel electrophoresis. J Clin Microbiol 2001; 39: 3481-5.

23. Tenover FC, Arbeit RD, Goering RV et al. Interpreting chromosomal DNA restriction patterns produced by pulsed-field gel electrophoresis: criteria for bacterial strain typing. $J$ Clin Microbiol 1995; 33: 2233-9.

24. Narum SR. Beyond Bonferroni: Less conservative analyses for conservation genetics. Conservation Genetics 2006; 7: 783-7.

25. Grundmann $\mathrm{H}$, Hori S, Tanner G. Determining confidence intervals when measuring genetic diversity and the discriminatory abilities of typing methods for microorganisms. $J$ Clin Microbiol 2001; 39: 4190-2.

26. Daeschlein G, Assadian O, Rangous I et al. Risk factors for Staphylococcus aureus nasal carriage in residents of three nursing homes in Germany. J Hosp Infect 2006; 63: 216-20.

27. Karabay O, Otkun MT, Yavuz MT et al. Nasal carriage of methicillin-resistant and methicillin-susceptible Staphylococcus aureus in nursing home residents in Bolu, Turkey. West Ind Med J 2006; 55: 183-7.

28. Lasseter G, Charlett A, Lewis D et al. Staphylococcus aureus carriage in care homes: identification of risk factors, including the role of dementia. Epidemiol Infect 2010; 138: 686-96.

29. SWAB. Antibioticaboekje. http://customid.duhs.duke.edu/NL/Main/Start.asp (date last accesed: 15 August 2012 ).

30. Rijnders MI, Wolffs PF, Hopstaken RM et al. Spread of the epidemic European fusidic acid-resistant impetigo clone (EEFIC) in general practice patients in the south of The Netherlands. $J$ Antimicrob Chemother 2012; 67: 1176-80.

31. Stevens DL, Bisno AL, Chambers HF et al. Practice guidelines for the diagnosis and management of skin and soft-tissue infections. Clin Infect Dis 2005; 41: 1373-406.

32. Falagas ME, Giannopoulou KP, Kokolakis GN et al. Fosfomycin: use beyond urinary tract and gastrointestinal infections. Clin Infect Dis 2008; 46: 1069-77.

33. Poeppl W, Tobudic S, Lingscheid T et al. Daptomycin, fosfomycin, or both for treatment of methicillin-resistant Staphylococcus aureus osteomyelitis in an experimental rat model. Antimicrob Agents Chemother 2011; 55: 4999-5003.

34. euPrevent MRSA. http://www.euprevent.eu/staticpages/view/home (Date last accessed: 21 May 2012).

35. Woltering R, Hoffman G, Daniels-Haardt I et al. MRSA-Prävalenz in medizinischen und pflegerischen Einrichtungen eines Landkreises. Dtsch Med Wochenschr 2008; 133: 999-1003.

36. Greenland K, Rijnders MI, Mulders $M$ et al. Low prevalence of methicillin-resistant Staphylococcus aureus in Dutch nursing homes. J Am Ger Soc 2011; 59: 768-9.

37. Neuhaus B, Bocter N, Braulke C et al. Studie zum Vorkommen von Methicillinresistenten Staphylococcus aureus in Alten- und Altenpflegeheimen in Nerdrhei-Westfalen. Bundesgesundtheitsbl - Gesundheitsforsch - Gesundheitsschutz 2002; 45: 894-904.

38. Mody L, Kauffman CA, Donabedian S et al. Epidemiology of Staphylococcus aureus colonization in nursing home residents. Clin Infect Dis 2008; 46: 1368-73. 
39. von Eiff $\mathrm{C}$, Becker $\mathrm{K}$, Machka $\mathrm{K}$ et al. Nasal carriage as a source of Staphylococcus aureus bacteremia. Study Group. N Engl J Med 2001; 344: 11-6.

40. Shurland SM, Stine OC, Venezia RA et al. USA300 methicillin-resistant S. aureus (USA300 MRSA) colonization and the risk of MRSA infection in residents of extended-care facilities. Epidemiol Infect 2012; 140: 390-9.

41. Robert Koch-Institut. Epidemiologisches Bulletin. 27 February 2012. Nr. 8.

42. Robert Koch-Institut. Epidemiologisches Bulletin. 4 July 2011. Nr. 26.

43. Schaumburg F, Kock R, Mellmann A et al. Population Dynamics among MethicillinResistant Staphylococcus aureus Isolates in Germany during a 6-Year Period. J Clin Microbiol 2012; 50: 3186-92.

44. Ghebremedhin B, Konig W, Witte W et al. Subtyping of ST22-MRSA-IV (Barnim epidemic MRSA strain) at a university clinic in Germany from 2002 to 2005. J Med Microbiol 2007; 56: 36575.

45. Coombs GW, Pearson JC, O'Brien FG et al. Methicillin-resistant Staphylococcus aureus clones, Western Australia. Emerg Infect Dis 2006; 12: 241-7.

46. Hsu LY, Koh YL, Chlebicka NL et al. Establishment of ST30 as the predominant clonal type among community-associated methicillin-resistant Staphylococcus aureus isolates in Singapore. J Clin Microbiol 2006; 44: 1090-3.

47. Grundmann H, Aanensen DM, van den Wijngaard CC et al. Geographic distribution of Staphylococcus aureus causing invasive infections in Europe: a molecular-epidemiological analysis. PLoS Med 2010; 7: e1000215.

48. Donk van der CFM, Schols JMGA, Driessen CJ et al. Prevalence and spread of multi drug resistant Escherichia coli isolates among nursing home residents in the southern part of the Netherlands. J Am Med Dir Assoc 2012. nov 6

49. McClean $\mathrm{P}$, Hughes $\mathrm{C}$, Tunney $\mathrm{M}$ et al. Antimicrobial prescribing in European nursing homes. J Antimicrob Chemother 2011; 66: 1609-16.

50. SWAB. Nethmap 2012 - Consumption of antimicrobial agents and antimicrobial resistance among medically important bacteria in the Netherlands. 2012. 



\section{Chapter 6 Is living in a border region a risk for a high prevalence of resistance?}

C.F.M. van der Donk, M.I.A. Rijnders, G.A. Donker, A.J. de Neeling, S. Nys, E.E. Stobberingh 


\begin{abstract}
This study assessed the differences in antimicrobial resistance and population structure of Staphylococcus aureus isolated from general practice (GP) patients and nursing home $(\mathrm{NH})$ residents in the province of Limburg (near the border with Germany and Belgium) in comparison with those obtained in the remaining provinces of the Netherlands.

A total of 617 and 418 S. aureus isolates were isolated from 2691 and 1351 nasal swabs from GP patients and NH residents, respectively. Quantitative antibiotic susceptibility testing was performed using a broth microdilution method. Putative MRSA isolates were tested for the presence of the mecA gene and spa typing was performed on all $S$. aureus isolates.

No significant differences in prevalence of resistance were found between the two groups of GP isolates but the isolates from the $\mathrm{NH}$ residents showed a lower resistance for trimethoprim-sulfamethoxazole $(p=0.003)$ in Limburg province compared with the remaining provinces in the Netherlands.

Among the isolates from $\mathrm{NH}$ residents in Limburg province the prevalence of spa-CC 084 was higher $(p=0.003)$ and that of spa-CC 002 lower $(p=0.01)$ compared with isolates from $\mathrm{NHs}$ in the remaining provinces of the Netherlands.

We observed no differences in resistance and population structure between S. aureus isolates from GP patients in Limburg and the remaining provinces of the Netherlands and only a few differences were observed between the $\mathrm{NH}$ populations. There was no higher prevalence of resistance among the GP and NH isolates from Limburg compared with the remaining provinces.
\end{abstract}




\section{Introduction}

In Europe, almost one third of its population lives in a border region. In the Netherlands one of those border regions is the province of Limburg, which has a border with Belgium and Germany of $351 \mathrm{~km}$ and a border with two other Dutch provinces (i.e. Noord-Brabant and Gerlderland) of only $113 \mathrm{~km}^{1}$. Limburg is also part of the Euregion Meuse-Rhine, a region with intensive cross border traffic ( $4 \%$ of all jobs in Limburg is fulfilled by Belgian and German citizens) and cross border patient mobility due to the (free) access to health care facilities on both sides of the border ${ }^{2-4}$.

Staphylococcus aureus is a frequent causative agent of community and hospital acquired infections varying from minor skin and soft tissue infections to invasive infections like bacteraemia and endocarditis ${ }^{5}$. In many European countries the antibiotic resistance of $S$. aureus is increasing ${ }^{6}$ and consequently an optimal empiric antibiotic choice for the treatment of $S$. aureus infections becomes more challenging. In particular, the prevalence of methicillin resistant $S$. aureus (MRSA) is a point of concern. In the Netherlands the prevalence of MRSA is still low ${ }^{7}$, which can at least in part be attributed to the national antibiotic policy and the infection control guidelines (including the "search and destroy" protocol). However, in recent years several reports mentioned MRSA outbreaks in Dutch nursing homes $(\mathrm{NHs})^{8-11}$

The prevalence of antibiotic resistance and MRSA is higher in Belgium and Germany than in the Netherlands ${ }^{6}$ with a prevalence of MRSA in hospitals of $20.5 \%, 20.9 \%$ and $1.2 \%$, respectively ${ }^{6}$. It is to be expected that these resistant isolates could spread more easily and could lead to a higher prevalence of resistance in the province of Limburg than to the other provinces in the Netherlands due to cross border traffic and access to healthcare across the border ${ }^{2}$. The differences in antibiotic resistance between these countries hamper patient mobility because of the risk of acquisition or spread of resistant isolates.

There is no information available whether residents of the province of Limburg have a higher prevalence of resistance among $S$. aureus isolates and whether these isolates have a population structure more at risk for acquiring the mecA gene encoding for resistance to methicillin than those in the remaining provinces of the Netherlands. Therefore, we evaluated the antibiotic resistance and population structure of $S$. aureus isolates from general practice (GP) patients and NH residents in the province of Limburg in comparison with those of the remaining provinces of the Netherlands.

\section{Methods}

\section{Study population and isolation of S. aureus}

In 2005, a total of 2691 nasal swabs (Amies agar gel swabs without charcoal 108C, Copan Diagnostics, Brescia, Italy) were taken from the anterior nostrils from GP patients with no apparent signs of infection from 10 GPs in Limburg province (GP-L) and $19 \mathrm{GPs}$ in the remaining provinces in the Netherlands (GP-NL). The nasal swabs were analyzed as described previously ${ }^{12}$. In 2009 and 2010 a total of 1351 nasal swabs were collected from $\mathrm{NH}$ residents from six NHs in the province of Limburg (NH-L) and 
from $24 \mathrm{NHs}$ in other provinces of the Netherlands (NH-NL, Table 1). The swabs were analyzed with the same methods as the GP swabs ${ }^{12}$. Informed consent was obtained from all participants.

\section{Quantitative susceptibility testing}

Quantitative susceptibility testing was performed using broth microdilution with Mueller-Hinton II cation-adjusted broth (Beckton-Dickinson, Sparks, MD, USA) and microtitre plates with freeze-dried antibiotics (MCS Diagnostics BV, Swalmen, the Netherlands). S. aureus ATCC 29213 was used as a control strain. The breakpoints for resistance were according to the European Committee on Antimicrobial Susceptibility Testing (EUCAST) ${ }^{13}$. Antibiotic susceptibility testing for fusidic acid and mupirocin was performed with a disk diffusion test with Mueller Hinton II agar plates (BD) and antibiotics tablets (fusidic acid $100 \mu \mathrm{g}$ and mupirocin $10 \mu \mathrm{g}$, Rosco, Taastrup, Denmark). Zone diameters of $>27 \mathrm{~mm}$ for fusidic acid and $>15 \mathrm{~mm}$ for mupirocin were considered susceptible ${ }^{14,15}$. Oxacillin resistant isolates were analyzed for the presence of the mecA gene using a PCR assay as described previously ${ }^{12}$.

\section{Typing of the spa locus}

Amplification of the spa locus, followed by sequencing, was performed as described previously ${ }^{16,17}$. The spa types were clustered into spa-clonal complexes (spa-CCs) using the Based Upon Repeat Pattern (BURP) algorithm with the Ridom StaphType software version 2.2.1 (http://www.ridom.de). The spa types with $<6$ repeats were excluded from the analysis and spa types were clustered if the cost was $<5$, to prevent the formation of too large and non specific spa clusters. After applying the BURP algorithm the associated multi locus sequence typing (MLST) clonal complexes (CCs) were allocated through the Ridom SpaServer (http://spaserver.ridom.de).

\section{Statistical analysis}

Significant statistical differences in antibiotic resistance were calculated using the Pearson chi-square test or a Fisher's exact test (PASW-software, version 18.0, IBM, Armonk, NY, USA). A modified false discovery rate (FDR) method developed by Benjamini and Yekutieli was used as correction for multiple testing ${ }^{18}$. A p-value $<0.05$ was considered statistically significant. The diversity of the groups of isolates regarding the spa types was determined with Simpson's Index of diversity ${ }^{19}$.

\section{Results}

\section{Prevalence of S. aureus carriage}

The prevalence of S. aureus nasal carriage was 23\%, 247 isolates out of 1096 swabs and 370 isolates out of 1595 swabs, among both GP-L and GP-NL, respectively (Table 1). The prevalence among the $\mathrm{NH}$ residents was 31\%, 100 isolates out of 291 swabs, in $\mathrm{NH}$ $\mathrm{L}$ and $29 \%, 318$ isolates out of 1060 swabs, in $\mathrm{NH}-\mathrm{NL}$. 
Table 1: Overview of collected swabs and S. aureus isolates

\begin{tabular}{llllll}
\hline Unit & GP-L & GP-NL & NH-L & NH-NL & Total \\
\hline No. of swabs & 1096 & 1595 & 291 & 1060 & $\mathbf{4 0 4 2}$ \\
No. of isolates & 247 & 370 & 100 & 318 & 1035 \\
Prevalence & $23 \%$ & $23 \%$ & $31 \%$ & $29 \%$ & $\mathbf{2 6 \%}$ \\
No. of spa types & 130 & 163 & 39 & 114 & $\mathbf{3 2 9}$ \\
\hline
\end{tabular}

GP-L: general practice patients in the province of Limburg, GP-NL: general practice patients in the remaining provinces of the Netherlands, NH-L: nursing home residents in the province of Limburg, NH-NL: nursing home residents in the remaining provinces of the Netherlands.

\section{Prevalence of antibiotic resistance}

The antibiotic susceptibility patterns of the isolates are shown in Table 2 . Unfortunately, for further analysis 22 of the S. aureus isolates could not be cultured from the frozen stock.

No significant differences in resistance were demonstrated between GP-L and GP-NL. Resistance to linezolid, trimethoprim-sulfamethoxazole, vancomycin, gentamicin and mupirocin was either not observed or less than $1 \%$. Four isolates were resistant to oxacillin (MIC 4 or $8 \mathrm{mg} / \mathrm{L}$ ) but none of these isolates harboured the mecA gene. These isolates had the following spa types: t062, t127, t224 and t1702.

Among the $\mathrm{NH}$ isolates the prevalence of resistance was lower for trimethoprimsulfamethoxazole $(p=0.003)$ and clarithromycin $(p=0.093)$ from $\mathrm{NH}-\mathrm{L}(0 \%$ and $2 \%$, respectively) compared with $\mathrm{NH}-\mathrm{NL}$ ( $9 \%$ and $8 \%$ respectively). All but one of the trimethoprim-sulfamethoxazole resistant isolates harboured spa t064. Six isolates (two in $\mathrm{NH}-\mathrm{L}$ and four in $\mathrm{NH}-\mathrm{NL}$ ) were resistant to oxacillin (MIC $8 \mathrm{mg} / \mathrm{L}$ to $>64 \mathrm{mg} / \mathrm{L}$ ), carried the mecA gene and had the following spa types: t002, t037, t091, t223, t740 and t2164. Resistance to vancomycin, gentamicin, mupirocin and linezolid was either not demonstrated or less than $1 \%$.

Table 2: Antibiotic resistance among S. aureus isolates collected from GP patients and $\mathrm{NH}$ residents

\begin{tabular}{lllll}
\hline Antimicrobial agent & $\begin{array}{l}\text { GP-L } \\
(247)\end{array}$ & $\begin{array}{l}\text { GP-NL } \\
(348)\end{array}$ & $\begin{array}{l}\text { NH-L } \\
(100)\end{array}$ & $\begin{array}{l}\text { NH-NL } \\
(318)\end{array}$ \\
\hline Oxacillin & $1 \%$ & $1 \%$ & $2 \%$ & $1 \%$ \\
Claritromycin & $7 \%$ & $5 \%$ & $2 \%$ & $8 \%$ \\
Clindamycin & $1 \%$ & $0 \%$ & $0 \%$ & $2 \%$ \\
Ciprofloxacin & $1 \%$ & $2 \%$ & $24 \%$ & $34 \%$ \\
Fusidic acid & $6 \%$ & $6 \%$ & $6 \%$ & $4 \%$ \\
Tetracyclin & $3 \%$ & $5 \%$ & $2 \%$ & $2 \%$ \\
Trimethoprim-sulfamethoxazole & $0 \%$ & $0 \%$ & $0 \% *$ & $9 \%$
\end{tabular}

GP-L: general practice patients in the province of Limburg, GP-NL: general practice patients in the remaining provinces of the Netherlands, NH-L: nursing home residents in the province of Limburg, NH-NL: nursing home residents in the remaining provinces of the Netherlands. * significant difference between the two groups of $\mathrm{NH}$ isolates. 


\section{Distribution of spa types and BURP analysis}

A total of 329 spa types were found. The most prevalent spa types among all isolates were t008 (6.6\%), t002 (5.8\%) and t091 (5.1\%). The other spa types accounted for $0.1 \%$ to $4.1 \%$ each. Among the GP-L isolates spa types t012 (6.5\%), t091 (5.7\%) and t002 $(4.0 \%)$ were most prevalent and among the GP-NL isolates t091 (5.5\%), t008 $(4.9 \%)$ and t012 (4.9\%). Among the NH-L isolates spa types t008 (22\%), t091 (10\%) and t026 (7\%) were most prevalent and among the $\mathrm{NH}-\mathrm{NL}$ isolates t002 (9.8\%), t064 (8.2\%) and t008 (6.6\%).

The spa types clustered into 16 spa-CCs (Table 3). Three clusters had no founder and 33 spa types $(3.3 \%)$ could not be clustered in a spa-CC and were classified as singletons. 70 isolates $(6.9 \%)$ were excluded from the analysis since these spa types consisted of less than five repeats and 11 isolates were not typable.

Overall, the percentage of isolates belonging to each spa-CC was similar for GP-L and GP-NL and for NH-L and NH-NL. The only difference was observed the NH isolates: the prevalence of spa-CC $084(7 \%)$ was higher $(\mathrm{p}=0.003)$ and that of spa-CC $002(17 \%)$ was lower $(p=0.01)$ among isolates collected from $\mathrm{NH}-\mathrm{L}$ compared with those from NH-NL.

There was also variation in diversity of the spa types among the $\mathrm{NH}$ isolates: 0.929 $(95 \% \mathrm{Cl} 0.896-0.962)$ and $0.971(95 \% \mathrm{Cl} 0.963-0.978)$ for the $\mathrm{NH}-\mathrm{L}$ and $\mathrm{NH}-\mathrm{NL}$ isolates, respectively.

Table 3: Distribution of spa-CCs among isolates collected from GP and NH patients

\begin{tabular}{lllllll}
\hline spa-CC & Isolates (\%) & spa (\%) & GP-L (\%) & GP-NL (\%) & NH-L (\%) & NH-NL (\%) \\
\hline spa-CC 012 & $299(30)$ & $100(30)$ & $73(30)$ & $110(32)$ & $29(29)$ & $87(27)$ \\
spa-CC 084 & $124(13)$ & $27(9)$ & $37(15)$ & $47(14)$ & $18(18)^{*}$ & $22(7)^{*}$ \\
spa-CC 002 & $105(10)$ & $26(8)$ & $19(8)$ & $26(7)$ & $5(5)^{*}$ & $55(17)^{*}$ \\
spa-CC 024 & $126(12)$ & $19(6)$ & $15(6)$ & $25(7)$ & $23(23)$ & $63(20)$ \\
spa-CC 078 & $36(4)$ & $19(6)$ & $17(7)$ & $14(4)$ & $1(1)$ & $4(1)$ \\
spa-CC 127 & $66(7)$ & $18(5)$ & $12(5)$ & $26(7)$ & $6(6)$ & $22(7)$ \\
spa-CC 166 & $35(3)$ & $15(5)$ & $11(4)$ & $15(4)$ & $0(0)$ & $9(3)$ \\
spa-CC 005 & $30(3)$ & $13(4)$ & $5(2)$ & $14(4)$ & $2(2)$ & $9(3)$ \\
spa-CC 159 & $17(2)$ & $10(3)$ & $7(3)$ & $9(3)$ & $0(0)$ & $1(0)$ \\
spa-CC 216 & $27(3)$ & $8(2)$ & $7(3)$ & $4(1)$ & $1(1)$ & $15(5)$ \\
spa-CC 160 & $12(1)$ & $6(2)$ & $6(2)$ & $5(1)$ & $0(0)$ & $1(0)$ \\
spa-CC 364 & $9(1)$ & $4(1)$ & $4(2)$ & $4(1)$ & $0(0)$ & $1(0)$ \\
spa-CC 1045 & $5(0)$ & $3(1)$ & $2(1)$ & $1(0)$ & $1(1)$ & $1(0)$ \\
No founder 1 & $3(0)$ & $2(1)$ & $0(0)$ & $3(1)$ & $0(0)$ & $0(0)$ \\
No founder 2 & $2(0)$ & $2(1)$ & $1(0)$ & $1(0)$ & $0(0)$ & $0(0)$ \\
No founder 3 & $3(0)$ & $2(1)$ & $2(1)$ & $1(0)$ & $0(0)$ & $0(0)$ \\
Singletons & $33(3)$ & $23(7)$ & $8(3)$ & $15(4)$ & $1(1)$ & $9(3)$ \\
Excluded & $70(7)$ & $32(10)$ & $19(8)$ & $25(7)$ & $11(11)$ & $15(5)$ \\
Not typable & $11(1)$ & $0(0)$ & $2(1)$ & $3(1)$ & $2(2)$ & $4(1)$ \\
\hline Total & 1013 & 329 & 247 & 348 & 100 & 318 \\
\hline
\end{tabular}

GP-L: general practice patients in the province of Limburg, GP-NL: general practice patients in the remaining provinces of the Netherlands, NH-L: nursing home residents in the province of Limburg, NH-NL: nursing home residents in the remaining provinces of the Netherlands. * significant difference between the NH-L and NH-NL isolates. 
The spa types were associated to a MLST ST or CC via the Ridom SpaServer (Table 4). No significant differences were found between the GP-L and GP-NL isolates ( $56 \%$ and $61 \%$, respectively) and the $\mathrm{NH}-\mathrm{L}$ and $\mathrm{NH}-\mathrm{NL}$ isolates (73\% and $79 \%$, respectively)

Table 4: Composition of the spa-CCs

\begin{tabular}{|c|c|c|}
\hline spa-CC & spa types & ALST CC (ST) \\
\hline spa-CC 012 & $\begin{array}{l}\text { t004, t012, t015, t018, t019, t021, t031, t034, t037, t040, t050, } \\
\text { t065, t069, t073, t074, t095, t096, t102, t116, t122, t138, t230, } \\
\text { t238, t266, t274, t275, t276, t300, t302, t318, t331, t338, t370, } \\
\text { t404, t406, t483, t505, t571, t576, t583, t589, t620, t630, t631, } \\
\text { t706, t740, t772, t822, t840, t861, t908, t937, t950, t1130, t1149, } \\
\text { t1238, t1239, t1281, t1504, t1510, t1574, t1827, t1932, t2077, } \\
\text { t2135, t2143, t2208, t2209, t2210, t2239, t2254, t2269, t2275, } \\
\text { t2387, t2479, t2489, t2496, t2539, t2540, t2541, t2544, t2548, } \\
\text { t2557, t2561, t2566, t2568, t2572, t2610, t2659, t2674, t2682, } \\
\text { t2821, t2864, t4441, t4905, t5834, t7110, t7126, t7143, t7147 }\end{array}$ & 30,45 \\
\hline spa-CC 084 & $\begin{array}{l}\text { t084, t085, t091, t094, t252, t279, t346, t348, t360, t393, t491, } \\
\text { t547, t774, t796, t853, t867, t1243, t1363, t1716, t1943, t2074, } \\
\text { t2543, t2556, t2567, t2616, t5875, t7134 }\end{array}$ & 7,15 \\
\hline spa-CC 002 & $\begin{array}{l}\text { t001, t002, t010, t041, t062, t067, t179, t242, t306, t311, t389, } \\
\text { t447, t509, t539, t548, t688, t837, t1215, t1340, t2070, t2164, } \\
\text { t2212, t2491, t2542, t2724, t6160 }\end{array}$ & 5 \\
\hline spa-CC 024 & $\begin{array}{l}\text { t008, t024, t064, t104, t190, t197, t334, t377, t530, t648, t701, } \\
\text { t711, t846, t1171, t2041, t3060, t3802, t4299, t5279 }\end{array}$ & 8 \\
\hline spa-CC 078 & $\begin{array}{l}\text { t056, t078, t081, t087, t150, t258, t353, t436, t469, t660, t775, } \\
\text { t814, t1102, t1312, t1541, t1671, t1898, t2039, t2078 }\end{array}$ & 25,101 \\
\hline spa-CC 127 & $\begin{array}{l}\mathrm{t} 114, \mathrm{t} 127, \mathrm{t} 177, \mathrm{t} 189, \mathrm{t} 224, \mathrm{t} 267, \mathrm{t} 286, \mathrm{t} 359, \mathrm{t} 376, \mathrm{t} 591, \mathrm{t} 1236, \\
\mathrm{t} 1407, \mathrm{t} 1787, \mathrm{t} 2500, \mathrm{t} 2569, \mathrm{t} 2612, \mathrm{t} 2819, \mathrm{t} 7123\end{array}$ & 1 \\
\hline spa-CC 166 & $\begin{array}{l}\mathrm{t} 089, \mathrm{t} 136, \mathrm{t} 153, \mathrm{t} 166, \mathrm{t} 240, \mathrm{t} 369, \mathrm{t} 884, \mathrm{t} 1014, \mathrm{t} 2038, \mathrm{t} 2071 \\
\mathrm{t} 2073, \mathrm{t} 2080, \mathrm{t} 2547, \mathrm{t} 2854, \mathrm{t} 7162\end{array}$ & \\
\hline spa-CC 005 & $\begin{array}{l}\text { t005, t060, t223, t474, t790, t1433, t1629, t2570, t2618, t2681, } \\
\text { t5485, t5926, t7156 }\end{array}$ & 22 \\
\hline spa-CC 159 & $\mathrm{t} 159, \mathrm{t} 171, \mathrm{t} 272, \mathrm{t} 284, \mathrm{t} 408, \mathrm{t} 645, \mathrm{t} 659, \mathrm{t} 738, \mathrm{t} 2213, \mathrm{t} 2820$ & 121 \\
\hline spa-CC 216 & $\mathrm{t} 172, \mathrm{t} 216, \mathrm{t} 471, \mathrm{t} 1293, \mathrm{t} 2079, \mathrm{t} 2488, \mathrm{t} 3527, \mathrm{t} 4303$ & 59 \\
\hline spa-CC 160 & $\mathrm{t} 156, \mathrm{t} 160, \mathrm{t} 213, \mathrm{t} 771, \mathrm{t} 1702, \mathrm{t} 3938$ & 12 \\
\hline spa-CC 364 & $\mathrm{t} 364, \mathrm{t} 493, \mathrm{t} 2492, \mathrm{t} 2680$ & \\
\hline spa-CC 1045 & t099, t100, t1045 & 9 \\
\hline No founder 1 & $\mathrm{t} 148, \mathrm{t} 2016$ & \\
\hline No founder 2 & $\mathrm{t} 186, \mathrm{t} 729$ & (88) \\
\hline No founder 3 & t246, t2495 & \\
\hline Singletons & $\begin{array}{l}\mathrm{t} 106, \mathrm{t} 344, \mathrm{t} 587, \mathrm{t} 818, \mathrm{t} 878, \mathrm{t} 1362, \mathrm{t} 1406, \mathrm{t} 2050, \mathrm{t} 2075, \mathrm{t} 2076, \\
\mathrm{t} 2490, \mathrm{t} 2494, \mathrm{t} 2558, \mathrm{t} 2559, \mathrm{t} 2573, \mathrm{t} 2615, \mathrm{t} 2617, \mathrm{t} 5874, \mathrm{t} 7108, \\
\mathrm{t} 7132 \\
\mathrm{t} 164 \\
\mathrm{t} 199 \\
\mathrm{t} 209\end{array}$ & $\begin{array}{l}(20) \\
(59) \\
(109)\end{array}$ \\
\hline Excluded & $\begin{array}{l}\mathrm{t} 059, \mathrm{t} 118, \mathrm{t} 287, \mathrm{t} 362, \mathrm{t} 502, \mathrm{t} 524, \mathrm{t} 535, \mathrm{t} 605, \mathrm{t} 643, \mathrm{t} 808, \mathrm{t} 929, \\
\mathrm{t} 1152, \mathrm{t} 1200, \mathrm{t} 1209, \mathrm{t} 1456, \mathrm{t} 1509, \mathrm{t} 2176, \mathrm{t} 2207, \mathrm{t} 2211, \mathrm{t} 2246, \\
\mathrm{t} 2365, \mathrm{t} 2383, \mathrm{t} 2493, \mathrm{t} 2571, \mathrm{t} 2611, \mathrm{t} 2613, \mathrm{t} 2614, \mathrm{t} 2853, \mathrm{t} 4386 \\
\mathrm{t} 026 \\
\mathrm{t} 233 \\
\mathrm{t} 386\end{array}$ & $\begin{array}{l}45 \\
(59) \\
(1)\end{array}$ \\
\hline
\end{tabular}

Overview of the spa types in every spa-CC and the associated MLST clonal complex (CC) or sequence type (ST), associated via the Ridom Spaserver. 


\section{Discussion}

In this study we observed no difference in prevalence of resistance between the $S$. aureus isolates from GP-L and GP-NL but a significantly lower prevalence of resistance to trimethoprim-sulfamethoxazole for the isolates from $\mathrm{NH}-\mathrm{L}$ compared with those from NH-NL. Significant differences in prevalence of spa-CC 084 and 002 were also found for the NH isolates. These few differences do not support the hypothesis that the cross border traffic between the province of Limburg, Belgium and Germany led to a higher prevalence of resistance and/or a population structure more at risk for acquiring the mecA gene among the residents of Limburg compared with the residents in the remaining provinces of the Netherlands.

The strength of the study is that all samples were analyzed at the same laboratory with the same methods. Bias due to differences in methods can, therefore, be excluded. The study has also some weaknesses: the number of $\mathrm{NH}-\mathrm{L}$ isolates was lower compared to the other groups of isolates. Also, clinical data was not available and although there was a difference in sampling period between the GP and NH isolates, we do not expect that this could explain the differences in prevalence of resistance observed $^{20}$.

The 23\% prevalence of nasal colonization with S. aureus among both groups of GP patients was in agreement with previous reports ${ }^{21}$, which also applies for the $29 \%$ and $31 \%$ prevalence among the $\mathrm{NH}$ resident populations. Previous studies reported $23.9-43 \%$ 22-24.

No differences in antibiotic resistance were found between isolates collected from the two groups of GP patients, but between the two groups of $\mathrm{NH}$ residents a difference in trimethoprim-sulfamethoxazole resistance was observed. The difference observed might be due to differences in antibiotic use. NH residents are a frail population with a high use of antibiotics and more risk factors for acquiring and retaining a more resistant S. aureus isolate ${ }^{22,}{ }^{25}$. However, among GP patients and $\mathrm{NH}$ residents resistance to trimethoprim-sulfamethoxazole was rare despite there relatively high use $^{26}$ and further studies seem warranted. The 27 resistant isolates (out of 1013) were found in 13 different NHs and all but one harbored spa type 064, which is a spa type associated with MLST CC 8, a MRSA associated MLST CC.

Quinolone resistance was higher among the $\mathrm{NH}$ residents compared with the GP patients. Higher use of quinolones in $\mathrm{NHs}$ is probably a main reason for the development of higher resistance ${ }^{27,28}$. However, the differences in resistance could also be attributed to a different living environment, higher age, co morbidities and indwelling devices ${ }^{23}$.

Among the isolates from the GP patients the four oxacillin resistant isolates were classified as borderline oxacillin resistant $S$. aureus (BORSA). Isolates like these have been described before, but mostly in a clinical setting ${ }^{29-31}$. The clinical relevance of these isolates remains questionable. 
From our resistance data we may conclude that the spread of resistant isolates from Belgium and Germany to the Province of Limburg is not higher than to other Dutch provinces. However, a different population structure of the $S$. aureus isolates (i.e. isolates with a more stable genomic environment for the $\mathrm{SCCmec}$ cassette e.g. CC 1, $\mathrm{CC} 5, \mathrm{CC} 8, \mathrm{CC} 22, \mathrm{CC} 30$ and $\left.\mathrm{CC}_{4} 5^{32}\right)$ in the province of Limburg might be an early warning for a country-to-country spread.

With BURP all spa types were allocated in spa-CCs. The only significant difference was found for spa-CC 084 and spa-CC 002 between the NH groups. Overall spa-CC 012 was quite large and could be associated to two very different MLST CCs i.e. CC 30 and 45. With more strict BURP settings (cost <4) this spa-CC could be divided into a few smaller clusters of which spa-CC 012, associated to MLST CC 30, and spa-CC 015, associated to MLST CC 45 , were the largest (74\% of all isolates in this group).

There was a difference in prevalence of isolates associated with a MRSA associated MLST CC between the groups from the NHs but this can be attributed to the differences in spa-CCs described above.

The diversity of the spa types from the GP isolates was comparable with previous reports $^{33,34}$. The lower diversity of the spa types among the $\mathrm{NH}$ isolates might be due to the enclosed living environment, transmission within the NHs and higher antibiotic use. These factors combined with the lower number of participating NHs in Limburg might explain the lower diversity among the $\mathrm{NH}$ isolates in Limburg.

In conclusion we observed only minor differences in antibiotic resistance and population structure between isolates collected from GP patients and $\mathrm{NH}$ resident in Limburg and the remaining parts of the Netherlands. We may conclude that cross border traffic in the Euregion Meuse-Rhine (between Belgium, Germany and the province of Limburg in the Netherlands) does not result in differences in prevalence of resistance and population structure between Limburg and the remaining provinces in the Netherlands. However, the impact of cross border traffic might be quite different in larger countries or perhaps that globalization has a greater influence on the antibiotic resistance ${ }^{35}$ and population structure of $S$. aureus of the entire Dutch community than the location of the province of Limburg on this province alone. Therefore, surveillance at a local and international level is warranted, to keep informed as to changes in prevalence of resistance over time. 


\section{References}

1. Provincie Limburg - feiten en cijfers.

http://www.limburg.nl/Over_Limburg/Feiten_en_cijfers (20 June 2012 - date last accessed).

2. Commission of the European Communities. Proposal for a directive of the European parliament and the council on the application of patients' rights in cross-border healthcare. Brussels, 2.7.2008. $\operatorname{COM}(2008) 414$ final.

3. E,til. Limburgse Pendel 2010 - Pendelstromen op provinciaal en gemeentelijk niveau. 2011.

4. Stadt Aachen - Euregion Maas-Rijn. http://www.aachen.de/nl/sb/euregio/index.html (20 June 2012 - date last accessed).

5. $\quad$ Lowy FD. Staphylococcus aureus infections. N Engl J Med 1998; 339: 520-32.

6. ECDC. Antimicrobial resistance surveillance in Europe 2010. Annual Report of the European Antimicrobial Resistance Surveillance Network (EARS-Net). 2011.

7. SWAB. Nethmap 2011 - Consumption of antimicrobial agents and antimicrobial resistance among medically important bacteria in the Netherlands. 2011.

8. AT5 - MRSA-uitbraak in verpleeghuis Bernardus.

http://www.at5.nl/artikelen/57488/mrsa-uitbraak-in-verpleeghuis-bernardus (20 June 2012 date last accessed).

9. Nursing voor verpleegkundigen - MRSA-uitbraak in verpleeghuis Delfzijl.

http://www.nursing.nl/home/nieuw/2853/mrsa-uitbraak-in-verpleeghuis-delfzijl (20 June 2012 date last accessed).

10. BN De Stem.nl - MRSA-bacterie in Janshove.

http://www.bndestem.nl/regio/breda/7969474/MRSAbacterie-in-Janshove.ece (20 June 2012 date last accessed).

11. Omroep Flevoland - MRSA-uitbraak Laarstaete gestopt.

http://www.omroepflevoland.nl/Nieuws/31528/mrsa-uitbraak-laarstaete-gestopt (20 June 2012 - date last accessed).

12. Donker GA, Deurenberg RH, Driessen C et al. The population structure of Staphylococcus aureus among general practice patients from The Netherlands. Clin Microbiol Infect 2009; 15: 137-43.

13. EUCAST. Breakpoint tables for interpretation of MICs and zone diameters - version 1.3, January 2011

14. Fuchs PC, Jones RN, Barry AL. Interpretive criteria for disk diffusion susceptibility testing of mupirocin, a topical antibiotic. J Clin Microbiol 1990; 28: 608-9.

15. Diagnostica R. EUCAST-and CLSI potency NEO-SENSITABS ${ }^{\mathrm{MM}}$, Interpretation Zones and MIC Breakpoints according to CLSI, Staphylococci, Document 3.3.0.

16. Frenay HM, Bunschoten AE, Schouls LM et al. Molecular typing of methicillin-resistant Staphylococcus aureus on the basis of protein A gene polymorphism. Eur J Clin Microbiol Infect Dis 1996; 15: 60-4.

17. Schouls LM, Spalburg EC, van Luit $M$ et al. Multiple-locus variable number tandem repeat analysis of Staphylococcus aureus: comparison with pulsed-field gel electrophoresis and spa-typing. PLoS One 2009; 4: e5082.

18. Narum SR. Beyond Bonferroni: Less conservative analyses for conservation genetics. Conservation Genetics 2006; 7: 783-7.

19. Grundmann H, Hori S, Tanner G. Determining confidence intervals when measuring genetic diversity and the discriminatory abilities of typing methods for microorganisms. $J$ Clin Microbiol 2001; 39: 4190-2. 
20. Heijer den CDJ, Bijnen van EME, Paget WJ et al. Prevalence and susceptibility of commensal S. aureus in nine European countries World Organization of Family Doctors Europe Conference, 2012.

21. Wertheim HF, Vos MC, Ott A et al. Risk and outcome of nosocomial Staphylococcus aureus bacteraemia in nasal carriers versus non-carriers. Lancet 2004; 364: 703-5.

22. Daeschlein G, Assadian O, Rangous I et al. Risk factors for Staphylococcus aureus nasal carriage in residents of three nursing homes in Germany. J Hosp Infect 2006; 63: 216-20.

23. Lasseter G, Charlett A, Lewis D et al. Staphylococcus aureus carriage in care homes: identification of risk factors, including the role of dementia. Epidemiol Infect 2010; 138: 686-96.

24. Karabay O, Otkun MT, Yavuz MT et al. Nasal carriage of methicillin-resistant and methicillin-susceptible Staphylococcus aureus in nursing home residents in Bolu, Turkey. West Ind Med J 2006; 55: 183-7.

25. Donk van der CFM, Schols JMGA, Driessen CJ et al. Prevalence and spread of multi drug resistant Escherichia coli isolates among nursing home residents in the southern part of the Netherlands. J Am Med Dir Assoc 2012; Nov 6.

26. SWAB. Nethmap 2009 - Consumption of antimicrobial agents and antimicrobial resistance among medically important bacteria in the Netherlands. 2009.

27. Goossens $\mathrm{H}$, Ferech $\mathrm{M}$, Vander Stichele $\mathrm{R}$ et al. Outpatient antibiotic use in Europe and association with resistance: a cross-national database study. Lancet 2005; 365: 579-87.

28. Vellinga A, Tansey S, Hanahoe B et al. Trimethoprim and ciprofloxacin resistance and prescribing in urinary tract infection associated with Escherichia coli: a multilevel model. $J$ Antimicrob Chemother 2012; 67: 2523-30.

29. Balslev U, Bremmelgaard A, Svejgaard E et al. An outbreak of borderline oxacillinresistant Staphylococcus aureus (BORSA) in a dermatological unit. Microb Drug Resist 2005; 11: 78-81.

30. Skinner S, Murray M, Walus T et al. Failure of cloxacillin in treatment of a patient with borderline oxacillin-resistant Staphylococcus aureus endocarditis. J Clin Microbiol 2009; 47: 85961.

31. Nadarajah J, Lee MJ, Louie L et al. Identification of different clonal complexes and diverse amino acid substitutions in penicillin-binding protein 2 (PBP2) associated with borderline oxacillin resistance in Canadian Staphylococcus aureus isolates. J Med Microbiol 2006; 55: 167583.

32. Nubel $U$, Roumagnac $P$, Feldkamp $M$ et al. Frequent emergence and limited geographic dispersal of methicillin-resistant Staphylococcus aureus. PNAS 2008; 105: 14130-5.

33. Mellmann A, Weniger $\mathrm{T}$, Berssenbrugge $\mathrm{C}$ et al. Characterization of clonal relatedness among the natural population of Staphylococcus aureus strains by using spa sequence typing and the BURP (based upon repeat patterns) algorithm. J Clin Microbiol 2008; 46: 2805-8.

34. Grundmann H, Aanensen DM, van den Wijngaard CC et al. Geographic distribution of Staphylococcus aureus causing invasive infections in Europe: a molecular-epidemiological analysis. PLoS Med 2010; 7: e1000215.

35. van der Bij AK, Pitout JD. The role of international travel in the worldwide spread of multiresistant Enterobacteriaceae. J Antimicrob Chemother 2012; 67: 2090-100. 



\section{Chapter 7}

A 12 year (1998-2009) antibiotic resistance surveillance of Klebsiella pneumoniae collected from intensive care and urology patients in 14 Dutch hospitals

C.F.M. van der Donk, P.S. Beisser, J.A.A. Hoogkamp-Korstanje, C.A. Bruggeman, E.E. Stobberingh on behalf of the Antibiotic Resistance Surveillance Group 


\section{Abstract}

\section{Objectives}

We evaluated the changes in antibiotic resistance from 1998-2009 of Klebsiella pneumoniae isolated from the intensive care unit (ICU) and urology service of 14 Dutch hospitals and the consequences for empirical therapy.

\section{Methods}

Quantitative antibiotic susceptibility testing of $K$. pneumoniae was performed in a central laboratory using a broth microdilution. Breakpoints were as defined by the European Committee on antimicrobial susceptibility (EUCAST). The prevalence of extended spectrum B-lactamase (ESBL) and carbapenemase producing isolates was determined.

\section{Results}

A significant increase of resistance among ICU isolates was observed for ceftazidime (4.2-10.8\%), ciprofloxacin (5.8-18.5\%) and trimethoprim-sulfamethoxazole (11.9$23.1 \%)$, and for cefuroxime (2.8-7.9\%) and trimethoprim-sulfamethoxazole (13.5-27.8\%) among urology isolates. Among ICU isolates the prevalence of ESBLs increased significantly from $2 \%$ to $8 \%$. Carbapenemase production was not demonstrated. The prevalence of multidrug-resistance increased and has been $12 \%$ or more since 2004 . Among urology isolates multidrug-resistance was highest in 2009 at $7.4 \%$. Overall resistance was significantly higher among ICU isolates.

\section{Conclusions}

We observed an increase of resistance among ICU and urology isolates and an increased prevalence of ESBLs among ICU isolates. Carbapenemase production was not demonstrated. A regular update of empiric treatment protocols based on actual surveillance data is justified. 


\section{Introduction}

The worldwide increase of antibiotic resistance among Gram negative bacteria including Klebsiella pneumoniae is alarming. ${ }^{1}$ In particular the emergence of ESBL producing bacteria is troublesome.

According to Dutch guidelines, empiric treatment of first choice for bloodstream infections is a B-lactam antibiotic (broad-spectrum penicillin-B-lactamase inhibitor combination or $3^{\text {rd }}$ generation cephalosporins) mostly in combination with an aminoglycoside. ${ }^{2}$ However, the choice of therapy is challenging because the prevalence of $K$. pneumoniae isolates resistant to those antibiotics is increasing. ${ }^{1,3}$ Therefore, surveillance of antibiotic resistance is needed to determine the prevalence of resistance and to make an appropriate empiric antibiotic choice.

This study describes the development of resistance over the past 12 years among $K$. pneumoniae isolates from the ICU and urology services of 14 hospitals in the Netherlands as well as the consequences for empirical treatment of first choice especially in bloodstream and urinary tract infections (UTI).

\section{Materials and Methods}

\section{Isolates}

K. pneumoniae isolates from 14 Dutch hospitals were collected from 1998 to 2009, as part of the annual intramural surveillance of the Dutch Working Party on Antibiotic Policy. ${ }^{3}$ The isolates were collected from the ICU and the urology service. ICU isolates were collected from various clinical samples, the urology isolates were derived from urine samples. Only one isolate per patient was included. Clinical data was not available.

The isolates were identified at the local laboratories, stored and sent to one central laboratory for susceptibility testing. Two laboratories functioned as central laboratory: that of the University Medical Centre St. Radboud Nijmegen (1998-2001) and that of the Maastricht University Medical Centre (since 2002).

\section{Susceptibility testing}

Quantitative susceptibility testing was performed using a broth microdilution with Mueller-Hinton II cation-adjusted broth (Becton-Dickinson, Sparks, MD, USA). Microtitre plates with freeze-dried antibiotics were obtained from MCS Diagnostics BV (Swalmen, the Netherlands). The minimal inhibitory concentration (MIC) was defined as the lowest concentration showing no growth after 18 hours of incubation at $35^{\circ} \mathrm{C}$. Escherichia coli ATCC 35218 and ATCC 25922 were used as control strains. The MIC data were recorded, stored and re-evaluated for this study using breakpoints defined as by the EUCAST. ${ }^{4}$ Intermediate results were considered resistant.

Multidrug-resistance was defined as resistance to three or more classes of antibiotics.

Seven isolates from one hospital were presumably part of a local outbreak of a multi resistant $K$. pneumoniae strain at the ICU in 2002. PFGE confirmed this presumption. Therefore, only the first isolate from this outbreak was included. 
Confirmation of ESBL and carbapenemase producing isolates

Confirmation of ESBL production was performed as described. ${ }^{5}$ Confirmation of carbapenemase production was performed on isolates with a meropenem $M I C \geq 0.5 \mathrm{mg} / \mathrm{L}$ and/or imipenem $\mathrm{MIC} \geq 2 \mathrm{mg} / \mathrm{L}$ using the modified Hodge test. ${ }^{6}$

\section{Statistical analysis}

The logistic regression analysis was performed to determine statistically significant trends during the study period. A p-value of $<0.05$ was considered statistically significant.

\section{Results}

A total of 1,578 isolates were collected: 720 from the ICUs and 858 from the urology services.

Table 1: The trends in antimicrobial resistance of $K$. pneumoniae strains isolated from 14 Dutch ICUs

\begin{tabular}{lccccc}
\hline Antimicrobial agent & \% '98 & \% '09 & p-value & OR & $95 \% \mathrm{Cl}$ \\
\hline AMC & $16.7 \%$ & $26.1 \%$ & 0.063 & 1.053 & $0.997-1.111$ \\
TAZ & $8.0 \%$ & $15.2 \%$ & 0.068 & 1.068 & $0.995-1.145$ \\
CXM & $8.0 \%$ & $15.5 \%$ & 0.058 & 1.070 & $0.998-1.148$ \\
CAZ & $4.2 \%$ & $10.8 \%$ & ${ }^{*} 0.040$ & 1.097 & $1.004-1.198$ \\
CFM & $3.5 \%$ & $11.2 \%$ & 0.072 & 1.093 & $0.992-1.204$ \\
FEP & $3.5 \%$ & $8.1 \%$ & 0.096 & 1.088 & $0.985-1.202$ \\
CTX & NT & $7.9 \%$ & 0.453 & 1.057 & $0.914-1.224$ \\
IPM & $0.0 \%$ & $0.0 \%$ & 0.272 & 0.447 & $0.106-1.882$ \\
MEM & $0.0 \%$ & $0.0 \%$ & 0.685 & 1.150 & $0.585-2.260$ \\
CIP & $5.8 \%$ & $18.5 \%$ & ${ }^{*} 0.001$ & 1.126 & $1.047-1.211$ \\
GEN & $9.9 \%$ & $11.7 \%$ & 0.634 & 1.017 & $0.948-1.092$ \\
SXT & $11.9 \%$ & $23.1 \%$ & ${ }^{*} 0.016$ & 1.075 & $1.014-1.141$ \\
AMC with GEN & $7.6 \%$ & $7.8 \%$ & 0.954 & 1.002 & $0.923-1.088$ \\
TAZ with GEN & $3.2 \%$ & $7.1 \%$ & 0.141 & 1.081 & $0.974-1.199$ \\
CAZ with GEN & $2.9 \%$ & $6.4 \%$ & 0.172 & 1.079 & $0.967-1.204$ \\
CTX with GEN & NT & $6.2 \%$ & 0.409 & 1.073 & $0.908-1.267$ \\
CIP with GEN & $3.7 \%$ & $9.3 \%$ & 0.065 & 1.092 & $0.994-1.200$ \\
\hline
\end{tabular}

$\mathrm{AMC}=$ amoxicillin/clavulanate, $\mathrm{TAZ}=$ piperacillin/tazobactam, $\mathrm{IPM}=$ imipenem, $\mathrm{MEM}=$ meropenem, $C X M=$ cefuroxime, $C A Z$ = ceftazidime, $C F M=$ cefixime, FEP = cefepime, $C T X=$ cefotaxime, $\mathrm{CIP}=$ ciprofloxacin, GEN = gentamicin, $\mathrm{SXT}=$ trimethoprim/sulfamethoxazole, $\mathrm{NT}=$ not tested. Quantitative susceptibilty testing of cefotaxime commenced in 2002. Percentages of resistance are those calculated by the logistic regression analysis. ${ }^{*}=$ significant increase of resistance 
ICUs

An increase in resistance was observed for most antibiotics among ICU isolates (Table 1). Trend-analysis showed a significant increase for ceftazidime, ciprofloxacin and trimethoprim-sulfamethoxazole (Table 1). ESBL production was demonstrated in 34 of 45 putative isolates; prevalence rose from $2 \%$ in 1998 to $8 \%$ in 2009 ( $p=0.026$, odds ratio (OR) $1.141(1.016-1.282))$ of all ICU isolates. Carbapenemase production was not demonstrated.

Considering empiric treatment options of first choice; resistance to amoxicillinclavulanate with gentamicin remained stable around $8 \%$, while resistance to the other antibiotic combinations increased slightly $(p>0.05)($ Table 1$)$. The prevalence of multidrug-resistant isolates in ICUs fluctuated between 0-23\%. However, since 2004 the prevalence has been at least $12 \%$.

Table 2: The trends in antimicrobial resistance of $K$. pneumoniae strains isolated from 14 Dutch Urology Services

\begin{tabular}{lccccc}
\hline Antimicrobial agent & \% '98 & \%R ${ }^{\circ} 09$ & p-value & OR & 95\% Cl \\
\hline AMC & $9.0 \%$ & $15.1 \%$ & 0.084 & 1.055 & $0.993-1.120$ \\
TAZ & $2.2 \%$ & $5.2 \%$ & 0.134 & 1.086 & $0.975-1.210$ \\
CXM & $2.8 \%$ & $7.9 \%$ & ${ }^{*} 0.033$ & 1.105 & $1.008-1.212$ \\
CAZ & $0.8 \%$ & $2.7 \%$ & 0.185 & 1.115 & $0.949-1.309$ \\
CFM & $0.5 \%$ & $2.7 \%$ & 0.091 & 1.172 & $0.975-1.408$ \\
FEP & $0.3 \%$ & $2.1 \%$ & 0.074 & 1.210 & $0.981-1.492$ \\
CTX & NT & $7.9 \%$ & 0.616 & 1.069 & $0.823-1.388$ \\
IPM & $0.0 \%$ & $0.0 \%$ & 0.467 & 0.861 & $0.575-1.289$ \\
MEM & $0.0 \%$ & $0.0 \%$ & 0.521 & 0.824 & $0.456-1.489$ \\
CIP & $5.1 \%$ & $9.3 \%$ & 0.137 & 1.060 & $0.982-1.144$ \\
GEN & $1.0 \%$ & $3.2 \%$ & 0.157 & 1.111 & $0.960-1.287$ \\
SXT & $13.5 \%$ & $27.8 \%$ & ${ }^{*} 0.001$ & 1.086 & $1.034-1.140$ \\
AMC with GEN & $0.2 \%$ & $1.9 \%$ & 0.111 & 1.225 & $0.954-1.573$ \\
TAZ with GEN & $0.4 \%$ & $0.3 \%$ & 0.998 & 1.000 & $0.722-1.385$ \\
CAZ with GEN & $0.1 \%$ & $1.3 \%$ & 0.168 & 1.262 & $0.906-1.758$ \\
CTX with GEN & NT & $1.1 \%$ & 0.519 & 1.141 & $0.765-1.702$ \\
CIP with GEN & $0.1 \%$ & $1.2 \%$ & 0.204 & 1.228 & $0.894-1.686$ \\
\hline
\end{tabular}

$\mathrm{AMC}=$ amoxicillin/clavulanate, $\mathrm{TAZ}=$ piperacillin/tazobactam, $\mathrm{IPM}=$ imipenem, $\mathrm{MEM}=$ meropenem, $C X M=$ cefuroxime, $C A Z$ = ceftazidime, $C F M=$ cefixime, $F E P=$ cefepime, $C T X=$ cefotaxime, $\mathrm{CIP}=$ ciprofloxacin, GEN = gentamicin, $\mathrm{SXT}$ = trimethoprim/sulfamethoxazole, NT = not tested. Quantitative susceptibilty testing of cefotaxime commenced in 2002. Percentages of resistance are those calculated by the logistic regression analysis. ${ }^{*}=$ significant increase of resistance

\section{Urology services}

An increase of resistance for most antibiotics was observed among isolates from the urology services, which was significant for cefuroxime and trimethoprimsulfamethoxazole (Table 2). The prevalence of ESBL producing isolates increased from $0 \%$ in 1998 and to 2\% in 2009 ( $p=0.101$, OR 1.462 (0.955-1.803)). Carbapenemase production was not demonstrated. Prevalence of resistance to the different antibiotic combinations increased over time and ranged in 2009 from $1.1 \%$ to $1.9 \%$, except for 
resistance to the combination of piperacillin-tazobactam with gentamicin, which remained stable at $0.3-0.4 \%$ (Table 2). Multidrug-resistance rose to $7.4 \%$ in 2009 .

\section{ICU vs. urology isolates}

Trend-analysis showed that antimicrobial resistance was significantly higher among ICU isolates except for the resistance to carbapenems, which was the same in both groups, and resistance to trimethoprim-sulfamethoxazole, which was higher in urology isolates but not significantly.

\section{Discussion}

We observed a significant increase in resistance to ceftazidime, trimethoprimsulfamethoxazole and ciprofloxacin among isolates from the ICUs. Among these isolates the increase in prevalence of ESBL producing isolates was significant too. Likewise, we observed a significant rise in resistance to cefuroxime and trimethoprimsulfamethoxazole among urology isolates. Overall the resistance levels of $K$. pneumoniae isolates from ICUs were significantly higher than resistance of isolates from the urology services. The increase in resistance to most antibiotics was in accordance with the global increase in antibiotic resistance. ${ }^{1,3}$

\section{ICUs}

The ICU is a ward with a relatively high use of broad-spectrum antibiotics. Empiric treatment of first choice is usually a combination of a beta-lactam antibiotic with an aminoglycoside. ${ }^{2}$ In 2009, resistance levels to these antibiotic combinations varied from $6 \%$ to $9 \%$. Although a resistance level with an upper limit of $10 \%$ is considered suitable for empiric treatment, ${ }^{7}$ from a clinical point of view a resistance level of $\leq 5 \%$ would be more appropriate for more severe illnesses. Whether a combination of agents is suitable for empiric therapy also depends on the prevalence of $K$. pneumoniae as the causative agent of an infection.

An alarming finding is the increase of resistance to $3^{\text {rd }}$ generation cephalosporins and the increasing prevalence of ESBLs. Recently, Sturm et al. ${ }^{8}$ described a ESBLprevalence of $5,2 \%$ in unselected $K$. pneumoniae isolates. In our study, the prevalence of putative and confirmed ESBLs in $K$. pneumoniae was approximately the same as in Germany (8.2\% in 2002) and France (5.\% in 2002), but higher than in the Scandinavian countries and lower than many other countries in Southern Europe (28\% in Italy 2002). ${ }^{1}$ This is very likely due to the lower use of cephalosporins in the Netherlands. ${ }^{3}$

\section{Urology services}

The urology service is a ward with a high use of specific antibiotics. In particular fluoroquinolones, trimethoprim-sulfamethoxazole, cefuroxime and amoxicillinclavulanate (with gentamicin) are often prescribed as empiric treatment of first choice. ${ }^{2}$ Nevertheless, resistance to amoxicillin-clavulanate and trimethoprimsulfamethoxazole was more than $10 \%$ and those antibiotics should not be used as empiric treatment for UTIs with $K$. pneumoniae. ${ }^{7}$ Resistance to other beta-lactam 
antibiotics was, in contrast to the antibiotics of first choice, much lower. Notably, also the prevalence of ESBLs (2\%) was still low. The increase in resistance for fluoroquinolones was not significant. Nevertheless the resistance of Escherichia coli to ciprofloxacin increased to $15 \%-20 \%$ and, therefore, empiric treatment with fluoroquinolones is not recommended for a UTI. ${ }^{3,7}$

Overall the resistance was higher in ICU isolates compared with urology isolates. This is probably due to the high use of broad-spectrum antibiotics: 132 defined daily doses (DDD) /100 patient days at the ICUs while the overall use in hospitals is $58.7 \mathrm{DDD} / 100$ patient days. ${ }^{3}$ This is in line with the generally accepted belief that antibiotic use is the main factor for the emergence of antibiotic resistance. ${ }^{9}$

Unfortunately, clinical data (e.g. patient characteristics and source of isolation) was not available. However, strengths of the study were that it was conducted over several years, the isolates were collected from 14 hospitals and quantitative susceptibility testing was performed in a central laboratory.

From our study we concluded that antibiotic resistance is increasing and that the prevalence of resistance was significantly higher at the ICU. Therefore, a regular update of empiric treatment protocols based on actual surveillance data is justified.

\section{Acknowledgements}

The authors would like to thank Y. Beeuwkes, P. Terporten, G. Oudhuis, S. de Jager and the laboratory technicians at the central laboratories at Maastricht University Medical Centre and University Medical Centre St. Radboud Nijmegen. 


\section{References}

1. Jones ME, Draghi DC, Thornsberry $C$ et al. Emerging resistance among bacterial pathogens in the intensive care unit--a European and North American Surveillance study (20002002). Ann Clin Microb Antimicrob 2004; 3: 14.

2. Stichting Werkgroep Antitbioticabeleid. Antibioticaboekje. http://customid.duhs.duke.edu/NL/Main/Start.asp (30 November 2010, date last accessed).

3. Stichting Werkgroep Antibioticabeleid. Nethmap, Consumption of antimicrobial agents and antimicrobial resistance among medically important bacteria in the Netherlands. 2008. (1 December 2010, date last accessed).

4. The European Committee on Antimicrobial Susceptibility Testing. EUCAST Clinical Breakpoint Table v1.1 2010-04-27.

5. Nederlandse Vereniging voor Medische Microbiologie. Richtlijn voor screening en confirmatie van extended spectrum beta-lactamase (ESBLs) in Enterobacteriaceae.

http://www.nvmm.nl/richtlijnen/esbl-screening-en-confirmatie (1 December 2010, date last accessed).

6. Centers for Disease Control and Prevention. Modified Hodge Test for Carbapenemase Detection in Enterobacteriaceae. http://www.ndhealth.gov/microlab/Uploads/HodgeTest.pdf (1 December 2010, date last accessed).

7. Vogelaers D, De Bels D, Foret $F$ et al. Patterns of antimicrobial therapy in severe nosocomial infections: empiric choices, proportion of appropriate therapy, and adaptation rates-a multicentre, observational survey in critically ill patients. Int J Antimicrob Agents 2009; 35: 375-81.

8. Sturm PD, Bochum ET, van Mook-Vermulst SV et al. Prevalence, molecular characterization, and phenotypic confirmation of extended-spectrum beta-lactamases in Escherichia coli, Klebsiella pneumoniae, and Klebsiella oxytoca at the Radboud University Nijmegen Medical Centre in The Netherlands. Microb drug res 2010; 16: 55-60.

9. Goossens $\mathrm{H}$, Ferech $\mathrm{M}$, Vander Stichele R et al. Outpatient antibiotic use in Europe and association with resistance: a cross-national database study. Lancet 2005; 365: 579-87. 


\section{Chapter 8 General discussion Summary Samenvatting}


Worldwide the prevalence of resistance is increasing ${ }^{1}$, which is mostly caused by the high use of antibiotic agents ${ }^{2}, 3$. The high prevalence of resistance complicates the optimal empirical antibiotic choice. When choosing an antibiotic agent for empirical treatment the expected prevalence of resistance should be less than $10 \%$ to $20 \%$, depending on the severity of the infection ${ }^{4}$. Therefore, current antibiotic resistance surveillance data are needed to make an optimal empiric choice.

These data must be obtained from the target patient population: i.e. data from hospitals are not suitable for general practice patients or nursing home residents or vice versa.

In this thesis we focused not only on different populations in the Netherlands, Germany and Belgium but we also wanted to know the influence of living near the border with Germany and Belgium on the prevalence of resistance. The reason is that the prevalence of resistance of these both countries is higher than in the Netherlands. We hypothesize that cross border traffic (for health care, social or economical reasons) influences the prevalence of resistance in the province of Limburg.

The antibiotic surveillance was carried out in the Netherlands and in the Euregion Meuse-Rhine (consisting of the provincie Limburg in the Netherlands, the provincie Limburg, the province de Liège and the Deutschsprachige Gemeinschaft in Belgium, and the Regio Aachen in Germany). The main focus of this thesis was to evaluate the prevalence of antibiotic resistance in a cross border region. Differences in antibiotic resistance between the three countries hamper cross border health care ${ }^{5}$.

We determined the prevalence of antibiotic resistance in different patient populations: general practice patients, nursing home residents, intensive care unit patients and urology services patients. These populations have expected differences in prevalence of resistance probably caused by differences in the amount and choice of antibiotics. The implications of the differences in antibiotic resistance on empiric antibiotic treatment are also discussed.

The micro-organisms of interest were S. aureus, as the representative of the Gram positive commensal microbiota and, Eschericha coli and Klebsiella pneumoniae representing the Gram negative commensal microbiota. The commensal microbiota was chosen as target micro-organisms as most infections are caused by the patient' own commensal microbiota ${ }^{6-9}$. Information on the prevalence of resistance of the commensal microbiota is, therefore relevant to make an optimal empiric choice for the treatment of infections. Another reason to choose representatives of the commensal microbiota is that the commensals are considered the main reservoir for antibiotic resistance genes and resistant microorganisms ${ }^{10,11}$. Resistance traits can be transferred from the resistant commensals to the potential pathogens via mobile genetic elements (horizontal gene transfer) ${ }^{10}$. Therefore, the commensal microbiota is considered the main reservoir for antibiotic resistant microorganisms; the resistance in the infecting microorganisms represents only the tip of the antibiotic resistance 'iceberg'. 


\section{Nursing home residents}

Nursing home residents are a frail and vulnerable, mostly elderly population who are living relatively close together and often need skilled nursing care due to comorbidities such as chronic wound infections and incontinence for feces and or urine. The prevalence of infections among nursing home residents is relatively high ${ }^{12}$, which has led to a high use of antibiotics.

In the Province of Limburg in the Netherlands the antibiotic resistance of $E$. coli isolated from nursing home residents was high, e.g. amoxicillin-clavulanic acid $23 \%$ and trimethoprim-sulfamethoxazole $19 \%$ (chapter 2). Among the $E$. coli isolates especially the high resistance to the fluoroquinolones $(16 \%)$ is a point of concern. This might be due to the high use of these agents (14.8 DDD/1000 residents/day). Fluoroquinolones are easy to administer, have a broad antibacterial spectrum, favorable pharmacodynamics and minor side effects ${ }^{13}$, but due to the high resistance rates the empirical use of these agents is not advisable. Resistance to nitrofurantoin was almost absent and, therefore, appropriate for empiric treatment. However, the poor tissue penetration $^{14}$ makes it unsuitable for complicated UTIs. We also demonstrated a difference in resistance between the participating nursing homes. This could be caused by differences in antibiotic use and characteristics of the nursing homes, such as size and ward dynamics. Furthermore, we demonstrated multi drug resistant $E$. coli isolates with the same PFGE profile in different nursing homes suggesting spread of these bacteria between nursing home residents.

The prevalence of resistance among $S$. aureus was investigated for nursing home residents in the Province of Limburg in the Netherlands and the regions of Euskirchen and Daun in Germany (chapter 5). The prevalence of MRSA was relatively high (3.5\%) in the German nursing homes compared with the Dutch nursing homes $(<1 \%)$. The German MRSA isolates were also resistant to the macrolides and ciprofloxacin, limiting the treatment options in case of an infection. The German MRSA isolates $(n=20)$ belonged to two globally prevalent clones ${ }^{15}$ and were found in six out of the ten nursing homes. In four nursing homes at least two residents were colonized with MRSA isolates with the same PFGE profile. These results strongly suggested the spread of resistant bacteria within the nursing homes and probably between nursing homes and hospitals and vice versa, a revolving door.

Among the Dutch nursing home residents the prevalence of antibiotic resistant $S$. aureus was low, e.g. erythromycin $2 \%$, clindamycin $0 \%$, as was the prevalence of MRSA $(<1 \%)$. For empiric treatment of a $S$. aureus infection many antibiotic options remain among both the German and Dutch nursing home residents. Only the use of clindamycin should be discouraged among the German nursing residents, since the prevalence of resistance was $15 \%$, exceeding the $10 \%$ resistance cut-off for appropriate empiric treatment ${ }^{4}$. Moreover, based on the spread of MRSAs among the German nursing homes, adherence to a nursing home specific infection control policy is warranted. 


\section{Hospital patients}

In this thesis two groups of hospital patients were included: the ICU patients, a group of patients with a high use and variety of broad spectrum antibiotics, and the urology patients, a patient group with a high use of a limited group of antibiotics e.g. fluoroquinolones. The urology isolates were collected from 9 services in the Euregion Meuse-Rhine.

Probably, due to the frequent use of antibiotics, many $E$. coli isolates were resistant to the agents of first choice for a complicated UTI, e.g. amoxicillin-clavulanic acid, fluoroquinolones and trimethoprim-sulfamethoxazole (chapter 2). However, the prevalence of resistance varied significantly in the three different regions isolates were collected from. In particular, resistance among the Belgian E. coli isolates was high: e.g. amoxicillin-clavulanic acid 39\%, ciprofloxacin $37 \%$ and trimethoprimsulfamethoxazole $36 \%$. Subsequently, alternatives options for oral empiric treatment are few. Only piperacillin-tazobactam, the $3^{\text {rd }}$ and $4^{\text {th }}$ generation cephalosporines, nitrofurantoin and aminoglycosides of which the prevalence of resistance was $10 \%$ or lower might be suitable for empiric treatment. However, they are unsuitable based on other factors such as oral unavailability and limited tissue penetration.

This chapter together with the prevalence of resistance among $K$. pneumoniae isolates from ICU and urology patients (chapter 7) also underlined that the prevalence of resistance differs between the different hospital wards. An antibiotic, which has a prevalence of resistance of less than $10 \%$ for ICU patients and is, therefore, appropriate for empiric treatment, might have a prevalence of more than $10 \%$ and unsuitable for urology patients, or vice versa. For example the prevalence of resistance among $K$. pneumoniae collected from ICU patients was $26 \%$ for amoxicillinclavulanic acid, $19 \%$ for ciprofloxacin and $23 \%$ for trimethoprim-sulfamethoxazole. These percentages were $15 \%, 9 \%$ and $28 \%$ among the urology isolates, respectively. This is probably related to the differences in antibiotics most used at the different wards. Therefore, current antibiotic surveillance data of the target population at a ward specific level are needed to help physicians make an optimal choice for empiric antibiotic treatment.

Nevertheless, just as for the nursing home residents, further research into alternative treatment options is warranted. This could be the development of new agents (not necessarily the classic chemical antibiotic substances) or the use of already existing agents with different indications. An example is fosfomycin. Until now this agent is mostly used and registered only for the treatment of uncomplicated UTIs. However, limited research has demonstrated its potential use for more severe infections and infections caused by different bacteria, such as S. aureus ${ }^{16-18}$, and further studies are warranted.

A high prevalence of resistance is also a point of concern among $K$. pneumoniae among ICU and urology patients in the Netherlands. K. pneumoniae is mostly an opportunistic pathogen often causing infections in those already ill ${ }^{19}$. Therefore, the appropriateness of empiric treatment is very important since the impact of inappropriate therapy is expected to be high among immunocompromised patients. However, over time also the prevalence of resistance among these bacteria increased especially for 
ceftazidime, ciprofloxacin and trimethoprim-sulfamethoxazole among the ICU isolates and cefuroxime and trimethoprim-sulfamethoxazole among the urology isolates, decreasing the antibiotic alternatives for empiric treatment (chapter 7).

\section{Spread of resistance}

Not only the emergence or increase of resistance is a point of concern but also the spread of the resistant strains is a problem. Bacteria do not recognize political borders, could spread to another country and pose a problem when causing an infection, which requires empiric antibiotic treatment.

Over the years there have been many reports of globally emerging resistant strains ${ }^{20}$, 21, which pose a threat to human health, such as the multi drug resistant ST131E. coli $^{22,23}$. In this thesis the presence of this strain was demonstrated in the entire Euregion among the general practice patients, nursing home residents, ICU and urology patients. Also the ST393 and ST88 E. coli isolates were found in the entire Euregion (chapter 4). PFGE analysis among the ST131, ST393 and ST88 isolates showed comparable and similar profiles in different parts and populations of the Euregion (chapter 2, 3 and 4). This demonstrates the presence and spread of ST131 in the Euregion. However, it is difficult to prove actual transfer from one healthcare facility in the Euregion to another. Previous research has demonstrated that resistant strains predominantly spread in a health care network ${ }^{24}$ and although there is cooperation between the health care institutes in the Euregion it might not be enough (in terms of patient transfer) to cause a spread of resistant strains. Follow up of the $E$. coli population is required to determine patterns of spread in the Euregion. Also, the results from the Euregion should be compared with results from the three individual countries separately to detect any differences in genetic background and to aid in the detection of spread of particular patterns of resistance.

Overall, the prevalence of antibiotic resistance is lower in the Netherlands compared with Germany and Belgium ${ }^{1}$. If resistant strains would spread from Belgium and Germany to the Netherlands it would affect the prevalence of resistance in the province of Limburg compared with the remaining provinces in the Netherlands. However, the differences in antibiotic resistance and population structure of S. aureus isolates collected from nursing home residents and general practice patients in the province of Limburg and the remaining provinces of the Netherlands were not significant. Therefore, the inhabitants of Limburg are probably not more or not yet at risk for an infection with a resistant $S$. aureus strain than the other Dutch inhabitants. However, one might argue that there still could be an increased risk but that the threat of international travel to countries with a high prevalence of multi drug resistant bacteria might play an even more important role than the regional cross border movements. This is a threat for all Dutch residents not only those in Limburg. Nowadays people travel around the globe also to countries with a high prevalence of multi drug resistant bacteria. These international movements facilitates the spread of resistant strains ${ }^{25}$. 


\section{Future recommendations}

Due to the globally increasing prevalence of antibiotic resistance among many clinically relevant potentially pathogenic micro-organisms it is essential to make the choice for empiric treatment with consideration. Since antibiotic use is the leading driving force for increasing antibiotic resistance ${ }^{2,26-28}$, it is of importance to use antibiotics only when necessary. To accomplish this many antibiotic stewardship programs have been developed. Antibiotic stewardship programs are an ongoing effort to optimize antimicrobial use in order to improve patient outcomes, ensure cost effective therapy and reduce adverse sequelae of antimicrobial use ${ }^{29}$. These programs have three goals $\left.{ }^{30}: 1\right)$ treatment with appropriate antibiotics according to the 4Ds as described by Joseph and Rodvold ${ }^{31}$ (right drug, right dose, right duration and deescalation to pathogen directed therapy), 2) prevent antibiotic overuse, misuse or abuse, 3) minimize the development of antibiotic resistance.

These programs have to be initiated and maintained in cooperation with all health care practitioners, not only in the hospitals but also in nursing homes and in general practice. We have to find the balance between what is best for the individual patient and what is best for the entire population. To determine the appropriateness of empiric antibiotic treatment regarding antibiotic resistance, accurate data on antibiotic resistance and the prevalence of multi drug resistance is essential ${ }^{32,33}$. Also, proper infection control is crucial as is optimal information on the clusters of resistant bacteria among specific patient populations.

For the optimal empiric choice surveillance of antimicrobial resistance is essential and should be continued both at a local, a (Eu)regional and a(n) (inter)national level to ensure a favorable patient outcome. These survey results should be used to adapt stewardship programs, treatment protocols and infection control policies, preferably to a local level.

An effort is required from all those working in healthcare, on associated research projects and also the patients themselves to prevent further increase and spread of antimicrobial resistance.

- Working together for a healthier tomorrow - 


\section{References}

1. ECDC. Antimicrobial resistance surveillance in Europe 2010. Annual Report of the European Antimicrobial Resistance Surveillance Network (EARS-Net). 2011.

2. Goossens $\mathrm{H}$, Ferech $\mathrm{M}$, Vander Stichele $\mathrm{R}$ et al. Outpatient antibiotic use in Europe and association with resistance: a cross-national database study. Lancet 2005; 365: 579-87.

3. Vellinga A, Tansey S, Hanahoe B et al. Trimethoprim and ciprofloxacin resistance and prescribing in urinary tract infection associated with Escherichia coli: a multilevel model. $J$ Antimicrob Chemother 2012; 67: 2523-30.

4. Gupta K, Hooton TM, Naber KG et al. International clinical practice guidelines for the treatment of acute uncomplicated cystitis and pyelonephritis in women: A 2010 update by the Infectious Diseases Society of America and the European Society for Microbiology and Infectious Diseases. Clin Infect Dis 2011; 52: e103-20.

5. Infection Prevention Working Party. MRSA Hospital. 2012.

6. Beerepoot MA, den Heijer CD, Penders J et al. Predictive value of Escherichia coli susceptibility in strains causing asymptomatic bacteriuria for women with recurrent symptomatic urinary tract infections receiving prophylaxis. Clin Microbiol Infect 2012; 18: E84-90.

7. Yamamoto S, Tsukamoto T, Terai A et al. Genetic evidence supporting the fecalperineal-urethral hypothesis in cystitis caused by Escherichia coli. J Urol 1997; 157: 1127-9.

8. Shurland SM, Stine OC, Venezia RA et al. USA300 methicillin-resistant S. aureus (USA300 MRSA) colonization and the risk of MRSA infection in residents of extended-care facilities. Epidemiol Infect 2012; 140: 390-9.

9. von Eiff C, Becker K, Machka $\mathrm{K}$ et al. Nasal carriage as a source of Staphylococcus aureus bacteremia. Study Group. NEJM 2001; 344: 11-6.

10. de Lastours V, Chau F, Tubach $\mathrm{F}$ et al. Independent behavior of commensal flora for carriage of fluoroquinolone-resistant bacteria in patients at admission. Antimicrob Agents Chemother 2010; 54: 5193-200.

11. Wardwell LH, Huttenhower C, Garrett WS. Current concepts of the intestinal microbiota and the pathogenesis of infection. Curr Infect Dis Rep 2011; 13: 28-34.

12. Engelhart ST, Hanses-Derendorf L, Exner $M$ et al. Prospective surveillance for healthcare-associated infections in German nursing home residents. J Hosp Infect 2005; 60: 4650 .

13. Oliphant CM, Green GM. Quinolones: a comprehensive review. Am Fam Physician 2002; 65: 455-64.

14. Guay DR. An update on the role of nitrofurans in the management of urinary tract infections. Drugs 2001; 61: 353-64.

15. Deurenberg RH, Stobberingh EE. The evolution of Staphylococcus aureus. Infect Genet Evol 2008; 8: 747-63.

16. Falagas ME, Giannopoulou KP, Kokolakis GN et al. Fosfomycin: use beyond urinary tract and gastrointestinal infections. Clin Infect Dis 2008; 46: 1069-77.

17. Poeppl W, Tobudic S, Lingscheid T et al. Daptomycin, fosfomycin, or both for treatment of methicillin-resistant Staphylococcus aureus osteomyelitis in an experimental rat model. Antimicrob Agents Chemother 2011; 55: 4999-5003.

18. Raz R. Fosfomycin: an old-new antibiotic. Clin Microbiol Infect 2012; 18: 4-7.

19. Podschun R, Ullmann U. Klebsiella spp. as nosocomial pathogens: epidemiology, taxonomy, typing methods, and pathogenicity factors. Clinical microbiology reviews 1998; 11 : 589-603.

20. Canton R, Novais A, Valverde A et al. Prevalence and spread of extended-spectrum beta-lactamase-producing Enterobacteriaceae in Europe. Clin Microbiol Infect 2008; 14 Suppl 1: 144-53. 


\section{Chapter 8}

21. Nordmann P, Naas T, Poirel L. Global spread of Carbapenemase-producing Enterobacteriaceae. Emerg Infect Dis 2011; 17: 1791-8.

22. Croxall $\mathrm{G}$, Hale J, Weston $\mathrm{V}$ et al. Molecular epidemiology of extraintestinal pathogenic Escherichia coli isolates from a regional cohort of elderly patients highlights the prevalence of ST131 strains with increased antimicrobial resistance in both community and hospital care settings. J Antimicrob Chemother 2011; 66: 2501-8.

23. Peirano G, Schreckenberger PC, Pitout JD. Characteristics of NDM-1-producing Escherichia coli isolates that belong to the successful and virulent clone ST131. Antimicrob Agents Chemother 2011; 55: 2986-8.

24. Grundmann H, Aanensen DM, van den Wijngaard CC et al. Geographic distribution of Staphylococcus aureus causing invasive infections in Europe: a molecular-epidemiological analysis. PLoS medicine 2010; 7: e1000215.

25. van der Bij AK, Pitout JD. The role of international travel in the worldwide spread of multiresistant Enterobacteriaceae. J Antimicrob Chemother 2012.

26. Colodner R, Rock W, Chazan B et al. Risk factors for the development of extendedspectrum beta-lactamase-producing bacteria in nonhospitalized patients. Eur J Clin Microbiol Infect Dis 2004; 23: 163-7.

27. Graffunder EM, Preston KE, Evans $A M$ et al. Risk factors associated with extendedspectrum beta-lactamase-producing organisms at a tertiary care hospital. J Antimicrob Chemother 2005; 56: 139-45.

28. Brugnaro P, Fedeli U, Pellizzer $G$ et al. Clustering and risk factors of methicillinresistant Staphylococcus aureus carriage in two Italian long-term care facilities. Infection 2009; 37: 216-21.

29. SWAB. De kwaliteit van het antibioticabeleid in Nederland - Advies aangaande het restrictief gebruik van antibiotica en het invoeren van Antibioticateams in de Nederlandse ziekenhuizen en in de Eerste lijn. 2011.

30. Doron S, Davidson LE. Antimicrobial stewardship. Mayo Clinic proceedings 2011; 86: 1113-23.

31. Joseph J, Rodvold KA. The role of carbapenems in the treatment of severe nosocomial respiratory tract infections. Expert Opin Pharmacother 2008; 9: 561-75.

32. Grundmann $\mathrm{H}$, Klugman KP, Walsh $\mathrm{T}$ et al. A framework for global surveillance of antibiotic resistance. Drug resistance updates 2011; 14: 79-87.

33. Masterton R. The importance and future of antimicrobial surveillance studies. Clin Infect Dis 2008; 47 Suppl 1: S21-31. 


\section{Summary}

Chapter 1: The commensal microbiota is an indispensable part of the human body. However, it also contains many potential pathogenic microorganisms such as Staphylococcus aureus, Escherichia coli and Klebsiella pneumoniae, which can cause many different infections, mild but also severe.

In the previous century antibiotic agents, such as penicillin, were introduced and were a cure for many infectious diseases, which would have been lethal without these antibiotics. During the second half of the $20^{\text {th }}$ century many antibiotics have been developed, all with their own mechanism of action and, therefore, all with their own antibacterial spectrum. However, parallel to the development and introduction of new antibiotics, the bacteria developed ways to survive the antibiotic action and be resistant. Well known examples are the methicillin resistant $S$. aureus (MRSA) and the extended spectrum beta-lactamase (ESBL) producing Gram negative bacteria. The MRSA is resistant due to an alteration of the drug target side and ESBL producers due to production of an enzyme that breaks down beta-lactam antibiotics. Resistance mechanisms to all antibiotics have been described. The main reason for the development and increase of resistance is the use of antibiotics. Other risk factors include the presence of invasive devices or foreign materials, co-morbidities, poor functional status and wounds.

Another major concern is the spread of the resistant bacteria. In our globalized world everything is becoming more interconnected, which also affects the spread of resistant bacteria. Previous research has shown that several clones of MRSA isolates and types of ESBLs and ESBL producers have emerged all around the globe but with differences between countries. Since bacteria do not stop at our borders, they could easily spread from one country to another, which hampers patient mobility, especially in a region with intensive cross border traffic, such as the Euregion Meuse-Rhine. Therefore, the prevalence of resistance should be monitored and action should be taken to control this increasing prevalence. Close cooperation in the Euregion regarding prevalence of resistance, antibiotic policies and infection control policies is required.

Chapter 2 describes the prevalence of resistance among $E$. coli isolates collected from urine samples from urology service patients in the Euregion Meuse-Rhine. There were significant differences in prevalence of resistance between the three subregions of the Euregion, which was highest among the Belgian isolates. The prevalence of ESBL producing isolates, of which most produced a CTX-M 15, was highest among the German isolates. For several tested antibiotics the prevalence of resistance exceeded $10 \%$ or even $20 \%$ and these agents are, therefore, not appropriate as empiric antibiotic treatment. These include amoxicillin-clavulanic acid, the fluoroquinolones and the folate pathway inhibitors. However, resistance to nitrofurantoin was low. The prevalence of the multi drug resistant $E$. coli isolates ranged from $11 \%$ in the Dutch region to $27 \%$ in the Belgian region $(\mathrm{p}<=0.001)$. MLST ST131 was the most prevalent type and several of those ST131 isolates, which were collected in the three regions of the Euregion, had a comparable or similar PFGE profile. This indicates the spread of ST131 E. coli among patients from the urology services in the Euregion. 
The prevalence of resistance among $E$. coli isolates collected from residents in five nursing homes in the province of Limburg in the Netherlands and the antibiotic use among those residents are presented in Chapter 3. The prevalence of resistance was higher compared with that among general practice patients, especially for the fluoroquinolones. Since the prevalence of resistance exceeded $10 \%$ for many antibiotics including the fluoroquinolones, those agents were not suitable for empiric antibiotic treatment. Nevertheless, the prevalence of resistance varied between the different nursing homes.

Multi drug resistant E. coli was observed among $13 \%$ of the isolates. Many of those belonged to ST131 and had a similar PFGE pattern. This suggested that spread within and between nursing homes spread of multi drug resistant isolates did occur.

Variations in the use of antibiotics between the different nursing homes were found but overall the use of amoxicillin-clavulanic acid and the fluoroquinolones were highest. Often high use could be linked to high prevalence of resistance but also other risk factors for resistance and differences in need for care might play a role.

Chapter 4 presents the prevalence of resistance, genetic background and spread of (multi drug resistant) $E$. coli isolates collected from general practice patients, nursing home residents, urology and ICU patients in the Euregion Meuse-Rhine. The prevalence of resistance varied significantly between the four populations. Amoxicillin-clavulanic acid reistance was highest among the ICU isolates, and ciprofloxacin resistance among the URO isolates. Approximately $11 \%$ of the $E$. coli isolates was multi drug resistant and/or an ESBL producer. The most prevalent ESBL type was CTX-M 15. In total, 47 differents STs were observed of which ST131 was the most prevalent one. PFGE analysis of the ST131 isolates suggested the spread of isolates belonging to the same PFGE group in the entire Euregion. The emergence of resistant strains, such as ST131, might be a precursor for an increasing prevalence of resistance in the near future.

In Chapter 5 the prevalence of resistance among MSSA isolates and the prevalence of MRSA isolates collected from nursing home residents in the province of Limburg in the Netherlands and the regions of Euskirchen and Daun in Germany are described. The MRSA prevalence was higher among the German nursing home isolates compared with the Dutch ones. The German MRSA isolates consisted of two globally prevalent clones and the isolates belonging to each clone had a very comparable PFGE profile. This demonstrated the spread of MRSA within and between the German nursing homes.

The prevalence of resistance among the MSSA isolates was highest among the Germany nursing home isolates, especially for the macrolides and clindamycin. Overall, the prevalence of resistance to the fluoroquinolones was high. The population structure determined with spa typing and BURP analysis also showed differences between the Dutch and German MSSA isolates disputing the spread between nursing homes cross the border.

The influence of cross border traffic from Belgium and Germany to the Province of Limburg on the prevalence of resistance and population structure among S. aureus collected from general practice patients and nursing home residents in the province of 
Limburg compared with isolates from the remaining provinces in the Netherlands is discussed in Chapter 6. No differences in prevalence of resistance and population structure for the two groups of general practice isolates were observed and only a lower resistance for trimethoprim-sulfamethoxazole among the nursing home isolates in Limburg province compared with the remaining provinces. Among the nursing home isolates in Limburg the prevalence of spa-CC 084 was higher and that of spa-CC 002 was lower compared with isolates from the nursing homes in the remaining provinces. Despite great differences in resistance in the intramural setting in the Euregion MeuseRhine, intensive cross border traffic does not result in a higher prevalence of resistance and population structure in Limburg compared with the remaining provinces in the Netherlands in the extramural setting and in the nursing homes.

The prevalence of resistance of $K$. pneumoniae collected from ICU and urology patients in the Netherlands over a period of 12 years is described in Chapter 7. An increase in prevalence of resistance was observed, especially for ceftazidime, ciprofloxacin and trimethoprim-sulfamethoxazole among the ICU isolates, and cefuroxime and trimethoprim-sulfamethoxazole among the urology isolates. Overall, the prevalence of resistance was highest among the ICU isolates except for the carbapenems and trimethoprim-sulfamethoxazole where the prevalence of resistance was comparable. The high prevalence of resistance may render several antibiotics, especially among the ICU isolates, unsuitable for empiric treatment.

Chapter 8: The high prevalence of resistance, the prevalence of ESBLs and the emergence and endurance of specific resistant clones, such as E. coli ST131 and ST225MRSA-II, in Euregion Meuse-Rhine and in the Netherlands, emphasize the need for continuation of antibiotic surveillance studies. Also further epidemiological studies investigating the genetic background of the resistant bacteria are warranted. These data are essential for development and adaptation of empiric antibiotic treatment protocols.

This thesis demonstrated differences in prevalence of resistance between countries and between different patient populations, but also within countries and within different patient populations. This underlines the need for surveillance at a local level, development and adaptation of empiric treatment protocols at a local level and the need for cooperation between health care institutes also in a cross border region.

Efforts from the entire health care sector are required to control the further increase of the prevalence of resistance. This includes the set up of local infection control policies. However, antibiotic stewardship programs including an empiric antibiotic treatment protocol should be implemented to decrease the overall use of antibiotics and the missuse of these agents. Due to the increasing prevalence of resistance the number of antibiotic agents suitable for empiric treatment is declining. Further studies to new or alternative agents are warranted. 


\section{Samenvatting}

Hoofdstuk 1 beschrijft de rol van de commensale flora, het gebruik van antibiotica, het voorkomen en verspreiden van antibiotica resistentie en risicofactoren voor de toename van antibiotica resistentie. De commensale flora, bestaande uit vele soorten micro-organismen, is een onmisbaar onderdeel van het menselijk lichaam. Deze flora bestaat deels uit potentieel ziekmakende micro-organismen zoals Staphylococcus aureus, Escherichia coli en Klebsiella pneumoniae. Deze bacteriën kunnen verschillende infecties veroorzaken variërend van onschuldig tot zeer ernstig.

In de vorige eeuw zijn verschillende antibiotica, zoals penicilline, geïntroduceerd. Deze antibiotica waren en zijn nog steeds essentieel voor de behandeling van vele infectieziekten, die anders dodelijk zouden zijn geweest. Echter, gelijktijdig met de ontwikkeling van antibiotica hebben de bacteriën een manier ontwikkeld om de werking van deze middelen te overleven. Ze werden resistent. Bekende voorbeelden zijn de methicilline resistente $S$. aureus (MRSA ook bekend als de zogenaamde ziekenhuisbacterie) en de extended spectrum beta-lactamase (ESBL) producerende Gram negatieve bacteriën. De voornaamste oorzaak voor de ontwikkeling en toename van resistentie is het gebruik van antibiotica. Een hoog gebruik leidt tot meer resistentie. Ook patiënt specifieke factoren zoals de aanwezigheid van kathethers of andere lichaamsvreemde materialen, onderliggend lijden, slechte lichamelijke conditie en/of aanwezigheid van wonden spelen een rol bij de toename van resistentie.

Behalve antibiotica gebruik leidt ook verspreiding van antibiotica resistente bacteriën tot een toename van het resistentie probleem. Bacteriën worden niet tegengehouden door landsgrenzen. Gebleken is dat bepaalde types van MRSA en ESBL producerende bacteriën zich over de hele wereld hebben verspreid, echter er zijn wel verschillen tussen landen.

De verspreiding van bacteriën over de landsgrenzen heeft negatieve gevolgen voor de zogenaamde "cross border mobiliteit" van patiënten zoals in de Euregio Maas-Rijn: de grensregio bestaande uit de provincie Limburg in Nederland, de provincie Limburg en Luik en de Duitssprekende gemeenschap in België en Regio Aken in Duitsland.

Hoofdstuk 2 beschrijft het voorkomen van resistentie bij $E$. coli isolaten afkomstig van urine monsters van urologie patiënten uit 9 ziekenhuizen in de Euregio Maas-Rijn. Er waren significante verschillen in het voorkomen van resistentie in de drie delen van deze Euregio. Resistentie was over het algemeen het hoogst bij de Belgische isolaten. Het voorkomen van ESBL producerende bacteriën, voornamelijk type CTX-M 15, was het hoogst bij de Duitse isolaten (8\%). Voor verschillende geteste antibiotica, zoals amoxicilline-clavulaanzuur, de fluoroquinolen en de foliumzuursyntheseremmers, was de resistentie hoger dan $10 \%$ of zelfs $20 \%$. Deze antibiotica zijn derhalve niet geschikt voor empirische antibiotische behandeling, omdat de kans op falen van de therapie dan groot is. Echter, de resistentie voor nitrofurantoine was laag in alle landen. Het voorkomen van multi resistente (resistentie voor 3 of meer klassen van antibiotica) $\mathrm{E}$. coli isolaten varieerde van $11 \%$ in de Nederlandse tot $27 \%$ in de Belgische regio $(\mathrm{p} \leq 0.001)$. E. coli type ST131 was het meest voorkomende type en verschillende van 
deze ST131 isolaten, uit de gehele Euregio, hadden een overeenkomend PFGE profiel, wat wijst op genetische verwantschap en verspreiding van dit ST131 type onder urologie patiënten in de Euregio. Deze bevinding is overeenkomstig de literatuur: $E$. coli ST131 is wereldwijd een veelvoorkomend vaak multi resistent type.

Het voorkomen van resistentie bij $E$. coli isolaten van bewoners van vijf verpleeghuzien in de provincie Limburg in Nederland en het antibiotica gebruik in deze huizen wordt beschreven in Hoofdstuk 3. Het voorkomen van resistentie was hoog vooral voor de fluoroquinolonen (16\%). De resistentie was voor meerdere antibiotica, waaronder de fluoroquinolonen, hoger dan 10\%. Deze middelen zijn daarom niet geschikt voor empirisch antibiotische behandeling. Tussen de verpleeghuizen werden wel verschillen in prevalentie van resistentie waargenomen, evenals verschillen in antibiotica gebruik. Over het algemeen was het gebruik van amoxicilline-clavulaanzuur en de fluoroquinolonen het hoogst. Vaak bleek een hoge resistentie in een bepaald verpleeghuis gerelateerd te kunnen worden aan een hoog antibiotica gebruik, maar ook andere risicofactoren en verschillen in zorgzwaarte spelen een rol.

Multi resistentie werd vastgesteld bij $13 \%$ van de isolaten. De meeste van deze isolaten waren van het ST131 type en hadden een vergelijkbaar PFGE profiel. Dit suggereert een verspreiding van multi resistente bacteriën in en tussen verpleeghuizen. Dit werd ook gezien in ziekenhuis isolaten (Hoofdstuk 2).

Hoofdstuk 4 beschrijft het voorkomen van antibiotica resistentie, de genetische achtergrond en verspreiding van (multi) resistente $E$. coli isolaten van vier verschillenden patiënten populaties: huisarts patiënten, verpleeghuisbewoners, urologie- en IC patiënten in de Euregio Maas-Rijn. Het voorkomen van resistentie verschilde significant tussen de vier populaties, verschillen tussen de landen waren relatief klein. De resistentie voor amoxicilline-clavulaanzuur was het hoogst bij de IC isolaten en de ciprofloxacine resistentie het hoogst bij de urologie isolaten. Ongeveer $11 \%(n=182)$ van de $E$. coli isolaten $(n=1651)$ was multi resistent en/of produceerde een ESBL. Het meest voorkomende ESBL type was CTX-M 15. In totaal werden er 47 verschillende E. coli types (ST types) aangetoond, waarvan het ST131 type het meeste voorkwam. Resultaten van de PFGE analyse van deze ST131 isolaten suggereerde een verspreiding van deze isolaten met een vergelijkbaar PFGE profiel in de hele Euregio. Het opkomen van bepaalde resistente types, zoals ST131, kan een voorbode zijn voor een toename van antibiotica resistentie in de nabije toekomst.

In Hoofdstuk $\mathbf{5}$ wordt het voorkomen van de antibiotica resistentie bij methicilline gevoelige S. aureus (MSSA) en methicilline resistentie $S$. aureus (MRSA) isolaten bij verpleeghuisbewoners in de provincie Limburg in Nederland en de regio's Euskirchen en Daun in Duitsland beschreven. Het voorkomen van MRSA was hoger bij de Duitse verpleeghuisisolaten $(3,5 \%, n=20)$ vergeleken met de Nederlandse $(<1 \%, n=2)$. De Duitse MRSA isolaten behoorden tot twee wereldwijd voorkomende types (ST225-MRSAII en ST22-MRSA-IV) en hadden een vergelijkbaar PFGE profiel. Dit suggereert de verspreiding van deze MRSA types in en tussen Duitse verpleeghuizen. Het voorkomen van resistentie bij de MSSA isolaten was ook het hoogste bij de Duitse 
verpleeghuisisolaten, met name de resistentie voor de macroliden en clindamycine (beiden 15\%). Bij zowel de Nederlandse als Duitse isolaten was de resistentie voor de fluoroquinolonen relatief hoog (25\% en $34 \%$ respectievelijk). De populatie structuur van de MSSA isolaten, bepaald met spa typering en BURP analyse, liet verschillen zien tussen de Nederlandse en Duitse isolaten. Dit spreekt eventuele verspreiding tussen verpleeghuizen tussen Nederland en Duitsland tegen.

De invloed van grensverkeer van België en Duitsland naar de provincie Limburg in Nederland op het voorkomen van resistentie en de populatie structuur van S. aureus bij huisarts patiënten en verpleeghuisbewoners in de province Limburg vergeleken met de andere provincies in Nederland wordt bediscussieerd in Hoofdstuk 6. Er waren geen verschillen in het voorkomen van resistentie en de populatie structuur van S. aureus tussen de twee groepen huisartsisolaten. Bij de verpleeghuisisolaten werd alleen een lagere resistentie voor trimethoprim-sulfamethoxazole gevonden in de provincie Limburg vergeleken met de andere provincies. Ook werd een verschil in populatie structuur gevonden: het voorkomen van spa-CC 084 was hoger en van spa-CC 002 was lager in de provincie Limburg vergeleken met de andere provinces. Ondanks verschillen in het voorkomen van antibiotica resistentie in de ziekenhuizen in de Euregio MaasRijn, leidt (intensief) grensverkeer blijkbaar niet tot een hogere prevalentie van resistentie en een andere populatie structuur bij huisartspatiënten en verpleeghuisbewoners in de provincie Limburg vergeleken met de andere provincies.

Het voorkomen van resistentie bij $K$. pneumoniae $(n=1578)$ bij IC en urologie patiënten van 14 ziekenhuizen in Nederland in een periode van 12 jaar wordt beschreven in Hoofdstuk 7. Een toename van het voorkomen van resistentie werd met name gezien voor ceftazidime (tot 11\%), ciprofloxacine (tot 19\%) en trimethoprim-sulfamethoxazole (tot $23 \%$ ) bij de IC isolaten en, cefuroxime (tot $8 \%$ ) en trimethoprim-sulfamethoxazole (tot $28 \%$ ) bij de urologie isolaten. Over het algemeen was de resistentie het hoogste bij de IC isolaten, maar niet voor de carbapenems en trimethoprim-sulfamethoxazole. Voor deze antibiotica was de resistentie in beide populaties vergelijkbaar. Door de hoge prevalentie van resistentie zijn vele van deze antibiotica, zoals amoxicilineclavulaanzuur (26\%), piperacilline-tazobactam (15\%) en ciprofloxacine bij de IC patiënten en amoxicilline-clavulaanzuur (15\%) en trimethoprim-sulfamethoxazole bij de urologie patiënten, niet geschikt voor empirische antibiotische behandeling.

Hoofdstuk 8: De relatief hoge prevalentie van antibiotica resistente isolaten, het voorkomen van ESBLs en bepaalde antibiotica resistente types, zoals $E$. coli ST131 en MRSA ST225-II, in de Euregio Maas-Rijn en in Nederland, benadrukt de noodzaak van (Euregionale) antibiotica surveillance studies en epidemiologische studies, die het voorkomen en de genetische achtergrond van resistente bacteriën onderzoeken. Deze data zijn essentieel voor het opstellen en aanpassen van empirische antibiotische behandelprotocollen.

Dit proefschrift toont aan dat er verschillen zijn in het voorkomen van resistentie tussen landen en tussen verschillende patiënten populaties, maar ook binnen landen en binnen patiënten populaties. Dit onderstreept de noodzaak van surveillance, het 
opstellen en aanpassen van protocollen op lokaal niveau en de noodzaak van samenwerking tussen zorginstanties, ook of met name in een grensregio.

Om verdere toename in resistentie te beheersen is de inzet van de gehele zorg sector vereist. Dit houdt o.a. in het opstellen van lokale infectie preventie protocollen. Ook een antibiotica stewardship programma zou geïmplementeerd moeten worden om het inadequaat gebruik van antibiotica terug te dringen.

Door het stijgen van de antibiotica resistentie is het aantal antibiotica dat geschikt is voor empirische behandeling afgenomen. Verder onderzoek naar nieuwe middelen of nieuwe toepassing van oude middelen is noodzakelijk. 

Dankwoord 
Er was eens niet zo lang geleden en niet zo ver hier vandaan een meisje dat aan haar promotie onderzoek begon...

4 jaar leek een ontzettend lange tijd en het leek dan ook geen probleem om alles af te krijgen in deze tijd. Maar zoals ze zeggen: Time flies when you're having fun!

Voor mij zijn die 4 jaar omgevlogen en is mijn promotietraject een tijd geweest waarin ik het ontzettend naar mijn zin heb gehad. Ik heb veel nieuwe collega's en vrienden gekregen. Ik heb veel mogen leren, ondernemen en beleven. Dit is dan ook iets wat ik nooit van mijn leven zal vergeten.

Uiteindelijk is het onderzoek afgerond ondanks een portie stress op het einde om alles op tijd af te krijgen, maar in mijn eentje had ik dit nooit klaar gespeeld en daarom wil ik graag een heleboel mensen bedanken.

Allereerst mijn copromotor, Ellen, het was ontzettend fijn om de afgelopen jaren met je samen te werken en ik heb ontzettend veel van je geleerd. We zijn allebei erg fan van knopen doorhakken en no-nonsense en dat werkte erg fijn. Ook had jij ondanks je overvolle schema altijd tijd, meestal tijdens een lange treinreis, om weer eens van mijn schrijfsels door de mangel te halen. Maar ook maakte je altijd tijd en ruimte als ik een ander probleem of voorstel wilde bespreken en had je altijd nuttige opmerkingen of kritiek waar ik dan weer mee verder kon. De laatste tijd, nu jij in Utrecht werkt en ik in Rotterdam, was het soms een beetje behelpen, maar zelfs nu reis je nog wat af voor mijn promotie en is het restaurant op station Eindhoven een goed alternatief gebleken. Bedankt voor alles en vooral tot snel.

Ook kan ik natuurlijk mijn promotor niet vergeten. Cathrien, bedankt voor de mogelijkheid die ik kreeg om bij de medische microbiologie in Maastricht onderzoek te doen. Het was een onvergetelijke tijd.

Het onderzoek in mijn proefschrift maakte deel uit van een groot project: het EurSafety Health net (EMR) project. Ik ben dan ook dank verschuldigd aan alle partners van dit project, die een bijdrage hebben geleverd aan dit proefschrift.

Ook wil ik graag mijn medeauteurs bedanken voor hun hulp bij het verzamelen van de benodigde materialen en, inbreng en kritische blik bij het schrijven van de verschillende artikelen.

Zoals het een origineel (Disney) sprookje betaamt, heb ik ook twee hele toffe sidekicks (lees: paranimfen).

Maike en Paul, familie is iets was je krijgt, maar ik zou jullie voor geen goud willen inruilen. Door de jaren heen hebben we veel meegemaakt, veel gedaan, veel gelachen, gehuild en soms ook gevochten (soms vochten alleen de barbies). Jullie zijn er altijd voor mij geweest, ook al was het simpelweg een dagje shoppen, een kop koffie/thee of gewoon down-to-earth commentaar leveren in je pyjama. Soms was er veel te vertellen, soms wat minder, maar het is altijd "thuis" en dat is fijn. Samen staan we sterk en ik vind het een eer dat jullie mijn paranimfen willen zijn. Bedankt! 
Het Interreg project was een groot project, waarbij er materialen werden verzameld en verwerkt uit 3 landen van 4 patiënt groepen. Gelukkig hoefde ik dat niet in mijn eentje te doen, want dat was me nooit gelukt. Ik heb heel veel hulp gehad van de collega's van bac research. Cheffin Christel, Jacqueline, Jacqueline, Mayk, Bram, Geert, Nathalie, Miranda en Marie-Louise: bedankt voor alle hulp bij het uitwerken van alle materialen, het MICcen en PCRen en alle andere testjes, die ik tussendoor nog bedacht en op jullie bordje dropte, maar ook bij het inpakken van dozen en ga zo maar door. Ik heb ontzettend veel van jullie geleerd en het was altijd erg gezellig. Natuurlijk mag ik ook Erik niet vergeten voor zijn immer rustige, maar erg nuttige tips als ik weer eens in het c-lab beland was.

Het Interreg project was ook het soort studie waar heel veel administratieve en regelneefachtige rompslomp bij kwam kijken. Als ik daarmee vast liep kon ik altijd aankloppen bij Resi. Ze was nooit te beroerd om het een of ander over te nemen, mee te gaan naar een verpleeghuis of om gewoon te luisteren als ik stoom af moest blazen. En ook al wil ze het waarschijnlijk niet hebben: Resi, bedankt!

Mijn collega AIO's en kamergenoten, Tanja, Michelle, Sander, Judith, Giel, Marijke, Amita, Anne, Chris, Wendy, Casper en Fahad: we hebben heel veel lol gemaakt, veel gegeind en gelachen. Dat zijn momenten om nooit te vergeten. Echter, promoveren gaat meestal niet zoals je dat vooraf bedacht had, dus waren er ook wel eens tegenvallers en verdriet. Ik denk dat deze momenten ons nog dichter bij elkaar hebben gebracht. Bedankt voor het echte "thuis" gevoel op mijn werk en alle ondersteuning, die ik van jullie heb gekregen, zo divers als maar kan zijn. Op verzoek wil ik graag deze zin wijden aan Tanja met wie ik zelfs mijn hele promotietijd een kamer heb gedeeld: deze is voor jou! Maar ook de volgende collega's mag ik niet vergeten: Ellen, Laura, Ray, John, Gert, Antoinette, Guy, Robin, Vishal, Fleur, Michiel, Ella, Carla, Charlotte, Danyta en alle andere collega's van het bac lab, de virologie, ziekenhuishygiëne, de moleculaire, het secretariaat en de staf. Ik heb een geweldige tijd gehad.

Recent heb ik dus het oude vertrouwde Maastricht achtergelaten en ben ik een nieuw avontuur begonnen in het Erasmus MC in Rotterdam. Gelukkig heb ik daar ook een nieuwe, gezellige club collega's getroffen. Mijn collega AIOS, de overstap was voor mij best groot, maar bedankt voor alle goeie zorgen, hulp bij het opstarten en de gezelligheid. Ook wil ik prof. Verbrugh bedanken dat ik überhaupt in het Erasmus $M C$ aan de slag mocht gaan. Ik heb er zin in.

Ook Dees, Maris en Nicky wil ik niet vergeten. Na een dag werken aan je promotie onderzoek is het minstens zo belangrijk om even te ontspannen. Hoe kan dat beter dan een gezellig etentje, avondje op de bank, shoppen of iets dergelijks. Dat is ook de ideale gelegenheid om je ei kwijt te kunnen en jullie waren altijd een luisterend oor, zelfs als ik weer eens doordraafde over die lastige beestjes. Bedankt voor alles, maar vooral voor de gezelligheid en het niet uitlachen natuurlijk. 
Graag wil ik op deze plek mijn hele familie bedanken. Jullie zijn een hele diverse, maar oh zo gezellige, groep mensen. Jullie stonden en staan waar nodig altijd voor mij klaar en zijn altijd heel belangstellend naar mijn bezigheden in Maastricht.

Maar niet minder belangrijk is dat het altijd super gezellig is en dat er veel gelachen wordt. Soms is het rustig en weloverwogen, soms weer druk en luid, maar het maakt mij niet uit want ik wil het voor geen goud missen. Ook wil ik ome Piet en tante Carla als mijn peetoom en peettante even speciaal noemen. Thanks voor alles!

Verder wil ik graag mijn schoonfamilie bedanken: Cor en Paula, de laatste 2 jaar zijn voor jullie ook een drukke tijd geweest. Toch bleven jullie de rust zelve, stonden jullie altijd voor Giel en mij klaar en waren jullie een luisterend oor waar nodig. Ook mocht ik Giel meenemen uit Maastricht naar het verre Eindhoven. Daar ben ik ontzettend blij mee.

Lieve Giel, 4 jaar geleden had ik niet gedacht dat we hier nu samen zouden staan. Hoe dingen toch raar kunnen lopen als je er niet op bedacht bent. Jij weet als geen ander wat promoveren inhoudt en het was dan ook super dat ik op jouw ervaringsdeskundigheid kon terugvallen. Je bent ook altijd mijn stok achter de deur, zeker bij die laatste loodjes. Ik laat het niet altijd duidelijk blijken, maar: thanks!

$\mathrm{Nu}$, na 2 jaar is er veel veranderd: ik weet ineens veel van voetballen en auto's, en werken we ook niet meer op dezelfde afdeling. Alle veranderingen waren niet altijd makkelijk. Ook de verhuizing naar Eindhoven was een grote stap. Maar, ik denk dat we het goed voor elkaar hebben en ik hoop dat we snel die reis naar IJsland kunnen maken. Ik ben blij dat we dit alles samen hebben kunnen delen. Op naar ons nog lang en gelukkig.

Lieve pap en mam, jullie kan ik nooit genoeg bedanken. Jullie hebben mij altijd door dik en dun gesteund in alles wat ik me dan weer in mijn blote hoofd haalde. Ook als ik steeds maar verder weg leek te gaan (eerst naar Maastricht en later zelfs even naar Australië), waren jullie er voor mij. Zelfs als jullie liever hadden dat ik wat dichter bij huis zou blijven. Nooit was iets te veel gevraagd, moest er wat geregeld of geklust worden, gereden of verhuisd worden: het kon allemaal.

Pap en mam: zonder jullie rotsvaste vertrouwen was ik nooit gekomen waar ik nu ben en $\mathrm{ik}$ ben ontzettend trots om jullie als ouders te hebben.

Laten we nu maar eerst een dikke borrel gaan drinken. 
Dankwoord 

Curriculum vitae 
Christel van der Donk werd geboren op 19 november 1984 in 's-Hertogenbosch en zij groeide op in het kleine plaatsje Middelrode. Van 1997 tot 2003 heeft zij het middelbaar onderwijs gevolgd aan het Gymnasium Bernrode te Heeswijk. In 2003 werd de grote overstap gemaakt naar het Limburgse Maastricht waar zij startte met de opleiding Geneeskunde aan de Universiteit van Maastricht. Tijdens deze opleiding heeft zij haar horizon verder uitbreid met verschillende stages in Birmingham, Mount Isa en Dublin.

Het laatste jaar van haar opleiding heeft zij haar klinische en wetenschappelijke stage gevolgd aan de afdeling medische microbiologie in het academisch ziekenhuis Maastricht, waarna zij haar opleiding afrondde in 2009. Na de geneeskunde opleiding kreeg zij de mogelijkheid om promotieonderzoek te starten bij dezelfde afdeling onder begeleiding van dr. Ellen Stobberingh en prof. dr. Cathrien Bruggeman. De resultaten van haar promotieonderzoek zijn te lezen in dit proefschrift. Tijdens de stage in het laatste jaar van de geneeskunde opleiding en gedurende haar promotieonderzoek is ze helemaal in de ban geraakt van de medische microbiologie. Sinds januari 2013 is zij in opleiding tot arts-microbioloog in het Erasmuc MC. Ook is zij na haar Limburgse avontuur weer teruggekeerd in het Brabantse, waar zij samen met haar vriend Giel Gaajetaan in Eindhoven woont. 
List of publications 
TA Mulders, Z Meyer, C van der Donk, AA Kroon, I Ferreira, CDA Stehouwer, SJ Pinto-Sietsma. Patients with premature cardiovascular disease and a positive family history for cardiovascular disease are prone to recurrent events. Int J Cardiol. 2011 Nov 17;153(1):64-7. Epub 2010 Sep 9.

CFM van der Donk, PS Beisser, JAA Hoogkamp-Korstanje, CA Bruggeman, EE Stobberingh. A 12 year (1998-2009) antibiotic resistance surveillance of Klebsiella pneumoniae collected from intensive care and urology patients in 14 Dutch hospitals. J Antimicrob Chemother. 2011 Apr;66(4):855-8.

J Beuving, CF van der Donk, CF Linssen, PF Wolffs, A Verbon. Evaluation of direct inoculation of the BD PHOENIX system from positive BACTEC blood cultures for both Gram-positive cocci and Gram-negative rods. BMC Microbiol. 2011 Jun 30;11:156.

TA Mulders, LF Maurissen, Z Meyer, M Hameeteman, C van der Donk, AA Kroon, I Ferreira, CD Stehouwer, TM Hackeng, SJ Pinto-Sietsma. A positive family history for premature cardiovascular disease identifies patients prone to recurrent arterial thrombotic events. Eur J Cardiovasc Prev Rehabil. 2011 Sep 13.

CFM van der Donk, JHB van de Bovenkamp, E De Brauwer, P De Mol, WM Kalka-Moll, S Nys, I Thoelen, TAM Trienekens, EE Stobberingh. The EurSafety Health-net EMR project: Antimicrobial resistance of Escherichia coli isolates collected from nine urology services in the Euregion MeuseRhine in 2009-2011. PLoS One. 2012;7(10). Epub 2012 Oct 17.

CFM van der Donk, JMGA Schols, CJ Driessen, RGP Hagenouw, A Meulendijks, EE Stobberingh. Antimicrobial resistance of Eschericha coli isolates and antimicrobial use among nursing home residents in the southern part of the Netherlands. J Am Dir Med Assoc. 2013 Mar;14(3):199-203. Epub 2012 Nov 7.

CFM van der Donk, CDJ den Heijer, EE Stobberingh. Optimal antibiotic use contributes to cutting healthcare costs. Int Hosp Equip Soll. 2013 Jan.

CFM van der Donk, EE Stobberingh, JMGA Schols. Multiresistente Escherichia coli rukt op. Tijdschr Ouderengeneesk. 2013(01) 18-19.

CFM van der Donk, MIA Rijnders, GA Donker, AJ de Neeling, S Nys, EE Stobberingh. Is living in a border region a risk for a high prevalence of resistance? Eur J Clin Microbiol Infect Dis. Epub 2013 Feb 10.

WLJ Hansen, C van der Donk, CA Bruggeman, EE Stobberingh, PFG Wolffs. A real-time PCR-based semi-quantitative breakpoint to aid in molecular identification of urinary tract infections. Accepted in PLOS ONE.

CFM van der Donk, JMGA Schols, V Schneiders, K-H Grimm, EE Stobberingh. Resistance and population structure of $S$. aureus in nursing homes in the border region of the Netherlands and Germany. submitted.

CFM van der Donk, JHB van de Bovenkamp, H Bamelis, CC Driessen, K-H. Feldhoff, WA KalkaMoll, K Magerman, EE Stobberingh. Prevalence and spread of multi drug resistant $E$. coli including ST131 in different patient populations in the Euregion Meuse-Rhine. submitted 
From now on, you shall be known as: Sharkbait

Gill (Finding Nemo) 
